\title{
Conservation of the Toxoplasma conoid complex proteome reveals a cryptic conoid in Plasmodium that differentiates between blood- and vector-stage zoites
}

Ludek Koreny ${ }^{1}$, Mohammad Zeeshan ${ }^{2}$, Konstantin Barylyuk ${ }^{1}$, Eelco C. Tromer ${ }^{1}$, Jolien J. E. van Hooff ${ }^{5}$, Declan Brady ${ }^{2}$, Huiling Ke ${ }^{1}$, Sara Chelaghma ${ }^{1}$, David J. P. Ferguson ${ }^{3,4}$, Laura Eme ${ }^{5}$, Rita Tewari ${ }^{*}$, Ross F. Waller ${ }^{1 *}$

${ }^{1}$ Department of Biochemistry, University of Cambridge, Cambridge, CB2 1QW, UK

${ }^{2}$ School of Life Sciences, Queens Medical Centre, University of Nottingham, Nottingham, NG7 2UH, UK

${ }^{3}$ Nuffield Department of Clinical Laboratory Science, University of Oxford, John Radcliffe Hospital, Oxford OX3 9DU, UK.

${ }^{4}$ Department of Biological and Medical Sciences, Faculty of Health and Life Science, Oxford Brookes University, Gipsy Lane, Oxford OX3 OBP, UK

${ }^{5}$ Université Paris-Saclay, CNRS, AgroParisTech, Ecologie Systématique Evolution, 91405, Orsay, France

*Correspondence: rfw26@cam.ac.uk, Rita.Tewari@nottingham.ac.uk

Key words: Apicomplexa, Myzozoa, Plasmodium, malaria, Toxoplasma, conoid, apical complex, invasion, evolution

\section{Abstract}

The apical complex is the instrument of invasion used by apicomplexan parasites, and the conoid is a conspicuous feature of this apparatus found throughout this phylum. The conoid, however, is believed to be heavily reduced or missing from Plasmodium species and other members of the class Aconoidasida. Relatively few conoid proteins have previously been identified, making it difficult to address how conserved this feature is throughout the phylum, and whether it is genuinely missing from some major groups. Moreover, parasites such as Plasmodium species cycle through three invasive forms and there is the possibility of differential presence of the conoid between these stages. We have applied spatial proteomics and high-resolution microscopy to develop a more complete molecular inventory and understanding of the organisation of conoid-associated proteins in the model apicomplexan Toxoplasma gondii. These data revealed molecular conservation of all conoid substructures throughout Apicomplexa, including Plasmodium, and even in allied Myzozoa such as Chromera and dinoflagellates. We reporter-tagged and observed the expression and location of several conoid complex proteins in the malaria model $P$. berghei and revealed equivalent structures in all of its zoite forms, as well as evidence of molecular differentiation between blood-stage merozoites and the ookinetes and sporozoites of the mosquito vector. Collectively we show that the conoid is a conserved apicomplexan element at the heart of the invasion mechanisms of these highly successful and often devastating parasites. 


\section{Introduction}

It is difficult to imagine a more insidious intrusion upon an organism's integrity than the penetration and occupation of intracellular spaces by another foreign organism. Apicomplexan parasites are masters of this transgression through actively seeking, binding to, and invading the cellular milieu of suitable animal hosts. From here, they manipulate and exploit these cells to promote their growth and onward transmission to other cells and other hosts. The impacts of these infection cycles include major human and animal diseases, such as malaria, toxoplasmosis and cryptosporidiosis in humans, and a spectrum of other diseases in livestock and wild animals [1-4]. The course of both human history and evolution has been shaped by these ubiquitous specialist parasites.

Key to the successful parasitic strategies of apicomplexans is the apical complex-a specialisation of the cell apical cortex that coordinates the interaction and penetration of host cells [5]. Most of the apicomplexan cell is encased in a pellicle structure of flattened membrane vesicles beneath the plasma membrane, as are all members of the infrakingdom Alveolata including dinoflagellates and ciliates [6]. These 'alveoli' sacs are supported by robust proteinaceous networks, and collectively this inner membrane complex (or IMC, as it is called in apicomplexans) provides shape and protection to the cell, as well as other functions such as gliding motility in apicomplexans by IMC-anchored motors [7]. The IMC, however, is a general obstruction to other cellular functions that occur at the plasma membrane, including exocytosis and endocytosis [8]. Thus, the apical complex has evolved alongside the IMC to provide a location for these functions. When apicomplexans attack their host's cells, the apical complex is the site of exocytosis; first of host-recognition and -binding molecules, and subsequently of molecules injected into the host that create a platform in its plasma membrane for parasite penetration $[9,10]$. In infections such as those that humans suffer from, upon host cell invasion, further exocytosed molecules create a modified environment in the host cell that facilitate the parasite's growth, reproduction, and protection from the host's immune system. In many gregarine apicomplexans, on the other hand, only partial penetration of the host occurs and the parasite endocytoses host cytosol via their embedded apical complex [11]. Near relatives of Apicomplexa, such as colpodellids and some dinoflagellates, similarly feed on prey and host cells through their apical complex-such is the apparent antiquity of this cell feature $[12,13]$. The apical complex is thus a coordination of the cell cytoskeleton that defines an available disc of plasma membrane, that is otherwise obscured by the IMC, for vesicular trafficking machinery to deliver and exchange with the extracellular environment. A protuberance of the cell at the apical complex also provides mechanical properties to this important site.

Functional studies of the apical complex have occurred in select experimentally amenable taxa, mostly Toxoplasma and Plasmodium, but a mechanistic understanding of this cell feature or its conservation is still in its infancy. Rather, the apical complex is most broadly understood from ultrastructural studies that show apical rings as the basis of this structure. An apical polar ring (APR1) coordinates the apical margin of the IMC, and a second APR (APR2) acts as a microtubule organising centre (MTOC) for the subpellicular microtubules (Fig 1) [14-16]. Within this opening created by the APRs are further rings, a notable one being the 'conoid' that is conspicuous throughout much of Apicomplexa [17]. The conoid is a tapered tubular structure of variable length and cone pitch. It interacts intimately with secretory organelles including micronemes, rhoptries and other vesicles that penetrate and occupy its lumen $[18,19]$. An open conoid (or 'pseudoconoid') seen in Perkinsus, another parasite and close relative of Apicomplexa, even has microneme-like vesicles physically tethered to it, and in Coccidia a pair of intraconoidal microtubules is lined by a chain of microvesicles $[18,20]$. In gregarines, endocytosis occurs through the conoid aperture [11]. Thus, while the APRs appear to play chiefly structural organising roles, the conoid is closely associated with the events and routes of vesicular trafficking-delivery and in some cases uptake. 
Fig 1. Conoid complex features in Toxoplasma tachyzoites. (A) Schematic of the recognised components of the conoid and their location within the apical structures of the cell pellicle in either retracted or protruded states. (B-E) Transmission electron micrographs of $T$. gondii tachyzoites with conoid either retracted $(B, C)$ or protruded $(D, E)$. Tubulin filaments of the conoid walls are evident in tangential section $(E)$ and two conoidal rings (CR) of the conoid canopy are evident at the conoid's anterior end $(D, E)$. The conoid is surrounded by two apical polar rings (P1 and P2) formed by the anterior aspect of the inner membrane complex and anchoring the subpellicular microtubules (Mt), respectively. Rhoptry ducts (RD) can be seen running to the apex through conoid (E). C, conoid; $M$, micronemes; $R$, rhopties; $V$, plant-like vacuole; $\mathrm{A}$, apicoplast; $\mathrm{Nu}$, nucleus; $\mathrm{Mi}$, mitochondrion; $\mathrm{G}$, Golgi apparatus. Scalebar represent 1 $\mu \mathrm{m}(\mathrm{B}, \mathrm{D})$ and $100 \mathrm{~nm}(\mathrm{C}, \mathrm{E})$.

In most known conoids, the walls of the conoid have a spiralling fibrous presentation by electron microscopy (Fig 1E), a trait that is chiefly attributed to the presence of tubulin polymers $[16,17,21]$. In the Toxoplasma conoid, tubulin forms unusual open fibres with a comma-shaped profile [21]. The ancestral state of conoid tubulin, however, is likely canonical microtubules as seen in gregarines, Chromera, and other apicomplexan relatives $[11,13,22]$. It is unclear if the modified tubulin fibres of the Toxoplasma conoid arose specifically within coccidians or are more widespread in apicomplexans due to the limits of resolution or preservation of this dense structural feature. Nevertheless, this tubulin component demonstrates a degree of plasticity of the conoid structure. Electron microscopy shows that the tubulin fibres are embedded in electron dense material, evidence of further conoid proteins (Fig 1C) $[14,17,23]$. This matrix extends to an open apical cover described as a 'delicate osmophilic . . . canopy' by Scholtzseck et al (1970) within which two conoidal rings are often seen (Fig 1A, C, E). These rings are now frequently referred to as 'preconoidal rings', however, in recognition of the continuity of conoid ultrastructure from spiral reinforced walls to canopy rings, this entire structure was designated as the conoid and the rings as 'conoidal rings' [17]. The apical conoid canopy is in closest contact, and probably interacts, with the cell plasma membrane $[14,23]$. Electron microscopy does not reveal any direct attachment fibres or structures from the conoid to the plasma membrane at its apex, or to the IMC at its base. However, in Toxoplasma it is known that at least one protein (RNG2) links the conoid directly to the APR2 [24], thus, there is evidence of molecular architecture beyond that observed by ultrastructure.

A predicted structural deviation to the apical complex in Apicomplexa is the interpretation of loss of the conoid in some groups, a state enshrined within the class name Aconoidasida. This class contains two important groups: Haemosporida, such as Plasmodium spp., and Piroplasmida. Aconoidasida are considered to have either completely lost the conoid (e.g. Babesia, Theileria), or at least lost it from multiple zoite stages, e.g. Plasmodium spp. stages other than the ookinete. However, while conoids have been attributed to micrographs of ookinete stages in some Plasmodium spp., in other studies these are alternatively labelled as 'apical polar rings' [17,25-27], and the prevailing understanding of many is that a conoid was lost outright.

The uncertainty over whether the conoid is present in Aconoidasida is a product of two problems. One is that we have little insight into the function of the conoid, so the consequences of its loss are difficult to predict. The other is that we still know relatively little of the molecular composition of the conoid that would allow the objective testing for the presence of a homologous structure [5]. The conspicuous ultrastructure of conoids such as those of coccidians draw attention to tubulin being a major element, however it is known that there are other conoid proteins responsible for its assembly, stability, and function during invasion [24,28-35]. To test if a homologous conoid cell feature is present in Aconoidasida, but cryptic by traditional microscopy techniques, fuller knowledge of the molecules that characterise this feature in a 'classic' conoid model is needed. In our study we have sought such knowledge for the Toxoplasma gondii conoid using multiple 
proteomic approaches. We then asked if these conoid-associated proteins are present in similar locations within Aconoidasida using the model Plasmodium berghei to investigate each of its zoite forms: ookinetes, sporozoites and merozoites. In doing so we address the question of what common machinery underpins the mechanisms of invasion and host exploitation that are central to these parasites' lifestyles and impact. Our data also explore the antiquity of this machinery and its presence in relatives outside of Apicomplexa.

\section{Results}

\section{Spatial proteomic methods identify new candidate conoid proteins.}

To expand our knowledge of the proteins that contribute to conoid structure and function we applied multiple spatial proteomics discovery approaches. The primary method used was hyperplexed Localisation of Organelle Proteins by Isotope Tagging (hyperLOPIT) that we have recently applied to extracellular $T$. gondii tachyzoites [36,37]. This approach entailed generating hyperLOPIT datasets from three independent samples. In each sample, mechanically disrupted cells were dispersed on density gradients, and the distinct abundance distribution profiles formed by different subcellular structures and compartments were used to identify proteins that belong to common cellular niches. Combining the data from the three experiments provided enhanced discriminating power of protein location assignments, and from the 3832 proteins that were measured in all three samples we reported 63 proteins assigned to one of the two apical protein clusters, apical 1 and apical 2, above a 99\% probability threshold. Another 13 proteins were assigned to these clusters but below this high-confidence cut-off. The two high-confidence clusters were verified as comprising proteins specific to the structures associated with the conoid, apical polar rings, and 'apical cap' of the IMC [36]. In addition to the 3832 proteins that we reported in this highresolution spatial proteome [36], a further 1013 proteins were quantified in either only two or one of the hyperLOPIT datasets due to the stochasticity of mass spectrometry sampling. While assignment of these proteins consequently had less data support, a further 32 proteins were assigned to the apical clusters (not reported in the Barylyuk et al study) from analysis of either the pairs of LOPIT experiments, or the single experiments. From these analyses, 95 proteins were assigned as putative apical proteins across these hyperLOPIT samples (Table S1).

Of the 95 putative apical protein assignments by hyperLOPIT, 13 had been validated as being located to the very apex of the cell during our hyperLOPIT study [36], 23 with this same specific apical location by us or others previously, and 21 proteins were known to be specific to the apical cap or other IMC elements (Table S1 and refs therein). This left a further 38 new protein candidates for which there was no independent validation of their apical location. To bolster support for conoidspecific location we applied a second spatial proteomic strategy, proximity dependent biotinylating and pulldown, or BiolD [38]. We made three apical BiolD 'baits' by endogenous 3' gene fusions with coding sequence for the promiscuous biotin-ligase BirA*. Two baits were known conoid markers: SAS6-like (SAS6L), a protein previously attributed to the conoid canopy ('preconoidal rings') in $T$. gondii [39] but by super-resolution imaging we observe this protein located in the body of the conoid (see below); and RNG2 where the C-terminus of this large protein is anchored to the APR2 that is in close proximity to the apical end of the conoid in intracellular parasites [24]. A third bait

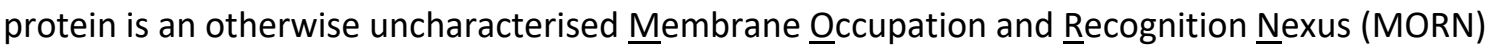
domain-containing protein (TGME49_245710) that we call MORN3. In an independent study of MORN proteins, we identified MORN3's location as being throughout the IMC but with greatest abundance in a band at the apical cap, although excluded from the very apex where the conoid is located (Fig 2A). Using these three BiolD baits we rationalised that SAS6L and RNG2 proximal proteins would be enriched for those near the conoid, and MORN3 proximal proteins would be enriched for apical cap and IMC proteins but not for conoid-proximal proteins. 
Fig 2. Apically targeted BiolD using baits RNG2, SAS6L and new apical cap protein MORN3. (A) Immuno-detection of HA-tagged MORN3 in T. gondii intracellular parasites co-stained for apical cap-marker ISP1. Upper panels show mature cells, lower panels show internal daughter pellicle buds forming during the early stages of endodyogeny. Scale bar $=5 \mu \mathrm{m}$. (B) Steptavidindetection of biotinylated proteins after 24 hours of growth with elevated biotin. Native biotinylated proteins Acetyl-CoA carboxylase (ACC1) and pyruvate carboxylase are seen in the parental control (lacking BirA*) and in the BiolD bait cell lines. Additional biotinylated proteins are seen in each of the bait cell lines grown with elevated biotin, including self-biotinylation of the bait fusion.

T. gondii cell lines expressing each of the BiolD bait proteins were grown for 24 hours in host cells with elevated exogenous biotin. Streptavidin-detection of biotinylated proteins on Western blots showed unique banding patterns of each cell line and when compared to parental controls (cells lacking Bir* fusions) (Fig 2B). Biotinylated proteins from each cell line were then purified on a streptavidin matrix and analysed by mass spectrometry. Proteins enriched $\geq 3$-fold compared to the control, or detected in the bait cell lines but not in the control, are indicated in Table S1. Of the hyperLOPIT-assigned apical proteins, 25 were also detected by BiolD with both SAS6L and RNG2 but not MORN3, and these included known conoid-associated proteins (e.g., $\mathrm{MyoH}, \mathrm{CPH} 1, \mathrm{CIP} 2, \mathrm{CIP} 3$, SAS6L, RNG2). Seven proteins were BiolD-detected by MORN3 but not SAS6L or RNG2, and these are all known apical cap or IMC proteins (AC4, AC8, AC9, AC10, AAP5, IMC9, IMC11). These data indicate that the BiolD spatial proteomics indeed enrich for apical proteins, with the differences between SAS6L/RNG2 and MORN3 labelling providing a level of discrimination for conoid-associated proteins when compared to apical cap proteins.

\section{Validation of conoid proteins and determination of their substructural location}

We confirmed the identification of new apical complex proteins in the region of the conoid in the hyperLOPIT study by endogenous 3'-tagging of candidate genes with reporters [36]. Imaging by wide-field fluorescence microscopy showed 13 of these proteins confined to a single small punctum at the extreme apex of the cell (Table 1). To test if our expanded hyperLOPIT analysis, including proteins with less hyperLOPIT apical assignment support, contained further proteins at the apical tip, seven of these were tagged by the same method (Table S1: TGME49_274160, TGME49_219070, TGME49_209200, TGME49_274120, TGME49_250840, TGME49_219500, TGME49_284620). All of these proteins were observed to show the same extreme apical location (Fig S1, S3, S4). All of these proteins that were independently tested for location were previously uncharacterised and were selected only based on sharing orthologues with other apicomplexan clades (see below), strong phenotypes identified by a genome-wide knockout screen [40] or presence of conserved domains that might ultimately provide clues of molecular function. Amongst the hyperLOPIT apical-assigned proteins tagged and located in either this or the Barylyuk et al (2020) study there were none that did not locate to the apical structures of the cell.

The conoid of $T$. gondii is a small structure $(\sim 400 \times 500 \mathrm{~nm})$ in close proximity to the APRs (Fig 1) so widefield fluorescence microscopy is less able to distinguish between proteins at either of these specific structures, nor subdomains of the conoid itself. To determine the specific locations of our conoid-proximal proteins we employed 3D-SIM super-resolution imaging in cells co-expressing either SAS6L or RNG2 with C-terminal epitope reporters. By 3D-SIM we observe SAS6L with C-terminal V5 epitope tag to locate to the tapered walls of the conoid (Fig 3-5), rather than exclusively to the rings of the apical conoid canopy as was previously reported for YFP-tagged SAS6L [39]. The fluorescence imaging used in the de Leon et al study was limited to lower resolution widefield microscopy. Immuno-TEM was employed also, however, contrary to the authors' conclusions, did show YFP presence throughout transverse and oblique sections of the conoid consistent with our detection of 
bioRxiv preprint doi: https://doi.org/10.1101/2020.06.26.174284; this version posted December 7, 2020. The copyright holder for this preprint (which was not certified by peer review) is the author/funder, who has granted bioRxiv a license to display the preprint in perpetuity. It is made available under aCC-BY-NC-ND 4.0 International license.

Table 1: Toxoplasma conoid-associated proteins and Plasmodium orthologues.

\begin{tabular}{|c|c|c|c|c|c|c|c|c|c|c|c|c|c|}
\hline \multirow[b]{2}{*}{$\begin{array}{l}{ }^{2} \text { T. gondii } \\
\text { ME49 }\end{array}$} & \multirow[b]{2}{*}{$\begin{array}{l}\text { Protein } \\
\text { Name }\end{array}$} & \multirow[b]{2}{*}{${ }^{\mathrm{b}}$ Known Localization } & \multirow[b]{2}{*}{$\begin{array}{c}\text { * Ref for } \\
\text { Localization }\end{array}$} & \multicolumn{3}{|c|}{${ }^{\mathrm{c}}$ Proteomics } & & \multirow[b]{2}{*}{$\begin{array}{l}{ }^{\mathrm{a}} P . \\
\text { berghei } \\
\text { ANKA }\end{array}$} & \multicolumn{2}{|c|}{$\begin{array}{l}{ }^{d} \text { zoite } \\
\text { stage }\end{array}$} & \multicolumn{2}{|c|}{$\begin{array}{l}{ }^{\mathrm{e}} \text { Mutant } \\
\text { Fitness } \\
\text { Scores }\end{array}$} & \multirow[b]{2}{*}{$\begin{array}{l}{ }^{f} \text { Conserved } \\
\text { Domains }\end{array}$} \\
\hline & & & & 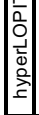 & 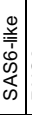 & & & & 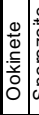 & & 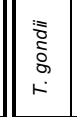 & $\begin{array}{l}\overline{2} \\
\frac{\pi}{0} \\
\frac{2}{0} \\
\stackrel{0}{0} \\
0\end{array}$ & \\
\hline 219070 & & conoid canopy punctum & TS & + & & & & 1025300 & $\cdot$ & $\bullet$ & -2.20 & -1.63 & EF, Crp, CAP_ED \\
\hline 274160 & & conoid canopy punctum & TS & + & & & & 1313300 & \begin{tabular}{|l|l} 
& \\
\end{tabular} & - & \begin{tabular}{|l|}
-2.80 \\
\end{tabular} & -3.14 & \\
\hline 209200 & & conoid canopy punctum & TS & + & & & & 1436500 & & & \begin{tabular}{|l|}
-1.55 \\
\end{tabular} & -2.53 & $\mathrm{EF}$ \\
\hline 284620 & & conoid canopy ring & TS & + & & & & 1316900 & & & \begin{tabular}{|l|}
-1.02 \\
\end{tabular} & -1.83 & LRR \\
\hline 253600 & & conoid canopy ring & $36, \mathrm{TS}$ & + & & & & 0713200 & & & -2.40 & -2.56 & \\
\hline 306350 & & conoid canopy ring & $36, \mathrm{TS}$ & + & & & & 1347000 & $\bullet$ & $\bullet$ & $\mid-0.84$ & -0.98 & \\
\hline 202120 & ICAP16 & conoid canopy ring & 40, TS & & & $\bullet$ & & 1419000 & $\bullet$ & 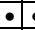 & -2.10 & -3.04 & PH-like \\
\hline 250340 & Centrin 2 & $\mathrm{CCR}+\mathrm{AA}$ & $45,44,46$ & + & & & & 1310400 & & & -4.41 & -2.08 & $\mathrm{EF}$ \\
\hline 222350 & & conoid body & $36,31, \mathrm{TS}$ & + & $\cdot$ & $\bullet$ & & 1229900 & & & \begin{tabular}{|l|}
-1.31 \\
\end{tabular} & 0.02 & \\
\hline 274120 & & conoid body & $31, \mathrm{TS}$ & + & $\bullet$ & - & & 0310700 & $\bullet$ & $\bullet$ & 0.64 & -0.38 & \\
\hline 291880 & & conoid body & $36, \mathrm{TS}$ & + & $\bullet$ & $\bullet$ & & 0616200 & & & \begin{tabular}{|l|}
1.77 \\
\end{tabular} & 0.15 & \\
\hline 297180 & & conoid body & $36, \mathrm{TS}$ & + & $\bullet$ & $\bullet$ & & & 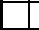 & 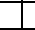 & -1.52 & & CRAL-TRIO \\
\hline 301420 & SAS6L & conoid body & $39,42, \mathrm{TS}$ & + & $\bullet$ & $\bullet$ & & 1414900 & $\bullet$ & - & \begin{tabular}{|l|}
-1.62 \\
\end{tabular} & -0.80 & SAS6_N \\
\hline 243250 & $\mathrm{MyoH}$ & conoid body & 28 & + & $\cdot$ & $\bullet$ & & & & & \begin{tabular}{|l|}
-3.94 \\
\end{tabular} & & Myo, Cal, RCC1 \\
\hline 295450 & DIP13 & conoid body & 43 & & & & & 1141900 & & & \begin{tabular}{|l|}
0.67 \\
\end{tabular} & -3.00 & \\
\hline 256030 & DCX & conoid body & 32,33 & + & $\bullet$ & $\bullet$ & $\bullet$ & 1232600 & & & \begin{tabular}{|c|}
-5.03 \\
\end{tabular} & -2.46 & UBQ, p25- $\alpha$ \\
\hline 226040 & CAM3 & conoid body & 30 & + & & & & & & & \begin{tabular}{|l|}
-3.25 \\
\end{tabular} & & $\mathrm{EF}$ \\
\hline 262010 & CAM2 & conoid body & 33,30 & \begin{tabular}{|l}
+ \\
\end{tabular} & & & & & & & \begin{tabular}{|c|}
-0.81 \\
\end{tabular} & & $\mathrm{EF}$ \\
\hline 246930 & CAM1 & conoid body & 44,28 & + & & & & & & & \begin{tabular}{|l|}
1.09 \\
\end{tabular} & & $\mathrm{EF}$ \\
\hline 246720 & & conoid base & $36,31, \mathrm{TS}$ & + & $\bullet$ & $\bullet$ & & 0109800 & $\bullet$ & $\bullet$ & \begin{tabular}{|l|}
0.24 \\
\end{tabular} & -2.83 & $\mathrm{EF}$ \\
\hline 258090 & & conoid base & $36,31, \mathrm{TS}$ & + & $\bullet$ & $\bullet$ & & 1216300 & $\bullet$ & $\cdot$ & -1.34 & -0.40 & \\
\hline 266630 & $\mathrm{CPH} 1$ & conoid base & $36,31, \mathrm{TS}$ & + & $\bullet$ & $\cdot$ & & 0620600 & & & -4.16 & -0.42 & ANK \\
\hline 244470 & RNG2 & conoid base + APR2 & $34,24, \mathrm{TS}$ & + & $\cdot$ & $\bullet$ & & & & & -4.21 & & \\
\hline 239300 & ICMAP1 & ICMT & 47 & + & & & & & & & \begin{tabular}{|l|}
-0.74 \\
\end{tabular} & & \\
\hline 208340 & & APR1 & $36, \mathrm{TS}$ & + & $\cdot$ & $\bullet$ & & 907700 & \begin{tabular}{|l|l}
$\cdot$ & -1
\end{tabular} & $\bullet$ & \begin{tabular}{|l|}
-0.81 \\
\end{tabular} & -3.05 & PH-like \\
\hline 250840 & MLC3 & APR1 & $28, \mathrm{TS}$ & + & & - & & & & & -1.91 & & $\mathrm{EF}$ \\
\hline 219500 & & APR1/2 & TS & + & & $\bullet$ & & 0919400 & & & 0.00 & -2.89 & Ribonuclease-like \\
\hline 227000 & & APR1/2 & $36,31, \mathrm{TS}$ & + & $\bullet$ & $\bullet$ & & 0510100 & & & \begin{tabular}{|l|}
-3.17 \\
\end{tabular} & -0.24 & \\
\hline 267370 & Kinesin A & APR1/2 & 29 & + & $\cdot$ & $\bullet$ & & & & & \begin{tabular}{|l|}
-2.70 \\
\end{tabular} & & Kinesin \\
\hline 278780 & & APR2 & $36, \mathrm{TS}$ & + & $\bullet$ & $\bullet$ & $\bullet$ & & & & \begin{tabular}{|l|}
-2.77 \\
\end{tabular} & & UBQ \\
\hline 320030 & & APR2 & $36,31, \mathrm{TS}$ & + & $\bullet$ & $\bullet$ & $\bullet$ & 1334800 & $\bullet$ & $\bullet$ & \begin{tabular}{|l|}
-0.19 \\
\end{tabular} & -2.43 & \\
\hline 243545 & RNG1 & APR2 & 34,48 & & & & & & & & \begin{tabular}{|l|}
2.54 \\
\end{tabular} & & \\
\hline 315510 & APR1 & APR2 & 29 & + & $\bullet$ & $\bullet$ & & & & & -0.05 & & \\
\hline 292120 & MORN2 & apical PM ring & $36, \mathrm{TS}$ & & & & & & & & \begin{tabular}{|l|}
-0.04 \\
\end{tabular} & & MORN \\
\hline 226990 & & apex & 31 & + & $\bullet$ & $\bullet$ & & & & & \begin{tabular}{|l|}
1.41 \\
\end{tabular} & & \\
\hline 234270 & & apex & 31 & + & $\bullet$ & & & & & & \begin{tabular}{|l|}
-0.44 \\
\end{tabular} & & \\
\hline 254870 & & apex & 31 & & & & & & & & \begin{tabular}{|l|}
0.64 \\
\end{tabular} & & TerD \\
\hline 255895 & & apex & 31 & + & $\cdot$ & $\bullet$ & & & & & \begin{tabular}{|l|}
0.23 \\
\end{tabular} & & \\
\hline 295420 & & apex & 36,31 & + & $\cdot$ & $\bullet$ & & & & & \begin{tabular}{|l|}
-1.57 \\
\end{tabular} & & TerD \\
\hline 313780 & & apex & 31 & + & $\bullet$ & $\bullet$ & & & & & \begin{tabular}{|l|}
0.71 \\
\end{tabular} & & \\
\hline 291020 & MyoL & apex & 51 & & & & & 1435500 & & & -1.83 & -2.97 & Myo, RCC1 \\
\hline 239560 & MyoE & apex & 51 & + & & & & & & & \begin{tabular}{|l|}
0.11 \\
\end{tabular} & & Myo \\
\hline 315780 & MLC7 & apex & 28 & + & & & & 0514800 & & & \begin{tabular}{|l|}
-0.12 \\
\end{tabular} & -3.04 & $\mathrm{EF}$ \\
\hline 311260 & MLC5 & apex & 28 & + & & & & & & & \begin{tabular}{|l|}
-0.33 \\
\end{tabular} & & $\mathrm{EF}$ \\
\hline 209890 & ICAP4 & apex & 40 & & & & & 1439000 & & & \begin{tabular}{|l|}
-4.84 \\
\end{tabular} & -2.17 & \\
\hline 312630 & GAC & apex & 53 & & & & & 1137800 & $\bullet$ & $\bullet$ & \begin{tabular}{|l|}
-3.53 \\
\end{tabular} & -3.05 & ARM \\
\hline 206430 & FRM1 & apex & 49 & \begin{tabular}{|l|l|}
+ & \\
\end{tabular} & & & & 1245300 & & & \begin{tabular}{|l|}
-3.24 \\
\end{tabular} & -2.92 & TPR \\
\hline 252880 & CRMP & apex & 54 & \begin{tabular}{|l}
+ \\
\end{tabular} & $\bullet$ & $\bullet$ & & & & & \begin{tabular}{|l|}
-2.35 \\
\end{tabular} & & Ax_dyn_light \\
\hline 225020 & CIP3 & apex & 31 & + & $\bullet$ & $\bullet$ & & 1309800 & & & \begin{tabular}{|l|}
-2.78 \\
\end{tabular} & -1.04 & \\
\hline 257300 & CIP2 & apex & 31 & + & $\bullet$ & $\bullet$ & & & & & \begin{tabular}{|l|}
-2.49 \\
\end{tabular} & & \\
\hline 234250 & CIP1 & apex & 31 & & $\bullet$ & $\bullet$ & & 1423000 & & & \begin{tabular}{|l|}
-2.02 \\
\end{tabular} & $\mid-2.77$ & \\
\hline 210810 & CAP1 & apex & 54 & & & & & & & & \begin{tabular}{|l|}
-0.73 \\
\end{tabular} & & \\
\hline 216080 & AKMT & apex & 50 & & $\cdot$ & $\bullet$ & & 0932500 & & & -4.30 & -2.08 & SET \\
\hline 310070 & AAMT & apex & 52 & & & & & 1318900 & & & -1.22 & -2.05 & Methyltrans \\
\hline
\end{tabular}

Footnotes:

a Proteins with location data by microscopy in this and the Barylyuk et al (2020) study shown in red.

b Known localization defined as 'apex' when low resolution imaging only has identified a punctum at the apex of the cell. CCP, conoid canopy punctum; CCR, conoid canopy ring; AA, apical annuli; APR, apical polar ring; APR1/2 indicates intermediate position between the two rings; PM, plasma membrane; ICMT, intraconoidal microtubules.

c Proteomic data: + , proteins represented in the hyperLOPIT data; $\bullet$, BiolD-detection of a protein with a given 'bait'.

$\mathrm{d} P$. berghei zoite stage presence $(\bullet)$ or absence $(\circ)$ of detectible protein-GFP expression by live-cell imaging. e Mutant phenotype fitness scores where more strongly negative scores indicate increasingly detrimental competitive growth in in vitro culture conditions for $T$. gondii tachyzoites [40] or $P$. falciparum blood-stage parasites [41].

${ }^{f}$ Conserved domain abbreviations: EF, EF-hand; Myo, myosin; Cal, Calmodulin-binding motifs; TPR,

Tetratricopeptide repeat; Methyltrans, Methyltransferase; Ax_dyn_light, Axonemal dynein light chain; LLR, leucine-rich repeat; ARM, armadillo repeat; Ribonucl-like, Ribonuclease-like.

* References for localization data: TS, this study. 
SAS6L throughout the conoid body. RNG2 C-terminal reporters locate within the region of the APRs and, given its adherence to the apical ends of the subpellicular microtubules after detergentextraction, it was presumed to be an APR2 location [14,24]. These two markers, for the mobile conoid body and apex of the IMC, provide spatial definition of the relative positions of the new proteins. Moreover, we exploited the motility of the conoid with respect to the apical polar rings to further discriminate which structures our new proteins were associated with by imaging with the conoid in both retracted and protruded positions (Fig 1).

Fig 3. Super-resolution imaging of $T$. gondii proteins at the conoid body and base. Immunodetection of HA-tagged conoid proteins (green) in cells co-expressing either APR marker RNG2 or conoid marker SAS6L (magenta) imaged either with conoids retracted within the host cell, or with conoids protruded in extracellular parasites. (A) Example of protein specific to the conoid body, and (B) examples of proteins specific to the conoid base. See Supplemental Fig S2 and S3 for further examples. All panels are at the same scale, scale bar $=5 \mu \mathrm{m}$, with zoomed inset from white boxed regions (inset scale bar $=0.5 \mu \mathrm{m}$ ).

Using the above strategy, four proteins were seen to be specific to the conoid body (TGME49_274120, TGME49_222350, TGME49_297180, TGME49_291880), the last of which was most enriched in the apical half of the conoid body (Fig 3A and S2). A further three proteins were either specific to (TGME49_246720, TGME49_258090) or enriched at (TGME49_266630, or 'CPH1') the conoid base (Fig 3B and S3A). Seven proteins were observed to be associated with the conoid canopy, four resolving as small rings (TGME49_253600, TGME49_306350, TGME49_202120, TGME49_284620) (Fig 4A and S3B) and three a punctum too small to resolve (TGME49_274160, TGME49_219070, TGME49_209200) (Fig 5A and S3C). All of these proteins showed motility with SAS6L during conoid protrusion and retraction consistent with being attached to the conoid.

Fig 4. Super-resolution imaging of $T$. gondii proteins at the conoid canopy rings and MORN2 at the plasma membrane. (A) Examples of proteins specific to the conoid canopy rings. (B) Peripheral membrane protein (cytosolic leaflet) MORN2 in intracellular parasites. Immunodetection of HA-tagged proteins as for Figure 3. See Supplemental Fig S3 for further examples. All panels are at the same scale, scale bar $=5 \mu \mathrm{m}$, with zoomed inset from white boxed regions (inset scale bar $=0.5 \mu \mathrm{m}$ ).

Fig 5. Super-resolution imaging of $T$. gondii proteins at conoid canopy puncta and the apical polar rings. Immuno-detection of HA-tagged proteins as for Figure 3. (A) Examples of protein specific to the conoid canopy puncta. (B) Examples of proteins specific to the apical polar rings in the vicinity of APR1 (TGME49_208340) and APR2 (TGME49_320030). See Supplemental Fig S3 and S4 for further examples. All panels are at the same scale, scale bar $=5 \mu \mathrm{m}$, with zoomed inset from white boxed regions (inset scale bar $=0.5 \mu \mathrm{m}$ ).

In addition to the conoid proteins, we identified apical proteins associated with the APRs. Two proteins collocated with RNG2 at APR2 (TGME49_320030, TGME49_278780) whereas two proteins (TGME49_208340, TGME49_250840) were distinctly anterior to RNG2 suggesting they might locate to the APR1 at the extreme apex of the IMC (Fig 5B, S4). The epitope markers for two further proteins (TGME49_227000, TGME49_219500) showed intermediate positions between APR1 and APR2 (Fig S4). All of these APR proteins where static with respect to RNG2 when the conoid was protruded.

All protein locations determined by super-resolution microscopy were consistent with proximity to, and detection by, the three BioID baits. 1) SAS6L/RNG2-positive but MORN3-negative signals detected conoid-proximal proteins: proteins of the conoid body, base and one in the canopy 
(TGME49_202120); proteins of APR1; and the proteins between APR1 and APR2. 2) Proteins negative for all three baits occurred at the conoid canopy apparently out of reach of even SAS6L. 3) Proteins detected by all three baits were at the APR2 where the three proteins converge. Thus, these data suggest that the combination of spatial proteomics methods used provided an effective enrichment of conoid-proximal proteins.

During the hyperLOPIT validation of proteins assigned as Plasma Membrane - peripheral 2 (on the cytosolic leaflet), one protein, MORN2, was found to be enriched as an apical punctum [36]. Given the close proximity of the conoid apex to the plasma membrane, and unknown molecular interactions between these cell structures that might occur there, we examined the location of MORN2 by 3D-SIM. MORN2 was seen as a small ring anterior to the conoid with a discernible gap between it and the SAS6L-labelled conoid body (Fig 4B). This location is consistent with MORN2 being associated with the plasma membrane and potentially forming a continuum of the annular structures through from the APRs, conoid base, body, and canopy, to the apical plasma membrane.

\section{Evolutionary conservation of Toxoplasma conoid proteins throughout Alveolata}

Using the expanded knowledge of conoid-associated proteins determined in this study, and previously identified conoid proteins, we then asked the following questions. How conserved is the T. gondii conoid proteome in other apicomplexans and related alveolate lineages (i.e. Apicomonada, Dinoflagellata, Ciliophora)? Is there genomic evidence of conoid presence in Aconoidasida taxa despite the suggestion that this feature was lost from this class of Apicomplexa? To test for the presence or absence of conoid protein orthologues, including highly divergent ones, we used a powerful Hidden Markov Model (HMM) profiling strategy. Briefly, the T. gondii apical proteins were first assigned to clusters of predicted orthologues (orthogroups) along with proteins of 419 taxa belonging to the Stramenopila-Alveolata-Rhizaria (SAR) clade using the OrthoFinder algorithm [56]. The sequences of each orthogroup were then used for sensitive detection of divergent homologues in all 419 taxa using HMM profile searches. To exclude putative paralogues and spurious matches from the potential oversensitivity of the HMM approach from these expanded orthogroups, all collected homologues were used as queries for reverse BLASTp-searches against the $T$. gondii proteome; only homologues that recovered the specific $T$. gondii conoid-associated protein as their best match (Fig 6, red), or no T. gondii proteins (potentially indicative of fast-evolving protein families, Fig 6 orange) were retained as putative orthologues.

Fig 6. Heatmap indicating conservation of conoid-associated proteins among Alveolata. Presences (red, orange) and absences (white) of putative orthologues of $54 \mathrm{~T}$. gondii conoidassociated proteins (Table 1) in 157 surveyed Alveolata species (see Fig S5 for taxa). ToxoDB protein numbers (left) and existing protein names (right) are shown. In case of a presence, the taxon either contains at least one homologous sequence that has the $T$. gondiii protein as its best BLASTp match (red), or it has only homologous sequences that were obtained via sensitive HMMer searches but that did not retrieve a $T$. gondii match by BLASTp, indicative of more divergent homologues (see Methods). The proteins are shown clustered according to their binary (presence-absence) patterns across the Alveolata. Known protein locations in T. gondii are indicated by colour (see key) where 'apex' indicates low resolution imaging of an apical punctum, only. The species tree (top) shows phylogenetic relationships and major clades: Piropl., Piroplasmida; Crypt., Cryptosporidium; Greg., Gregarinasina; green shading, Perkinsozoa; brown shading, Colponemida. Columns for species of interest are darkened and indicated by a triangle at the bottom of the figure (A-P) - A: Toxoplasma gondii; B: Sarcocystis neurona; C: Eimeria tenella; D: Plasmodium berghei; E: Plasmodium falciparum; F: Babesia bovis; G: Theileria parva; H: Nephromyces sp.; I: Cryptosporidium parvum; J: Chromera velia; K: Vitrella brassicaformis; L: Symbiodinium microadriaticum; M: Perkinsus marinus; N: Tetrahymena thermophila; O: Stentor coeruleus; P: Colponemida. For each species the source of 
the protein predictions is indicated: genome (DNA, green) or transcriptome (RNA, dark red), along with BUSCO score as estimates of percentage completeness.

The presence or absence of orthologues for the 54 conoid-associated proteins found in 157 Alveolata taxa is displayed in Fig 6, with proteins clustered according to their phylogenetic distributions. This orthology inventory shows that $T$. gondii conoid-associated proteins are most highly conserved in other coccidians. In Sarcocystidae (other than Toxoplasma) average completeness is $92 \%$, whereas in the Eimeriidae it is $69 \%$ (Table S3). In other major apicomplexan groups, the average representation of the $T$. gondii conoid-associated proteins are; Plasmodium spp. 53\%, Piroplasmida $33 \%$, Cryptosporidium spp. $50 \%$, and Gregarinasina $36 \%$ (but over $60 \%$ for some taxa). It is noteworthy that Cryptosporidium spp. and gregarines possess conspicuous conoids and that they share a similar subset of the $T$. gondii conoid proteome with members of the Aconoidasida. Furthermore, these common proteins include proteins that locate to specific conoid substructures in $T$. gondii: conoid base, body and conoid canopy. Taxon-specific absences of $T$. gondii orthologues could represent protein loss in those taxa, gain of novel proteins specific to coccidians, or rapid evolution of the primary protein sequence that results in failure of orthologue detection. Collectively, however, these data support the conoid and associated structures as being conserved throughout apicomplexans, including members of the Aconoidasida.

Many putative orthologues of conoid-related proteins are also found in the related clades of Myzozoa (Fig 6, Table S3). Apicomonada, that includes the nearest photosynthetic relatives of apicomplexans such as Chromera velia, have on average 33\% of the T. gondii proteins and up to 53\% for the free-living predatory Colpodella angusta. Dinoflagellates have on average $48 \%$ of $T$. gondii proteins, but up to $70 \%$ for some early-branching parasitic taxa (Amoebophyra spp.). Molecular evidence in many of these taxa is based on RNA-Seq so might be less complete than when genomic data is available, as is suggested by lower BUSCO scores (this is also the case for many gregarines) (Fig 6, Table S3). Nevertheless, there is strong evidence of conservation of the core conoid proteome in these clades also (Fig 6). These data are consistent with ultrastructural evidence of a conoid and apical complex involved in feeding and parasitism in these taxa $[5,57]$. Ciliates show evidence of fewer of the conoid proteins being present, yet some are found even in this basal clade of Alveolata. There is further evidence of broadly conserved apical proteins in alveolates detected by our spatial proteomic approaches (95 proteins, Fig S5, Table S3), but many of these remain to have their specific apical locations determined.

\section{Conoid proteins locate to apical rings in Plasmodium zoites}

To test if orthologues of $T$. gondii conoid-associated proteins occur in equivalent apical structures in Plasmodium, nine orthologues were selected for reporter tagging in P. berghei (Table 1). This model provided ready access to all three invasive zoite forms of the parasite: the ookinete and sporozoite forms produced in the mosquito vector, and the merozoite form of the mammalian blood-staged infection. The nine proteins represented the three sites associated with the conoid (base, walls and canopy) as well as APR1 and APR2 (PBANKA_907700 and PBANKA_1334800, respectively). GFP fusions of these proteins were initially observed in the large ookinete form by live cell widefield fluorescence imaging, and an apical location was seen for all (Fig 7A). Eight of these proteins were resolved only as a dot or short bar at the extreme apical end of the cell, whereas the APR2 orthologue (PBANKA_1334800) presented as an apical cap.

Fig 7. Live cell widefield and super-resolution imaging of $P$. berghei ookinetes expressing GFP fusions of conoid complex orthologues. T. gondii orthologue locations are shown in Figs 3-5. (A) Widefield fluorescence imaging showing GFP (green), Hoechst 33342-stained DNA (grey), and live cy3-conjugated antibody staining of ookinete surface protein P28 (magenta). (B,C) 3DSIM imaging of fixed GFP-tagged cell lines for conoid orthologues (B) or apical polar ring 
orthologues (C) with same colours as before (A). Inset for APR protein (1334800) shows rotation of the 3D-reconstruction to view the parasite apex face on. All panels are at the same scale, scale bar $=5 \mu \mathrm{m}$, with zoomed inset from yellow boxes (inset scale bar $=0.5 \mu \mathrm{m}$ or $1 \mu \mathrm{m}$ for 1334800).

To further resolve the location of the $P$. berghei apical proteins, 3D-SIM was performed on fixed ookinetes for eight proteins representing the different presentations found in $T$. gondii. The $P$. berghei orthologue of the conoid wall protein (PBANKA_0310700) was resolved as a ring at the cell apex, and this structural presentation was also seen for orthologues of the conoid base (PBANKA_1216300) and canopy rings (PBANKA_1347000, PBANKA_1419000) (Fig 7B). Further, two orthologues that are unresolved conoid canopy puncta in $T$. gondii are seen in $P$. berghei to mimic this presentation either as an apical punctum (PBANKA_1025300) or a barely resolved small ring (PBANKA_1313300) (Fig 7B). The APR2 orthologue (PBANKA_1334800) that showed a broader cap signal by widefield imaging was revealed as a ring of much larger diameter than the rings of the conoid orthologues (Fig 7B). Furthermore, short spines radiate from this ring in a posterior direction that account for the cap-like signal at lower resolution. The location of this protein is consistent with an APR2 function, although more elaborate in structure than what is seen in T. gondii (see Fig 5B). Finally, the APR1 orthologue (PBANKA_0907700) also resolved as a ring of larger diameter than the conoid orthologues, and apparently closer to the apical cell surface than APR2 orthologue PBANKA_1334800 (Fig 7B). In all cases examined, the locations and structures formed by the Plasmodium orthologues were equivalent to those of $T$. gondii, strongly suggestive of conservation of function.

Transmission electron micrographs (TEMs) of $P$. berghei ookinetes further support the presence of conoidal ring structures implied by our proteomic data and microscopy (Fig 8, Fig S6). At the apex of Plasmodium ookinetes, the IMC and subpellicular microtubules are separated by a thick collar that presents as an outer electron-dense layer and an inner electron-lucent layer (Fig 8B-F). This collar displaces the APR2 approximately $100 \mathrm{~nm}$ posterior to APR1. Within the APR1, three further rings can be seen in either cross section or tangential section, the posterior of the three rings is thicker than the anterior two (Fig 8B-D). The most apical of these rings is often seen to distend the plasma membrane creating a small apical protrusion, and thin ducts from the micronemes can be seen extending through all three of these rings to the plasma membrane (Fig $8 \mathrm{~A}$ inset, B-E). This ultrastructure is consistent with equivalent conoidal ring structures observed in Toxoplasma (Fig 1): two conoid canopy rings atop conoid walls that are reduced in height and skeletal components compared to Toxoplasma and other apicomplexans.

Fig 8. Ultrastructure of conoid complexes of $P$. berghei zoites. Transmission electron micrographs of $P$. berghei zoites: ookinetes (A-F), sporozoites (G-J), and blood stream merozoites (K-M). (A) Longitudinal section through an ookinete showing the apical complex with micronemes (M) plus the crystalline body ( $\mathrm{Cr}$ ). Insert: Detail of the apical cytoplasm showing a microneme (M) with a duct running towards the anterior (arrows). (B-E) Details of longitudinal and tangential sections through the apical complex with either two or three conoidal rings (CR) evident with the anterior collar consisting of an outer electron dense layer (cd) closely adhering to the IMC which formed the anterior polar ring (P1) and an inner electron lucent layer $(\mathrm{Cl})$ which is closely associated with subpellicular microtubules $(\mathrm{Mt})$ which forms the inner polar ring (P2). Underlying micronemes (M) with ducts (D) extend to the cell apex. F. Cross section through part of the apical collar showing the ookinete plasma membrane (pl) with the underlying IMC closely adhering to the electron dense layer of the collar (cd) with the more electron lucent region (cl) closely associated with subpellicular microtubules (Mt). (G) Longitudinal section through a sporozoite showing the anteriorly located rhoptries $(R)$ and micronemes $(\mathrm{M})$ and the central nucleus $(\mathrm{Nu})$. $(\mathrm{H}-\mathrm{I})$. Detail of the anterior of the mature 
sporozoites showing the conoidal rings (CR) and the in-folding of the IMC to form the first apical polar ring (P1) with second apical polar ring beneath (P2) associated with the subpellicular microtubules (Mt). Note the angled formed by the apical polar rings relative to the longitudinal cell axis. (J) Longitudinal section of an early stage in sporozoite formation showing apical conoidal rings $(\mathrm{CR})$ and the perpendicular projection of the conoidal and apical polar rings. (K) Longitudinal section through a spherical shaped merozoite released from an erythrocyte showing the rhoptries (R), micronemes (M) and nucleus (Nu). (L-M) Enlargement of the apical region showing the conoidal rings (CR) and the closely applied polar rings (P1, P2). Scalebar represent $1 \mu \mathrm{m}(\mathrm{A}, \mathrm{G}, \mathrm{K})$ and $100 \mathrm{~nm}$ in all others. See also Fig S6 and S7.

\section{Conoid-type structures are present but compositionally distinct between vector and mammalian Plasmodium zoite forms}

The presence of a possible conoid in Plasmodium has been previously attributed to the ookinetestage [26], but the conoid is widely considered to be absent from asexual blood-stage merozoites. With our new markers for components of apparent conoid-associated structures in P. berghei, we tested for presence and location of these proteins in the other zoite stages: sporozoites and merozoites (Fig 8G-M). In sporozoites all proteins tested for are detected at the cell apex (Fig 9A) and super-resolution imaging of five of these again showed either a ring or unresolved apical punctum (Fig 9B).

Fig 9. Live cell widefield, and super-resolution imaging of $P$. berghei sporozoites expressing GFP fusions of conoid complex orthologues. (A) Widefield fluorescence imaging showing GFP (green) and Hoechst 33342-stained DNA (grey). All panels are at the same scale, scale bar $=5$ $\mu \mathrm{m}$, with the exception of zoomed images from white boxed regions in the merge. $(B, C)$ Superresolution imaging of GFP-fused conoid complex proteins (green) in fixed cells shown with the cell surface stained for sporozoite surface protein 13.1 (magenta). All panels are at the same scale, scale bar $=5 \mu \mathrm{m}$, with zoomed inset from white boxed regions (inset scale bar $=0.5 \mu \mathrm{m}$ ).

In merozoites, of the nine proteins tested for, only six were detected in this alternative zoite form of the parasite, and this is generally consistent with differential transcript expression profiles of these nine genes (Table 1, Fig S8). The conoid wall (PBANKA_0310700) and base (PBANKA_1216300) orthologues were not detected in this cell form, nor was the APR2 protein (PBANKA_1334800). However, all five of the other conoid orthologues are present in merozoites as well as the APR1 protein (PBANKA_0907700), each forming an apical punctum juxtaposed to the nucleus consistent with apical location (Fig 10). These data support conservation of conoid constituents in the apical complex of both sporozoites and merozoites, but either a reduction in the complexity of this structure in merozoites or the possible substitution for other proteins that are yet to be identified.

Fig 10. Live cell imaging of $P$. berghei merozoites expressing GFP fusions of conoid complex orthologues. Widefield fluorescence imaging showing GFP (green) and Hoechst 33342-stained DNA (grey) with some parasites seen pre-egress from the erythrocyte and others post egress. All panels are at the same scale, scale bar $=5 \mu \mathrm{m}$ shown, with zoomed inset from white boxed regions (inset scale bar $=2 \mu \mathrm{m}$ ).

\section{Discussion}

The discovery of the conoid was one of the early triumphs of electron microscopy applied to thin biological samples. The term 'conoid' was coined by Gustafson et al in 1954 to describe the hollow truncated cone observed first in Toxoplasma [58]. They described this structure as having "no close anatomical parallel ... in other protists", and it provided the first identification of the penetration device used by apicomplexan parasites. While the spiralling tubulin-rich fibres of the conoid wall 
attract most attention, this cell feature is actually part of a continuum of structures better described as the 'conoid complex' (Fig 11) [5]. This complex starts at the apical limits of the IMC coordinated by the two APRs $[23,59,60]$. The conoid is tethered by its base within these APRs [24] and is in close proximity and probable interaction with the plasma membrane via the apical conoid canopy. Proteins have been previously located to all of these 'substructures' including some linking one substructure to the next [5]. Indeed, the apparent spatial separation of compartments by ultrastructure is smaller than the size of many of the individual molecules that build it [24]. Thus, at a molecular level it is unclear what the limits of any one substructure are, if this is even a biologically relevant notion.

Fig 11. Conservation and variability of the conoid complex in apicomplexan zoite forms. Schematics of cell apices from Toxoplasma and Plasmodium showing presence of common structures but displaying variability in their size and arrangement. Toxoplasma is shown with either the conoid retracted or protruded. A row of vesicles of unknown function line the intraconoidal microtubules in Toxoplasma and other coccidians. Schematics draw on both TEM and EM tomography data that is presented or cited throughout the report.

In this study we have provided a substantial expansion of knowledge of the molecular composition and architecture of the conoid complex in T. gondii. Previous identification of conoid complex proteins used methods including subcellular enrichment, correlation of mRNA expression, and proximity tagging (BioID) $[30,31,44]$. Amongst these datasets many components have been identified, although often with a high false positive rate. For example, the seminal conoid proteomic work of Hu et al. (2006) [44] detected approximately half of the proteins that we report (49 of 95, see Table S1). However, in their study a further 329 proteins that fractionated with the conoid ( $\geq 2$ fold enriched; ToxoDB Release 49) included many identifiable contaminants including known cytosolic, ribosomal, mitochondrial, apicoplast and microneme proteins. We have found the hyperLOPIT strategy to be a powerful approach for enriching for proteins specific to the apex of the cell, and BiolD has further refined identification of proteins specific to the conoid complex region. Collectively, we now know of 54 proteins that locate at the conoid complex (Table 1), with a dataset of many further proteins that await closer inspection (Table S1). Moreover, we have used highresolution microscopy to define the specific locations of many, and these show dedicated locations from the APRs through to proteins tethered to the plasma membrane. These data reveal a molecularly complex feature well beyond its tubulin component.

The conservation of a large part of the conoid complex proteome throughout Apicomplexa suggests that this is a cell feature maintained throughout the phylum. Conservation includes proteins from all substructural elements suggesting the maintenance of this structure in its entirety rather than only select elements. Where clade-specific losses of sets of genes are seen, these are not enriched for specific conoid complex locations that would indicate losses of select substructures (Fig 6, S3). It is to be noted that, in some cases, the predicted absence of proteins might represent false negative due to extreme protein divergence. While our reverse BLASTp criterion performed well to prevent inclusion of non-homologous proteins and distant paralogues, it might have eliminated highly divergent, but bona fide, orthologues. The phylogenetic distributions of identifiable conoid complex proteins may also provide some clues to protein function. Proteins that interact or contribute to a common molecular function are likely to co-evolve. The phylogenetic distributions of presence, absence or divergence of conoid complex proteins might, therefore, provide evidence of molecular cooperation, including that spanning or linking conoid complex substructures. Gene knockout studies in both $T$. gondii and $P$. falciparum indicate that proteins in all parts of the conoid complex play key roles in parasite viability, including in the blood-stage of Plasmodium that has an apparently reduced or modified conoid complex (Table 1). Collectively, our data strongly suggest the 
conservation of the conoid complex in Aconoidasida, including in the piroplasms where microscopy has, so far, also failed to identify some of these structures.

Conoid complex proteins are also seen in Apicomplexa's sister clades, most notably in other lineages of Myzozoa. These data provide the first molecular support for previous hypotheses that the similar ultrastructure of 'apical complexes', that function in both parasitism and predation in these myzozoan relatives, represent genuine homologous structures of the apicomplexan conoid complex $[5,12]$. The presence of some conoid complex protein homologues in ciliates and the ancestral freeliving predatory colponemids might indicate an even more ancient origin of this structure, or perhaps the repurposing of existing ancestral proteins into a derived apical complex structure in apicomplexans. Further protein phylogenetic analyses combined with proteomics and microscopy in non-apicomplexan lineages will be necessary to test these hypotheses.

The prior interpretation of a conoid being absent in Plasmodium stages, and in other Aconoidasida, mostly stems from the lack of a conspicuous extended tubulin fibrous conoid wall as seen by electron microscopy in coccidians, Cryptosporidium spp. and gregarines. A microtubular component of the conoid, however, has been reported from other members of order Haemosporida such as in ookinetes of Leucocytozoon and Haemoproteus, although in dramatically reduced form [59,61]. In both taxa three conoidal rings are present with the posterior one containing microtubules. In Leucocytozoon only a few microtubules remain, observable in longitudinal section but with some difficulty due to the surrounding density of other molecules. With any further reduction in the tubulin component in Plasmodium spp., or other Aconoidasida, detection of conoid tubulin by ultrastructural approaches would be even more challenged. However, the very recent application of ultrastructure expansion microscopy (U-ExM), in combination with anti-tubulin staining, has revealed that a ring of tubulin is present in $P$. berghei ookinetes at the very apex of the cell, beyond the apical termini of the subpellicular microtubules at APR2 [62]. This position is consistent with the location of the three conoidal rings we observe by TEM (Fig 8B-D) and the thicker posterior conoidal ring is the most likely location of this tubulin given its presence here in Haemoproteus and Leucocytozoon. It is unknown if this tubulin forms a canonical microtubule, or a modified fibre such as that in the Toxoplasma conoid. Nevertheless, it is now apparent that there can be tubulin components of the apical complex ring(s) in apicomplexans that have previously evaded detection by electron microscopy. This presence of tubulin in a Plasmodium conoid complex provides additional support to our data showing the conservation of numerous conoid-associated proteins in all Plasmodium zoite forms. We have previously shown that SAS6L and Myosin B locate to an apical ring in Plasmodium also [42,63], and these co-locate with the tubulin ring in Plasmodium ookinetes [62].

Collectively, these data suggest that the core architectural and compositional elements of the conoid complex are present in most apicomplexan zoites, although with variation in the size and presentation of some of these features (Fig 11). The apical polar rings APR1 and APR2 manage the apical opening in the cell pellicle. In Plasmodium ookinetes, the conspicuous thick collar defines the separation of the IMC from the subpellicular microtubules. We note that in Plasmodium sporozoites an annular plaque of electron-lucent material is also present and corresponds to a tight reorientation of the apical IMC with respect to the APR2 (Fig 8H-I, 11, S7) [64]. In merozoites, and also Toxoplasma tachyzoites, APR1 and APR2 are even closer together than in these other zoites, however, it is likely that some proteinaceous network manages their relative positions also. We note electron density between these rings in both of these zoite forms that might provide this function (Fig 1B-C, 8K-M, S7). In support of a common 'collar', the APR protein (PBANKA_1334800) apparently contributes to the collar of ookinetes as spines (Fig 7) reminiscent of the translucent columns, socalled 'tines', of ookinetes of other Haemosporida species [59,60,65]. In sporozoites and $T$. gondii tachyzoites this protein also forms a ring although without the spines, consistent with the 
contraction of this collar structure. Our study has identified multiple other T. gondii APR proteins with distinct anterior or posterior positions at the sites of these rings. Caution is required making inferences of precise protein occupancy with protein terminal reporters and the high spatial resolution achieved by 3D-SIM [24]. Nevertheless, our data suggest that some proteins might be specific to APR1, some to APR2, and some are at intermediate positions that might represent further collar components. These subtle differences in APR protein location seen in $T$. gondii are consistent with the positions of their orthologues in P. berghei (Fig 7B, PBANKA_1334800 versus PBANKA_090770).

Within the APRs of all Plasmodium zoite forms are further conoidal rings, variously named 'apical rings', 'apical polar rings' or 'polar rings' in past literature for previous lack of recognisable identity $[25,27,66]$. Three discernible conoidal rings in ookinetes are consistent with substantial contraction of the tubulin-containing conoid body walls and persistence of the two apical conoidal rings (Fig 11). In sporozoites the number of conoidal rings is less clear, we discern at least two (Fig $8 \mathrm{H}-\mathrm{J}$ ) although others have suggested more $[67,68]$. In merozoites there are more clearly only two $[27,69]$. It is unknown if this reduction represents loss or merger of conoidal rings. However, the presence in all of these Plasmodium forms of proteins that occur at the base, walls and canopy of the Toxoplasma conoid suggests compression of the overall conoid rather than loss of distinct elements.

The variation in the length of the conoid in Plasmodium compared with that seen in coccidians, Cryptosporidium and gregarines might reflect different mechanical properties and needs for these cells within their target host environments. It is presumed that the conoid in Toxoplasma, with its pronounced motility, provides a mechanical role in invasion. It is poorly known if this high level of motility is seen more widely in other apicomplexans, but it might be an adaptation in Toxoplasma to the tremendously wide range of hosts and cell types that its zoites must invade, including penetrating thick mucilaginous layers at the gut epithelium. A reduction in this structural and mechanical element of the Plasmodium conoid complex likely reflects either the different invasion challenges presented by its hosts, or different solutions that these parasites have evolved.

Evolutionary change in the architecture and composition of the conoid complex across taxa is further supported by differentiation of its proteome between the different Plasmodium zoite forms. We observe the blood-stage merozoite conoid proteome to be further reduced, or modified, when compared to ookinetes and sporozoites, and we previously observed SAS6L to be also absent from merozoites but present in ookinetes and sporozoites (Table 1) [42]. The differentiation of the merozoite apical complex also includes the absence of the APR2 protein that extends into the collar. Perhaps this elaboration of the collar in ookinetes is a Plasmodium adaptation in lieu of the extendibility of the conoid complex displayed by Toxoplasma and other coccidians [17]. In Plasmodium these compositional and structural differences have likely been produced by the different zoite stages' invasion requirements between merozoites entering erythrocytes and the multiple penetration events for the ookinetes to reach the mosquito gut basal lamina, or the sporozoites to reach this vector's salivary glands and then mammalian hepatocytes [70]. Ookinete and sporozoite apical complexes might be under further selection by their need for high invasion competence. Each stage represents a transmission bottleneck with success among only one or few parasites required for onward transmission [71]. Increased investment in a robust and reliable apparatus might be justified at these important transmission points.

Evidence of conserved elements of the conoid and conoid complex throughout Apicomplexa, despite differences in construction and ultrastructure, raises the question of what are the functions of this structure and are they common throughout the phylum? Indeed, even in Toxoplasma the function of the conoid is relatively poorly understood. Most studies of individual protein elements have identified molecules required for its assembly and stability [29,31-35]. But other studies have 
bioRxiv preprint doi: https://doi.org/10.1101/2020.06.26.174284; this version posted December 7,2020 . The copyright holder for this preprint (which was not certified by peer review) is the author/funder, who has granted bioRxiv a license to display the preprint in perpetuity. It is made available under aCC-BY-NC-ND 4.0 International license.

implicated roles in control processes, including activating motility and exocytosis, both of which are requirements for invasion as well as host egress events $[24,28,30]$. Indeed, the conoid is intimately associated with both exocytic vesicles and the apex of the plasma membrane, and this is a common trait throughout not just Apicomplexa but other myzozoans including perkinsids and dinoflagellates $[18-20,72]$. The conoid complex proteome is enriched for domains that mediate protein-protein interactions as well as responses to regulatory molecules (e.g., $\mathrm{Ca}^{2+}$, cyclic nucleotides) or regulatory protein modifications, and these features are seen in many of the proteins conserved widely amongst taxa (Table 1, Fig 6). This speaks to the conoid complex comprising an ordered regulatory platform for control of vesicle trafficking, fusion and fission, as well as initiation of cell motility. Such a feature as this seems unlikely to be superfluous and lost in these parasites so heavily dependent on mediating complex interactions with hosts through this portal in an otherwise obstructed elaborate cell pellicle. Recognising the common components and importance of the conoid complex throughout Apicomplexa is highly relevant to understanding the mechanisms of invasion and host interaction and the pursuit of better drugs and intervention strategies to combat the many diseases that they cause.

\section{Acknowledgments:}

We are grateful to Mike Deery who performed the LC-MS/MS analysis of peptide samples, Julie Howard Murkin for data processing of the BioID LC-MS/MS (both at the Cambridge Centre for Proteomics), Emilie Daniel for technical assistance with P. berghei cell line generation, and Yi-Wei Chang and Maryse Lebrun for useful discussions. We are grateful for support and assistance with super-resolution imaging at the Cambridge Advanced Imaging Centre and the Gurdon Institute, and thank Nicola Lawrence for imaging support. This work was supported by the Medical Research Council (MR/M011690/1 to R.F.W.; G0900278 and MR/K011782/1 to R.T.) the Wellcome Trust through Investigator Award $214298 / Z / 18 / Z$ to R.F.W and an equipment grant to D.J.P.F, the Isaac Newton Trust - Leverhulme Trust through Early Career Fellowship ECF-2015-562 to K.B., and the Biotechnology and Biological Sciences Research Council (BB/N017609/1) to R.T. L.E. is supported by an ERC Starting Grant from the European Research Council (ERC) (grant agreement No 803151). 


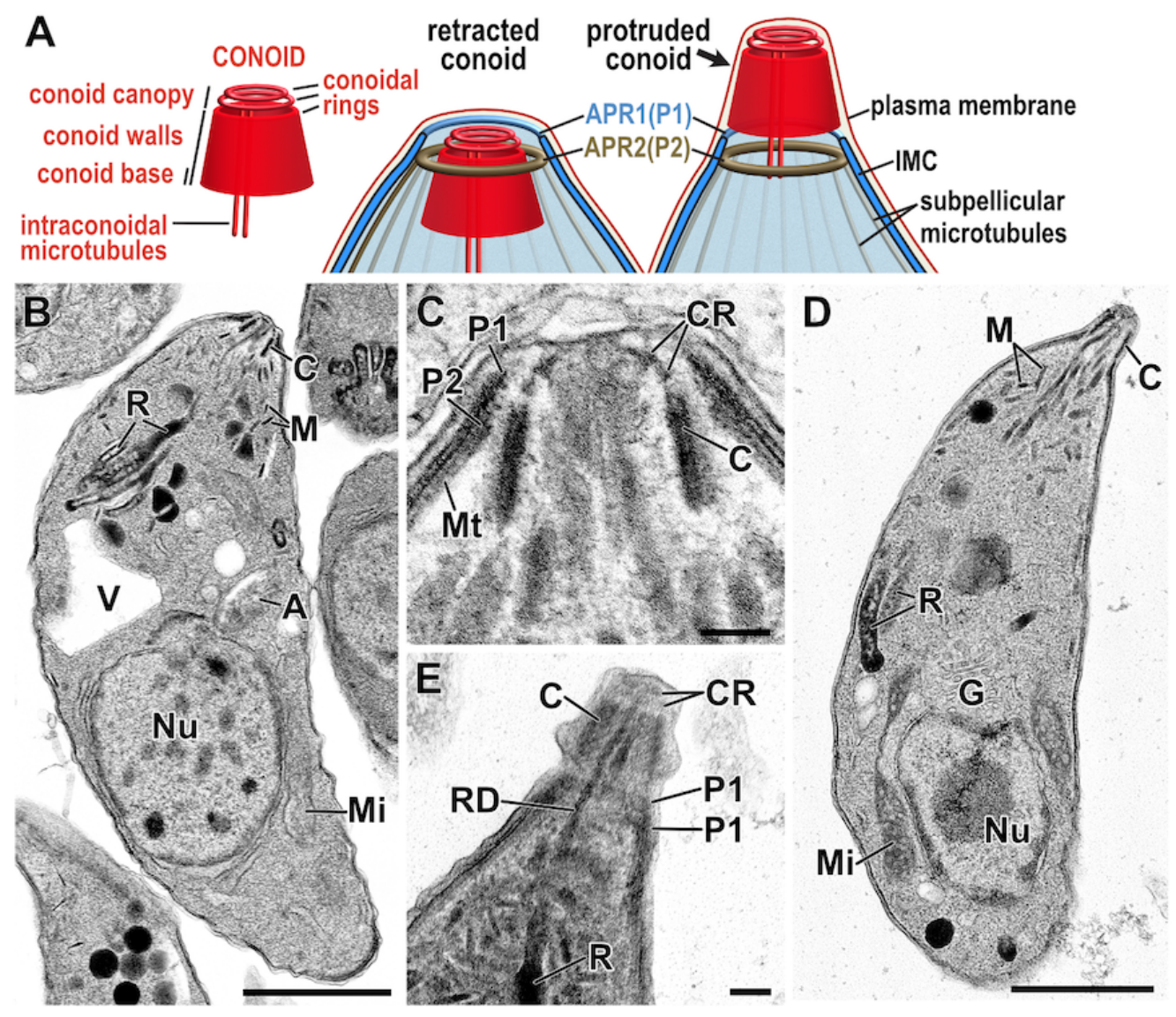

Fig 1. Conoid complex features in Toxoplasma tachyzoites. (A) Schematic of the recognised components of the conoid and their location within the apical structures of the cell pellicle in either retracted or protruded states. (B-E) Transmission electron micrographs of $T$. gondii tachyzoites with conoid either retracted $(B, C)$ or protruded $(D, E)$. Tubulin filaments of the conoid walls are evident in tangential section (E) and two conoidal rings (CR) of the conoid canopy are evident at the conoid's anterior end $(D, E)$. The conoid is surrounded by two apical polar rings (P1 and P2) formed by the anterior aspect of the inner membrane complex and anchoring the subpellicular microtubules (Mt), respectively. Rhoptry ducts (RD) can be seen running to the apex through conoid (E). C, conoid; $M$, micronemes; $R$, rhopties; $V$, plant-like vacuole; $\mathrm{A}$, apicoplast; $\mathrm{Nu}$, nucleus; $\mathrm{Mi}$, mitochondrion; $\mathrm{G}$, Golgi apparatus. Scalebar represent $1 \mu \mathrm{m}(B, D)$ and $100 \mathrm{~nm}(C, E)$. 

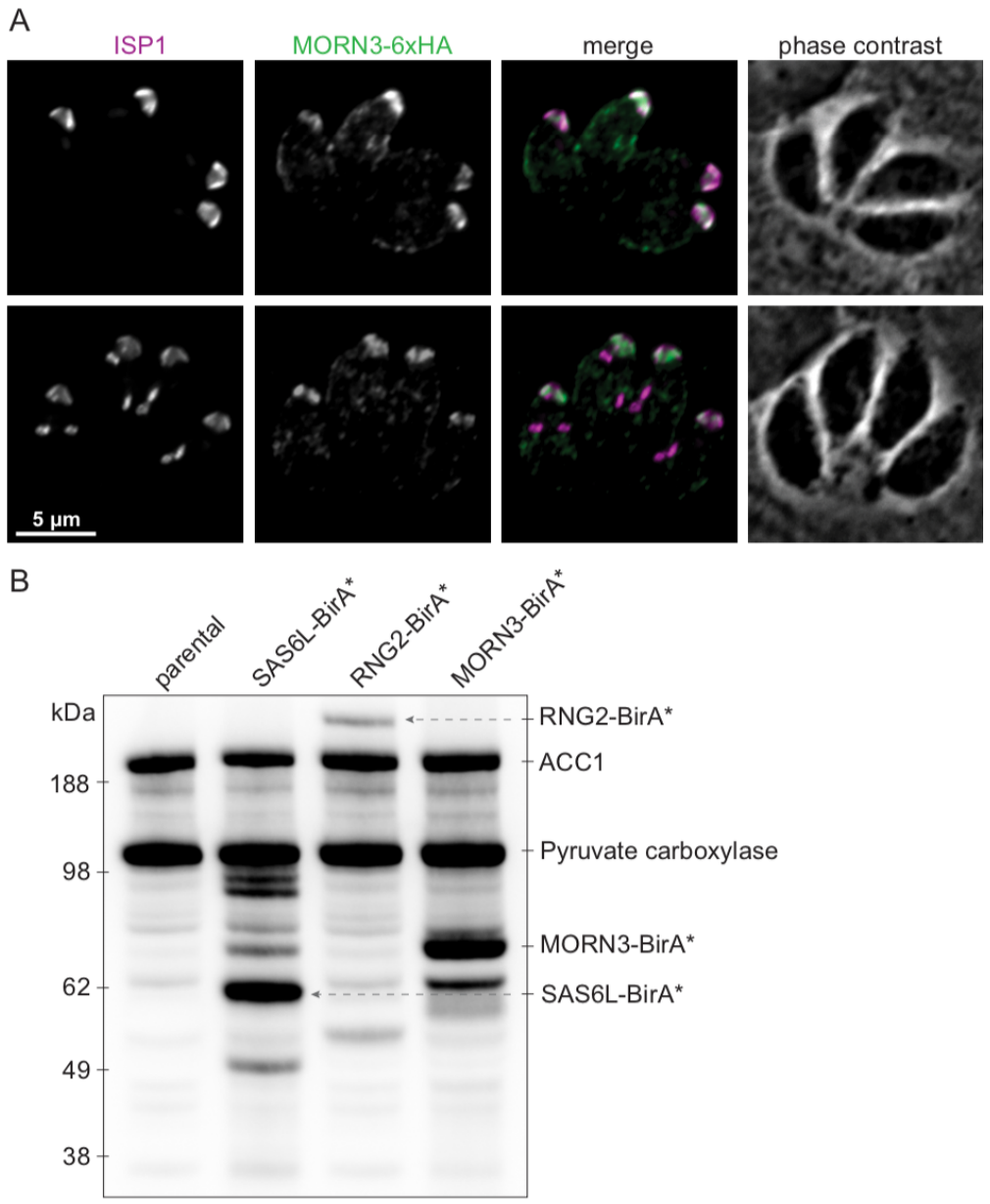

Fig 2. Apically targeted BioID using baits RNG2, SAS6L and new apical cap protein MORN3. (A) Immuno-detection of HA-tagged MORN3 in T. gondii intracellular parasites co-stained for apical cap-marker ISP1. Upper panels show mature cells, lower panels show internal daughter pellicle buds forming during the early stages of endodyogeny. Scale bar $=5 \mu \mathrm{m}$. (B) Steptavidin-detection of biotinylated proteins after 24 hours of growth with elevated biotin. Native biotinylated proteins Acetyl-CoA carboxylase (ACC1) and pyruvate carboxylase are seen in the parental control (lacking BirA*) and in the BiolD bait cell lines. Additional biotinylated proteins are seen in each of the bait cell lines grown with elevated biotin, including self-biotinylation of the bait fusion. 

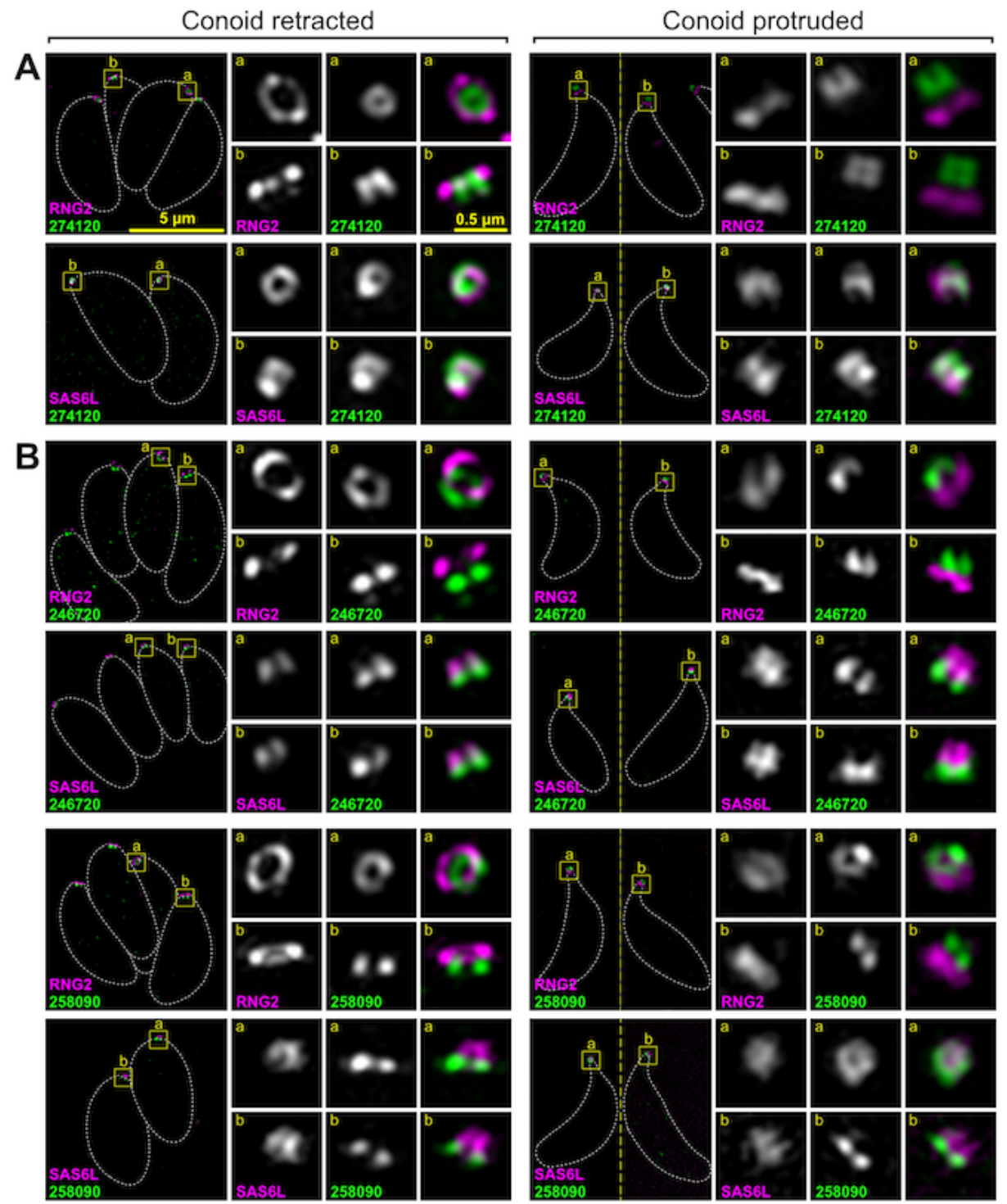

Fig 3. Super-resolution imaging of $T$. gondii proteins at the conoid body and base. Immunodetection of HA-tagged conoid proteins (green) in cells co-expressing either APR marker RNG2 or conoid marker SAS6L (magenta) imaged either with conoids retracted within the host cell, or with conoids protruded in extracellular parasites. (A) Example of protein specific to the conoid body, and (B) examples of proteins specific to the conoid base. See Supplemental Fig S2 and S3 for further examples. All panels are at the same scale, scale bar $=5 \mu \mathrm{m}$, with zoomed inset from white boxed regions (inset scale bar $=0.5 \mu \mathrm{m}$ ). 
A
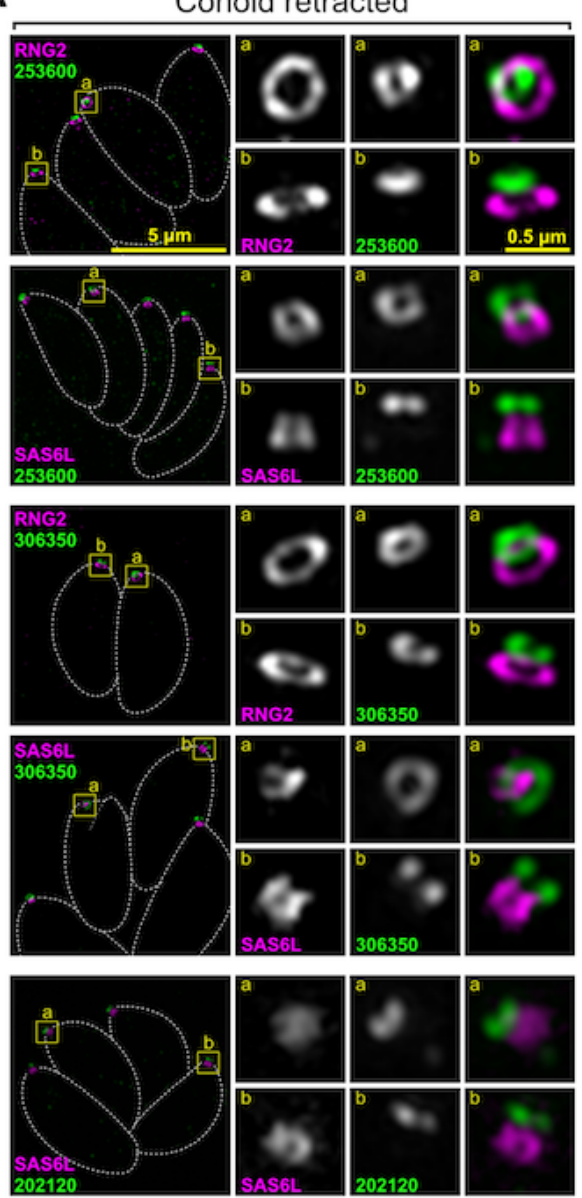

B

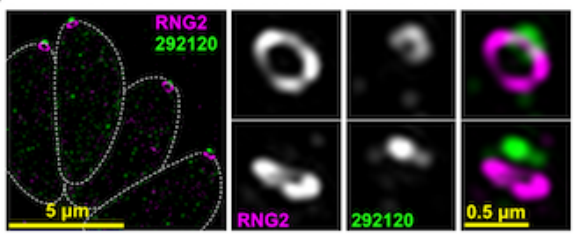

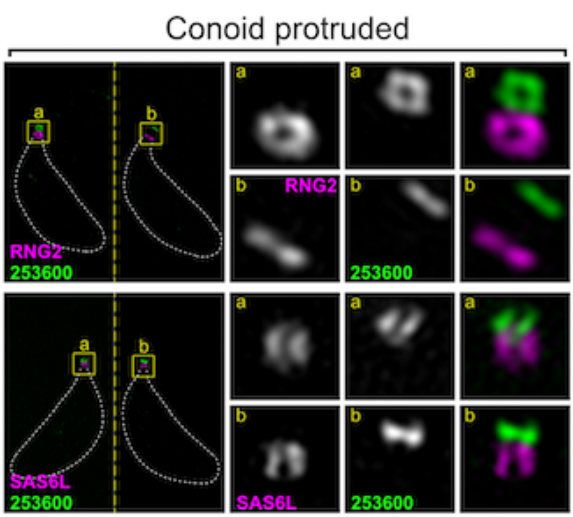
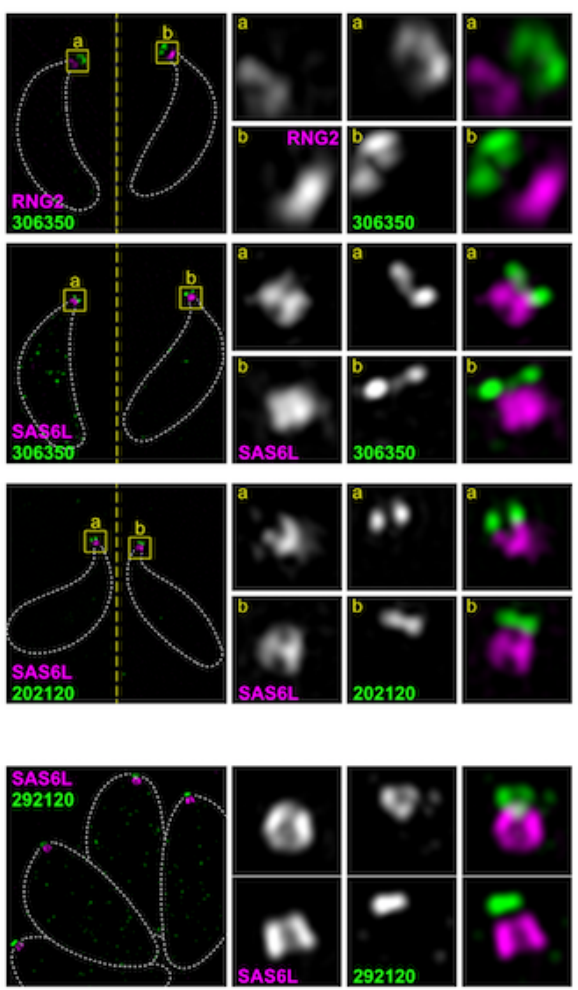

Fig 4. Super-resolution imaging of $T$. gondii proteins at the conoid canopy rings and MORN2 at the plasma membrane. (A) Examples of proteins specific to the conoid canopy rings. (B) Peripheral membrane protein (cytosolic leaflet) MORN2 in intracellular parasites. Immunodetection of HA-tagged proteins as for Figure 3. See Supplemental Fig S3 for further examples. All panels are at the same scale, scale bar $=5 \mu \mathrm{m}$, with zoomed inset from white boxed regions (inset scale bar $=0.5 \mu \mathrm{m}$ ). 

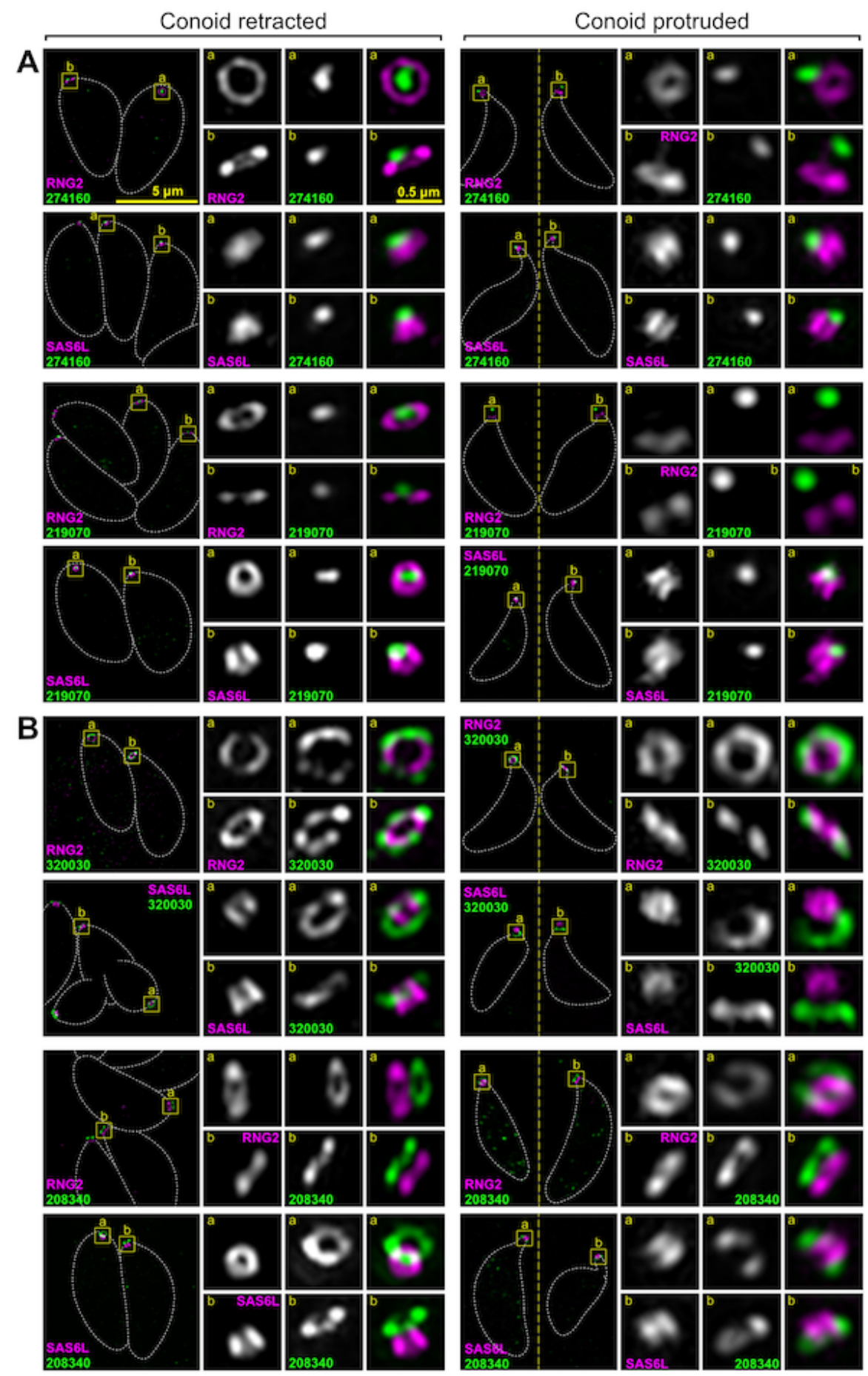

Fig 5. Super-resolution imaging of $T$. gondii proteins at conoid canopy puncta and the apical polar rings. Immuno-detection of HA-tagged proteins as for Figure 3. (A) Examples of protein specific to the conoid canopy puncta. (B) Examples of proteins specific to the apical polar rings in the vicinity of APR1 (TGME49_208340) and APR2 (TGME49_320030). See Supplemental Fig S3 and S4 for further examples. All panels are at the same scale, scale bar $=5 \mu \mathrm{m}$, with zoomed inset from white boxed regions (inset scale bar $=0.5 \mu \mathrm{m}$ ). 
bioRxiv preprint doi: https://doi.org/10.1101/2020.06.26.174284; this version posted December $7,2020$. The copyright holder for this preprint (which was not certified by peer review) is the author/funder, who has granted bioRxiv a license to display the preprint in perpetuity. It is made available under aCC-BY-NC-ND 4.0 International license.

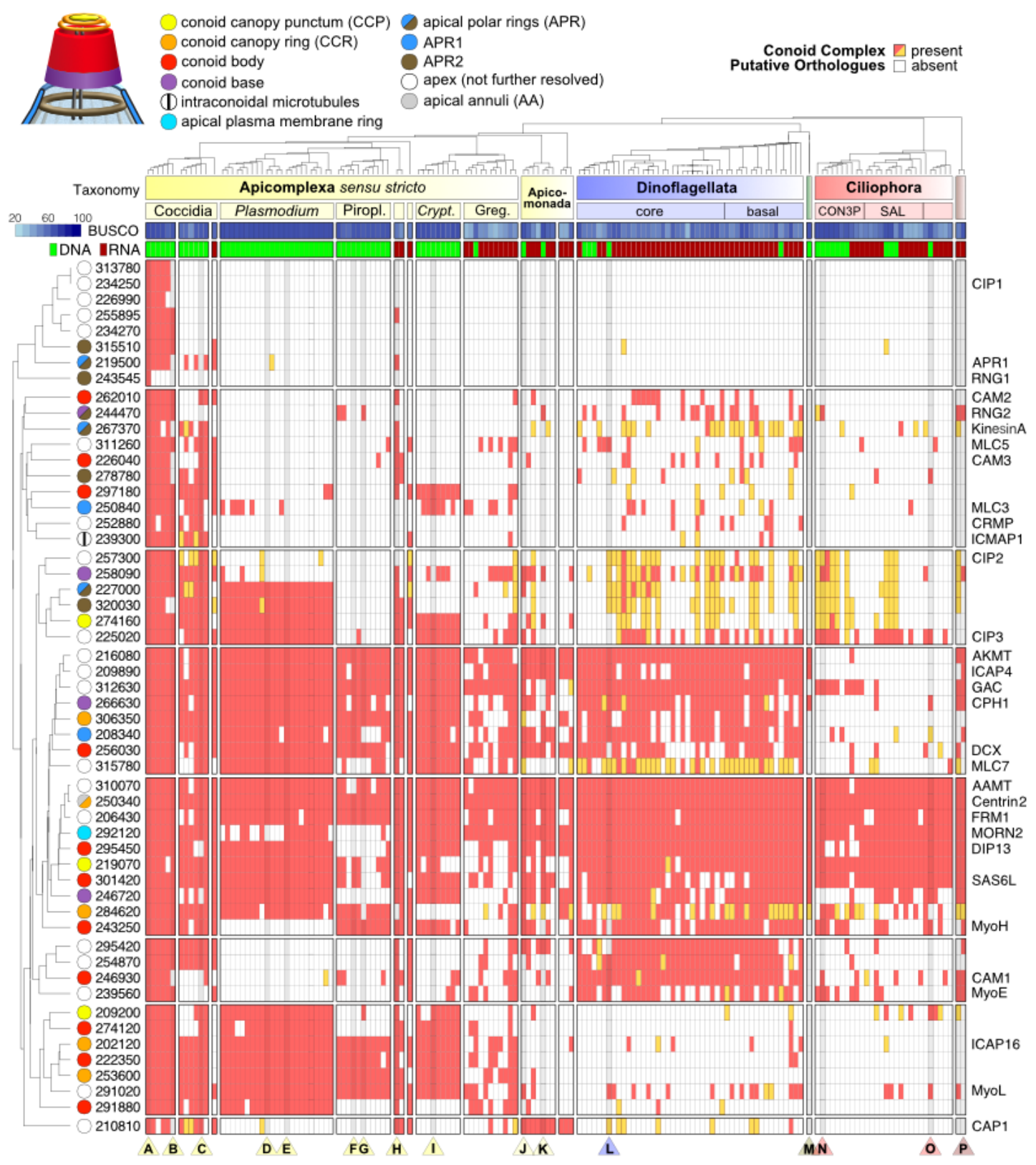

Fig 6. Heatmap indicating conservation of conoid-associated proteins among Alveolata. Presences (red, orange) and absences (white) of putative orthologues of $54 T$. gondii conoidassociated proteins (Table 1) in 157 surveyed Alveolata species (see Fig S5 for taxa). ToxoDB protein numbers (left) and existing protein names (right) are shown. In case of a presence, the taxon either contains at least one homologous sequence that has the $T$. gondiii protein as its best BLASTp match (red), or it has only homologous sequences that were obtained via sensitive HMMer searches but that did not retrieve a $T$. gondii match by BLASTp, indicative of more divergent homologues (see Methods). The proteins are shown clustered according to their binary (presence-absence) patterns across the Alveolata. Known protein locations in T. gondii are indicated by colour (see key) where 'apex' indicates low resolution imaging of an apical punctum, only. The species tree (top) shows phylogenetic relationships and major clades: Piropl., Piroplasmida; Crypt., Cryptosporidium; Greg., Gregarinasina; green shading, Perkinsozoa; brown shading, Colponemida. Columns for species of interest are darkened and indicated by a triangle at the bottom of the figure (A-P) - A: Toxoplasma gondii; B: Sarcocystis neurona; C: Eimeria tenella; D: Plasmodium berghei; E: Plasmodium falciparum; F: Babesia bovis; G: Theileria parva; H: Nephromyces sp.; I: Cryptosporidium parvum; J: Chromera velia; 
bioRxiv preprint doi: https://doi.org/10.1101/2020.06.26.174284; this version posted December 7, 2020. The copyright holder for this preprint (which was not certified by peer review) is the author/funder, who has granted bioRxiv a license to display the preprint in perpetuity. It is made available under aCC-BY-NC-ND 4.0 International license.

K: Vitrella brassicaformis; L: Symbiodinium microadriaticum; M: Perkinsus marinus; N: Tetrahymena thermophila; O: Stentor coeruleus; P: Colponemida. For each species the source of the protein predictions is indicated: genome (DNA, green) or transcriptome (RNA, dark red), along with BUSCO score as estimates of percentage completeness.
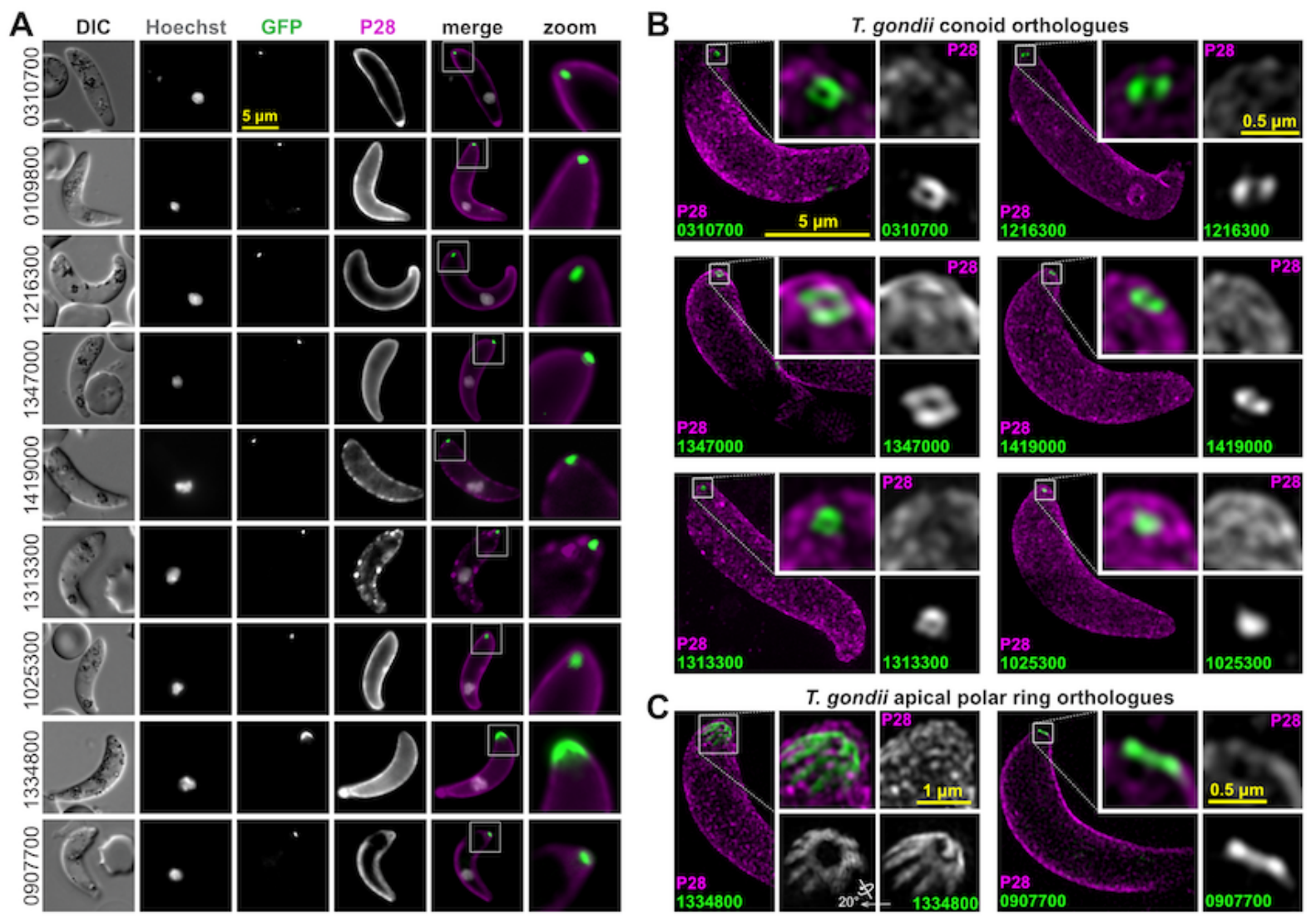

Fig 7. Live cell widefield and super-resolution imaging of $P$. berghei ookinetes expressing GFP fusions of conoid complex orthologues. T. gondii orthologue locations are shown in Figs 3-5. (A) Widefield fluorescence imaging showing GFP (green), Hoechst 33342-stained DNA (grey), and live cy3-conjugated antibody staining of ookinete surface protein P28 (magenta). (B,C) 3D-SIM imaging of fixed GFP-tagged cell lines for conoid orthologues (B) or apical polar ring orthologues (C) with same colours as before (A). Inset for APR protein (1334800) shows rotation of the 3D-reconstruction to view the parasite apex face on. All panels are at the same scale, scale bar $=5 \mu \mathrm{m}$, with zoomed inset from yellow boxes (inset scale bar $=0.5 \mu \mathrm{m}$ or 1 $\mu \mathrm{m}$ for 1334800). 


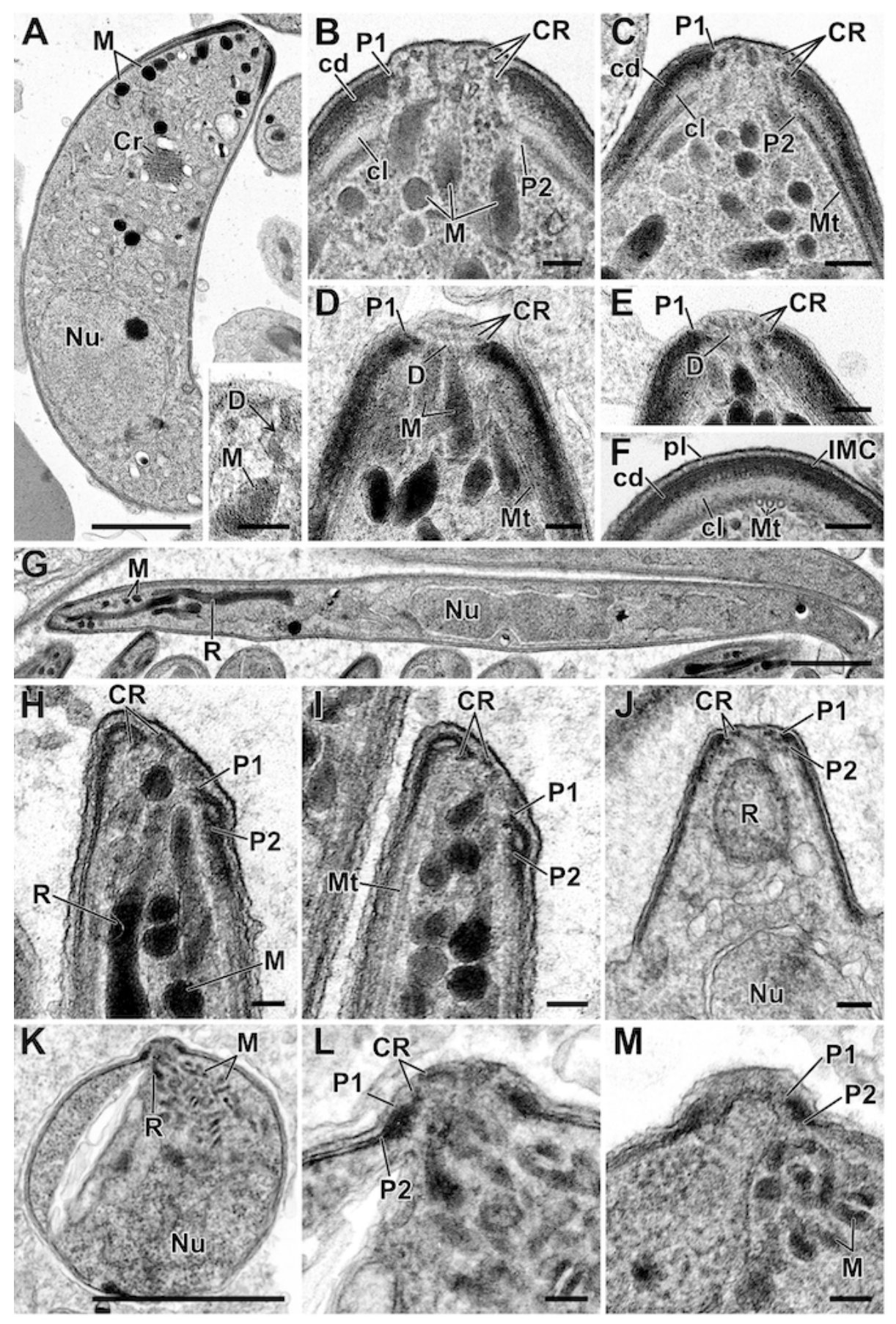

Fig 8. Ultrastructure of conoid complexes of $\boldsymbol{P}$. berghei zoites. Transmission electron micrographs of $P$. berghei zoites: ookinetes (A-F), sporozoites (G-J), and blood stream merozoites (K-M). (A) Longitudinal section through an ookinete showing the apical complex with micronemes (M) plus the crystalline body $(\mathrm{Cr})$. Insert: Detail of the apical cytoplasm showing a microneme (M) with a duct running towards the anterior (arrows). (B-E) Details of longitudinal and tangential sections through the apical complex with either two or three conoidal rings (CR) evident with the anterior collar consisting of an outer electron dense layer (cd) closely adhering to the IMC which formed the anterior polar ring (P1) and an inner electron lucent layer $(\mathrm{cl})$ which is closely associated with subpellicular microtubules (Mt) which forms the inner polar ring (P2). Underlying micronemes (M) with ducts (D) extend to the cell apex. F. Cross section through part of the apical collar showing the ookinete plasma 
membrane (pl) with the underlying IMC closely adhering to the electron dense layer of the collar (cd) with the more electron lucent region (cl) closely associated with subpellicular microtubules (Mt). (G) Longitudinal section through a sporozoite showing the anteriorly located rhoptries $(\mathrm{R})$ and micronemes $(\mathrm{M})$ and the central nucleus $(\mathrm{Nu})$. $(\mathrm{H}-\mathrm{I})$. Detail of the anterior of the mature sporozoites showing the conoidal rings $(C R)$ and the in-folding of the IMC to form the first apical polar ring (P1) with second apical polar ring beneath (P2) associated with the subpellicular microtubules (Mt). Note the angled formed by the apical polar rings relative to the longitudinal cell axis. (J) Longitudinal section of an early stage in sporozoite formation showing apical conoidal rings (CR) and the perpendicular projection of the conoidal and apical polar rings. (K) Longitudinal section through a spherical shaped merozoite released from an erythrocyte showing the rhoptries $(R)$, micronemes $(M)$ and nucleus ( $\mathrm{Nu}$ ). (L-M) Enlargement of the apical region showing the conoidal rings (CR) and the closely applied polar rings (P1, P2). Scalebar represent $1 \mu \mathrm{m}(\mathrm{A}, \mathrm{G}, \mathrm{K})$ and $100 \mathrm{~nm}$ in all others. See also Fig $\mathrm{S} 6$ and $\mathrm{S7}$.

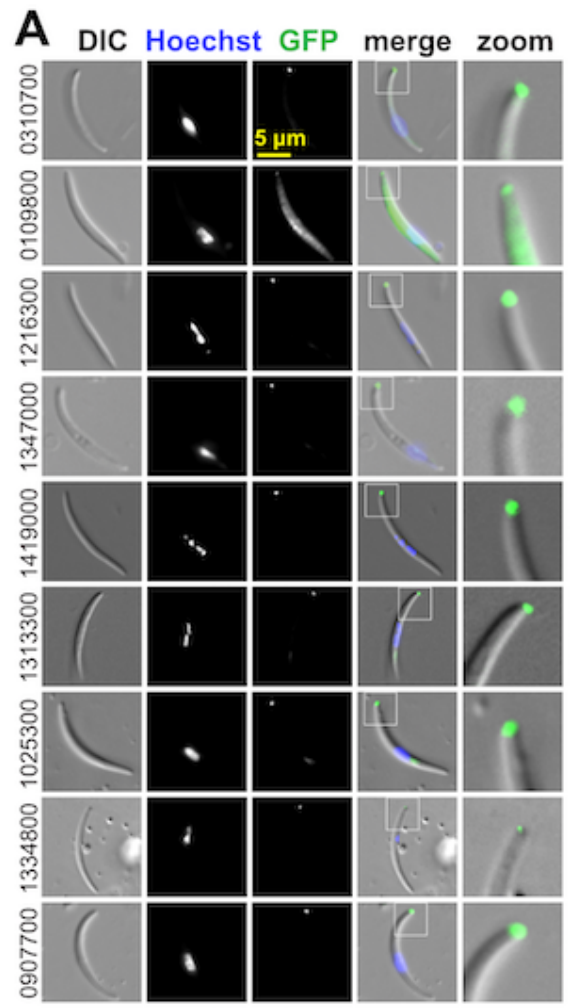

B
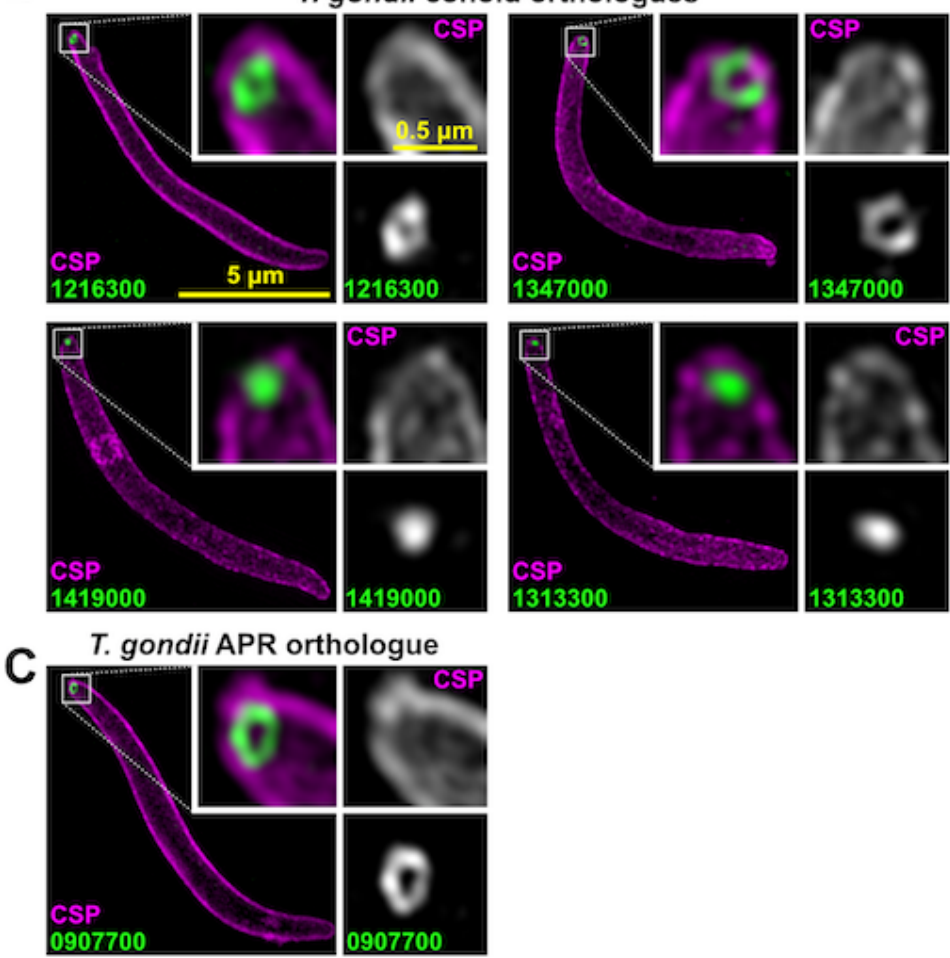

Fig 9. Live cell widefield, and super-resolution imaging of $P$. berghei sporozoites expressing GFP fusions of conoid complex orthologues. (A) Widefield fluorescence imaging showing GFP (green) and Hoechst 33342-stained DNA (grey). All panels are at the same scale, scale bar $=5 \mu \mathrm{m}$, with the exception of zoomed images from white boxed regions in the merge. $(B, C)$ Super-resolution imaging of GFP-fused conoid complex proteins (green) in fixed cells shown with the cell surface stained for sporozoite surface protein 13.1 (magenta). All panels are at the same scale, scale bar $=5 \mu \mathrm{m}$, with zoomed inset from white boxed regions (inset scale bar $=0.5 \mu \mathrm{m}$ ). 

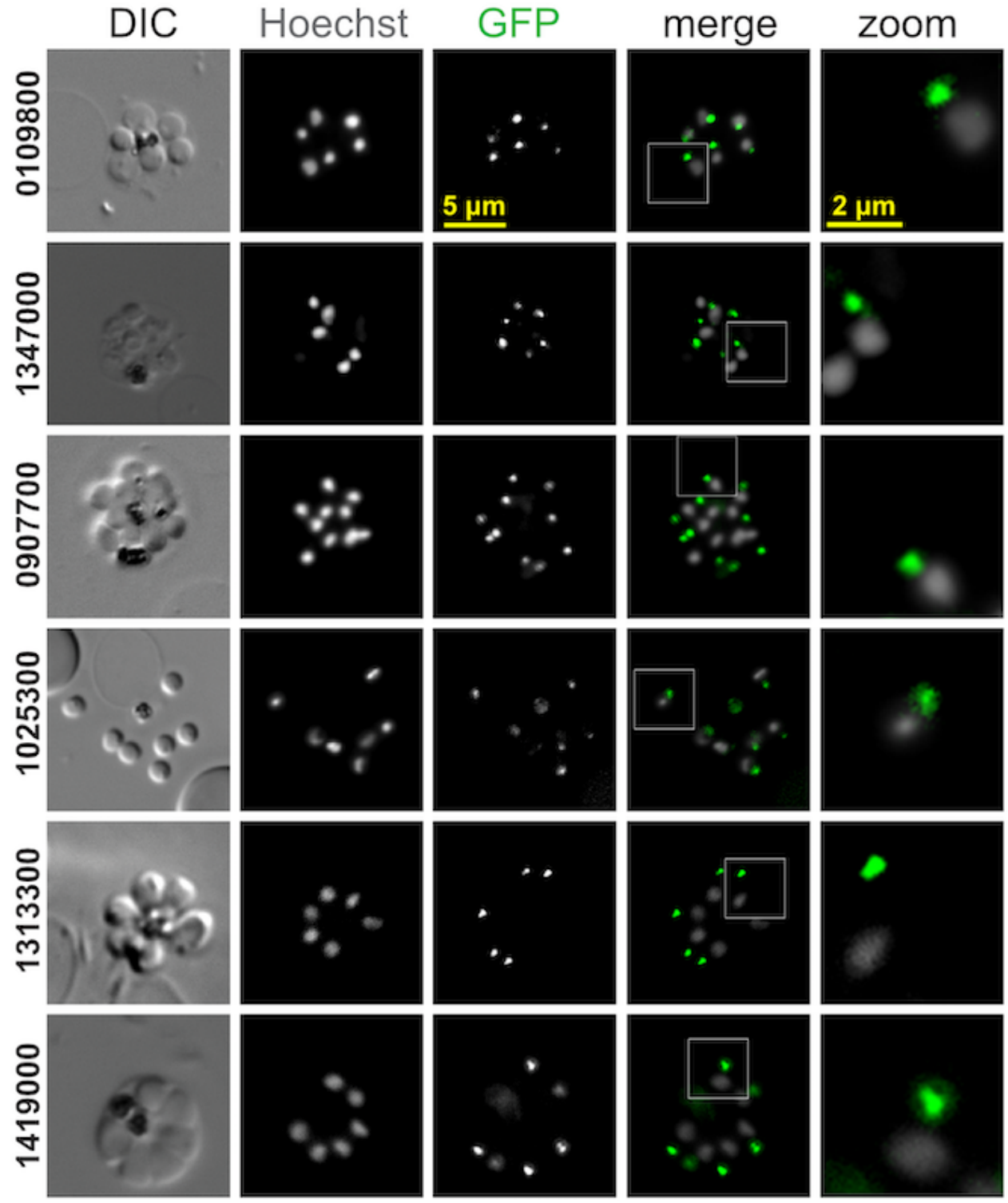

Fig 10. Live cell imaging of $P$. berghei merozoites expressing GFP fusions of conoid complex orthologues. Widefield fluorescence imaging showing GFP (green) and Hoechst 33342stained DNA (grey) with some parasites seen pre-egress from the erythrocyte and others post egress. All panels are at the same scale, scale bar $=5 \mu \mathrm{m}$ shown, with zoomed inset from white boxed regions (inset scale bar $=2 \mu \mathrm{m}$ ). 
bioRxiv preprint doi: https://doi.org/10.1101/2020.06.26.174284; this version posted December 7, 2020. The copyright holder for this preprint (which was not certified by peer review) is the author/funder, who has granted bioRxiv a license to display the preprint in perpetuity. It is made available under aCC-BY-NC-ND 4.0 International license.

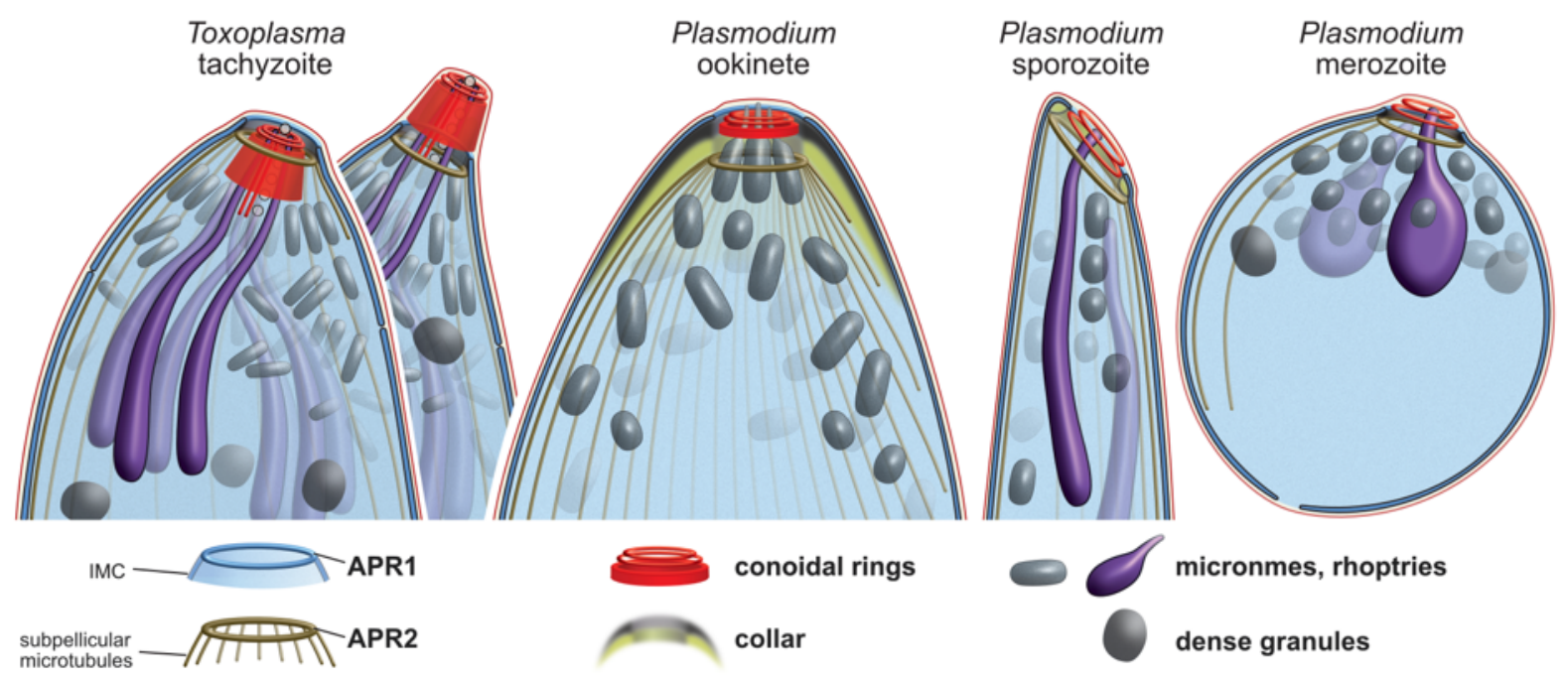

Fig 11. Conservation and variability of the conoid complex in apicomplexan zoite forms. Schematics of cell apices from Toxoplasma and Plasmodium showing presence of common structures but displaying variability in their size and arrangement. Toxoplasma is shown with either the conoid retracted or protruded. A row of vesicles of unknown function line the intraconoidal microtubules in Toxoplasma and other coccidians. Schematics draw on both TEM and EM tomography data that is presented or cited throughout the report. 


\section{Supplemental Material}

Table S1: Toxoplasma candidate apical proteins identified by hyperLOPIT and BioID methods Footnotes:

${ }^{a}$ Known localization defined as 'apex' when low resolution imaging only has identified a punctum at the apex of the cell. CCR, conoid canopy ring; AA, apical annuli; APR, apical polar ring; PM, plasma membrane; ICMT, intraconoidal microtubules.

${ }^{\mathrm{b}}$ LOPIT assignment strength: $\bullet$, Protein assigned to one of the two apical clusters at $>99 \%$ probability in (before ' $/$ ') the analysis of concatenated three or two datasets where the protein was full quantified or (after ' $/$ ') the analysis of individual hyperLOPIT datasets; $\bullet$, as for above except apical assignment probability is below the $99 \%$ threshold; $\bullet$, assignment to a cluster other than apical in one non-catenated hyperLOPIT datasets. For BiolD proteomic experiments the detection of a protein by a given bait is indicated by $\bullet$. For Hu et al 2006 proteomic study, proteins enriched with conoid fractions by at least 2 -fold (ToxoDB Release 49 ) are indicated by $\bullet$.

${ }^{\mathrm{C}}$ Mutant phenotype fitness scores where more strongly negative scores indicate increasing detrimental competitive growth in in vitro culture conditions for T. gondii [40].

${ }^{*}$ References for localization data: TS, this study.

\section{Table S2: Oligonucleotide primers used for $T$. gondii and $P$. berghei gene tagging} Footnotes:

${ }^{a}$ PCR plasmid templates P5 and P6 as described in Barylyuk et al (2020) [36]

${ }^{\mathrm{b}}$ Endogenous gene fusion method for epitope-tagging or birA*-tagging as described in Barylyuk et al (2020) or Wall et al (2016), respectively.

Table S3: Sources and numbers of detected putative orthologues of apical proteins (Table 1, S1 Table) across Alveolata.

This table contains information on the alveolate species included in this study, including their full species and strain name, the data used, completeness of the predicted proteome using BUSCO, the percentages of conoid-associated (Table 1) and all apical (Table $1+$ S1 Table) proteins for which a putative ortholog was found in this species, and the numbers of putative orthologues for each individual protein.

S4 Table: GenBank/UniProt/PlasmoDB identifiers for putative Plasmodium falciparum 3D7 and Plasmodium berghei ANKA orthologues

For P. falciparum, we had selected strain 'IT' for our 419 SAR proteomes set. As a result, our sets of orthologues originally contained sequences from this particular strain. However, because strain '3D7' is the one more commonly studied, we mapped the $P$. falciparum IT sequences to $P$. falciparum 3D7 by searching for reciprocal best blast hits among their proteomes. Therefore, $P$. falciparum 3D7 identifiers in the FASTA files (S1 Data) also provide information on which $P$. falciparum IT sequence was linked by.

\section{S1 Data: FASTA files containing putative Alveolata orthologues for each $T$. gondii apical protein} (Table 1, S1 Table, Fig 6, Fig S5, Methods).

Files are named according to the $T$. gondii apical protein query. The sequence headers comprise the protein identifiers in our in-house proteome database for the SAR clade (Methods), starting with an abbreviation for the species strain (see Table S3). The headers furthermore contain either the descriptor 'self', indicating that this sequence is the original $T$. gondii query, or ' $r b h$ ', indicating that it has the original $T$. gondii query as its best $T$. gondii hit in a BLASTp search, or 'none', indicating that it has no BLASTp hit in $T$. gondii (see Methods). For sequences of $P$. falciparum 3D7, the header also indicates by which $P$. falciparum IT sequence it was gathered and if it was gathered via reciprocal 
bioRxiv preprint doi: https://doi.org/10.1101/2020.06.26.174284; this version posted December 7, 2020. The copyright holder for this

preprint (which was not certified by peer review) is the author/funder, who has granted bioRxiv a license to display the preprint in perpetuity. It is made available under aCC-BY-NC-ND 4.0 International license.

best BLAST hits ('rbh') or via unidirectional best BLAST ('bh'). The latter is only the case for the putative orthologue of T. gondii's TGME49_219070 (see also S4 Table).

\section{Supplemental Figures}

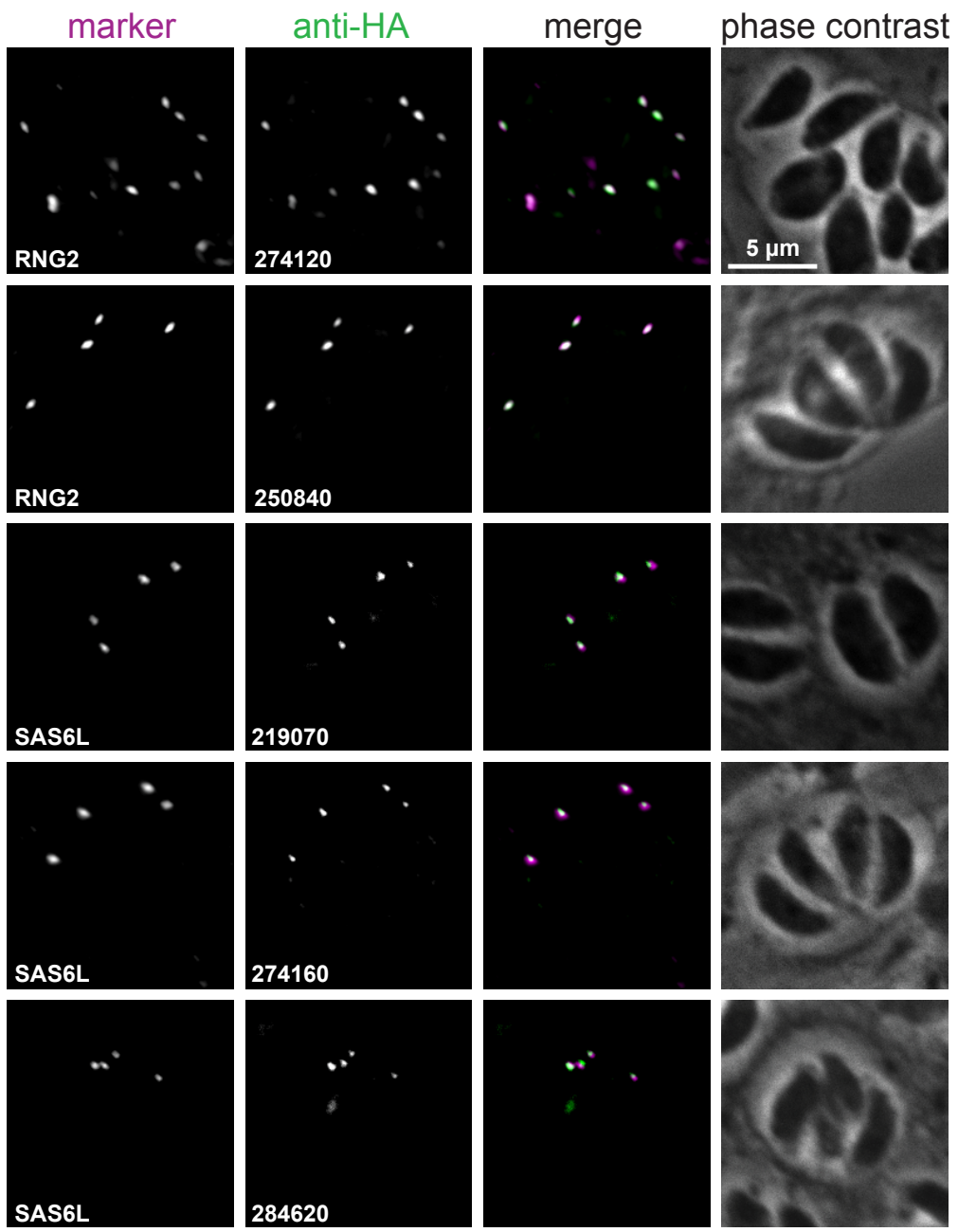

Fig S1. Immuno-detection of candidate conoid complex proteins, identified by hyperLOPIT and BioID approaches, in $T$. gondii intracellular parasites. Widefield fluorescence imaging of HA-tagged candidates (green) co-expressing either APR marker RNG2 or conoid marker SAS6L (magenta). All images are at the same scale, scale bar $=5$ $\mu \mathrm{m}$. 

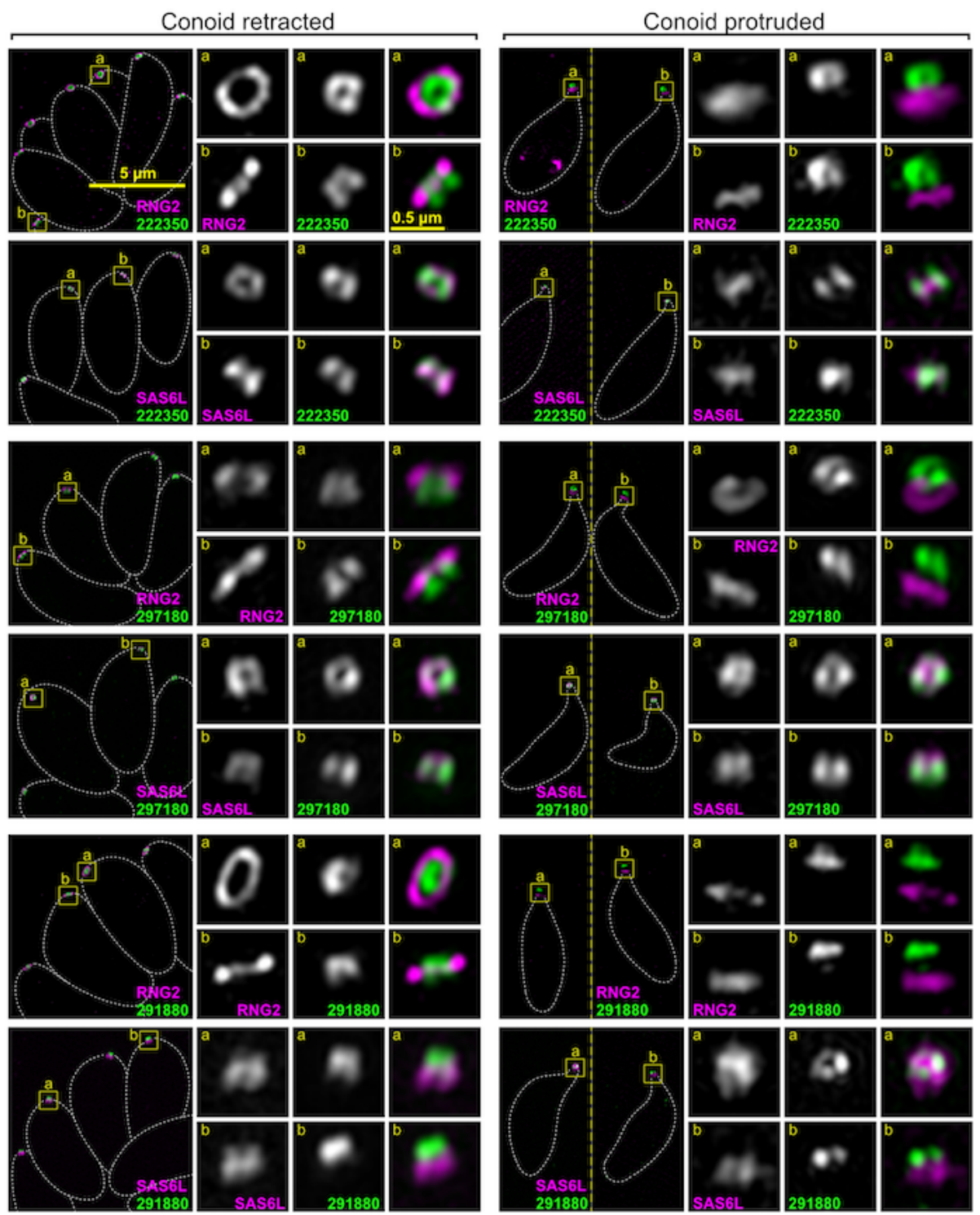

Figure S2: Super-resolution imaging of $T$. gondii proteins at the conoid body. Immunodetection of HA-tagged conoid proteins (green) in cells co-expressing either APR marker RNG2 or conoid marker SAS6L (magenta) imaged either with conoids retracted within the host cell, or with conoids protruded in extracellular parasites. This figure shows further examples of conoid body proteins to those shown in Fig $3 \mathrm{~A}$. All panels are at the same scale, scale bar $=5 \mu \mathrm{m}$, with zoomed inset from yellow boxes (scale bar $=0.5 \mu \mathrm{m}$ inset). 


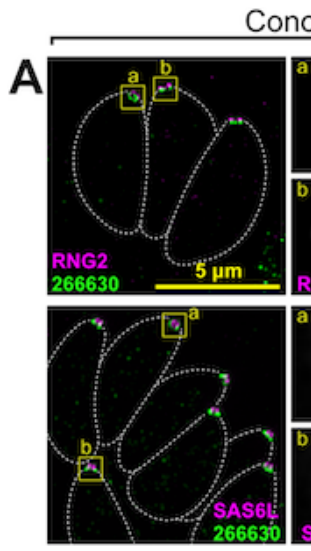

onoid retracted
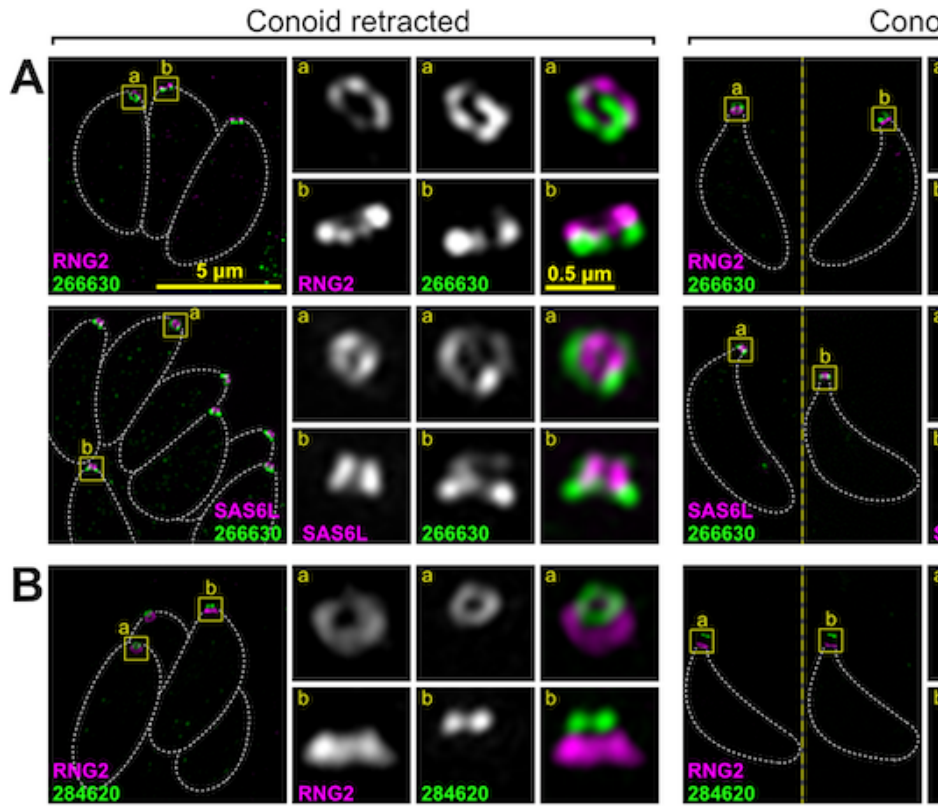

Conoid protruded
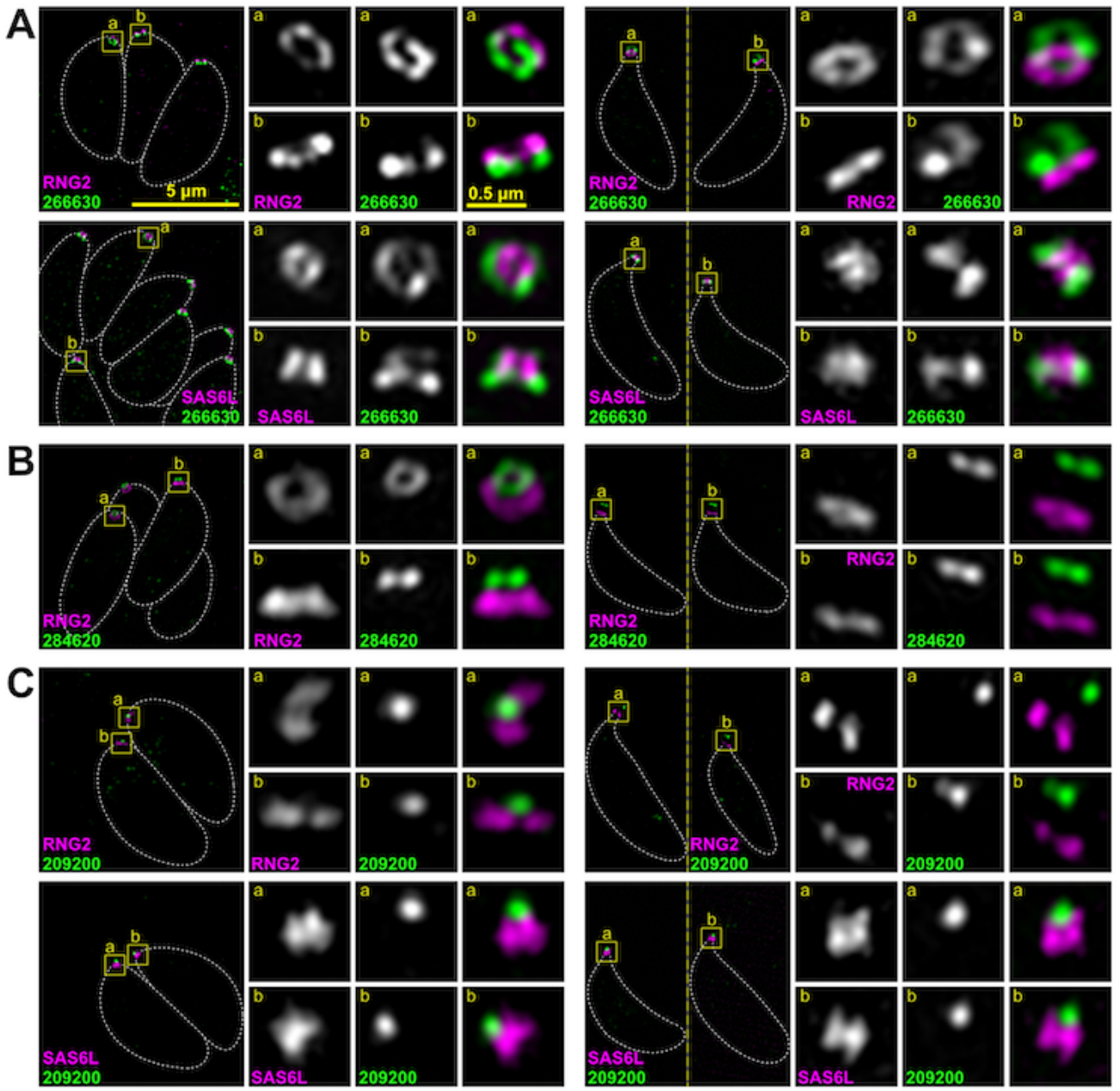

Figure S3: Super-resolution imaging of $T$. gondii proteins at the conoid base, conoid canopy rings and conoid canopy punctum. Immuno-detection of HA-tagged conoid proteins (green) in cells co-expressing either APR marker RNG2 or conoid marker SAS6L (magenta) imaged either with conoids retracted within the host cell, or with conoids protruded in extracellular parasites. This figure shows further examples of conoid proteins to those shown in Fig 3B. 4A and 5A. All panels are at the same scale, scale bar $=5 \mu \mathrm{m}$, with zoomed inset from yellow boxes (scale bar $=0.5 \mu \mathrm{m}$ inset) 

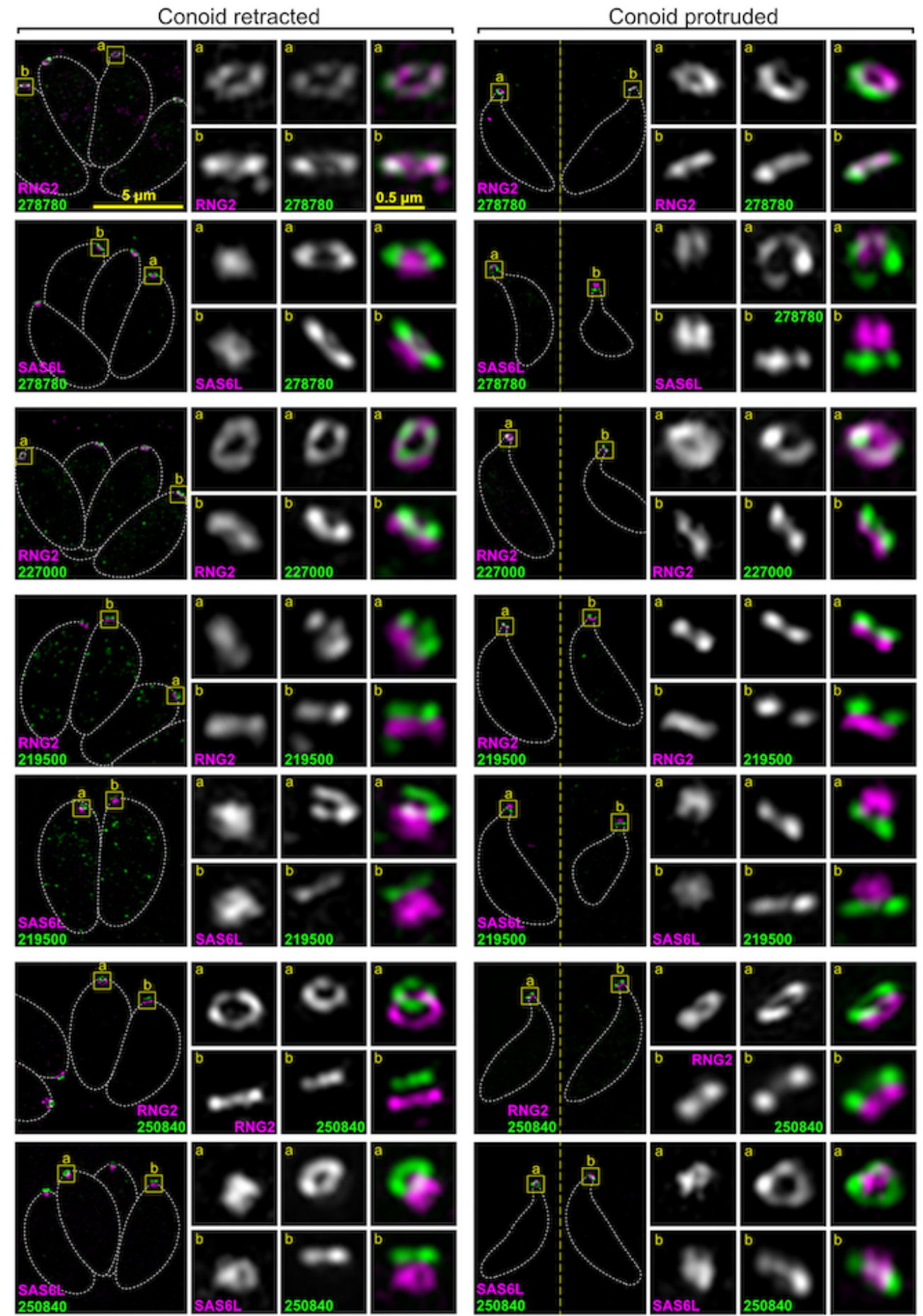

Figure S4: Super-resolution imaging of $T$. gondii proteins at the apical polar rings. Immuno-detection of HA-tagged proteins (green) in cells co-expressing either APR marker RNG2 or conoid marker SAS6L (magenta) imaged either with conoids retracted within the host cell, or with conoids protruded in extracellular parasites. This figure shows further examples of apical polar ring proteins to those shown in Fig 5B. All panels are at the same scale, scale bar $=5 \mu \mathrm{m}$, with zoomed inset from yellow boxes (scale bar $=0.5 \mu \mathrm{m}$ inset). 


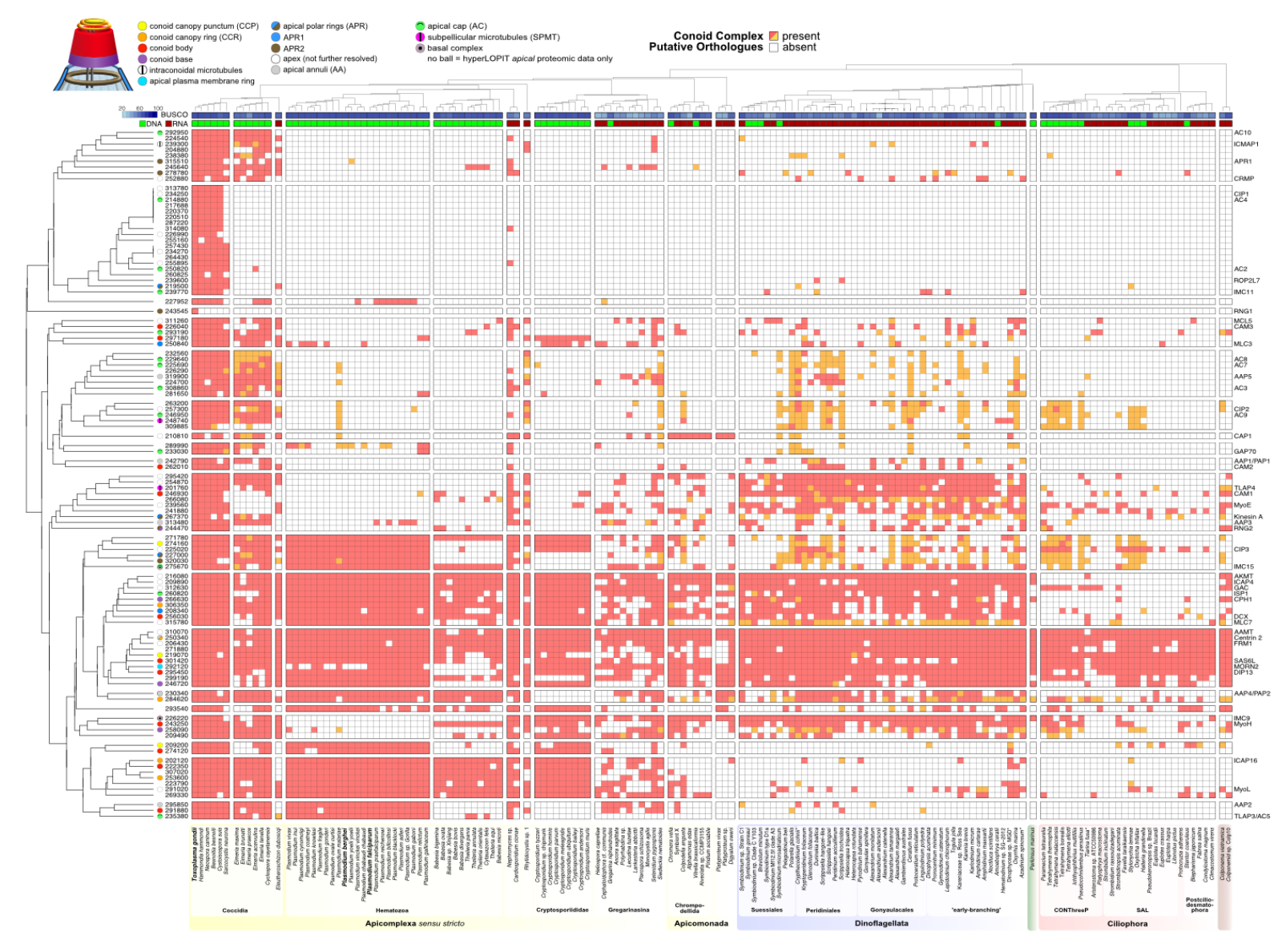

Fig S5. Heatmap indicating conservation of putative orthologues of apical proteins among Alveolata. Presences (red, orange) and absences (white) of putative orthologs of apical proteins in 157 surveyed Alveolata species (selection based on Table $1+$ Table S1, numbers indicate identifiers of the predicted proteome of Toxoplasma gondii ME49). In case of a presence, the species either contains at least one homologous sequence that has the $T$. gondiii protein as its best BLASTp match (red) or it has only homologous sequences that did not yield any hit in $T$. gondii, but were only obtained via (iterative) sensitive homology searches using HMMer (see Methods). The proteins were clustered based on the binary (presence-absence) patterns across the Alveolata, not making a distinction between the 'red' and 'orange' cells. Cluster visualisation was based on manual curation of readily identifiable clusters. Known localization defined as 'apex' when low resolution imaging only has identified a punctum at the apex of the cell. SPMT, subpellicular microtubules; IMC, inner membrane complex; $\mathrm{AC}$, apical cap. The species tree (top) outlines the phylogenetic relationships of the examined species, based on current literature (see Methods). The clades (bottom) are coloured according to the following clades: Apicomplexa sensu stricto (yellow), related Apicomonada (light-yellow), Dinoflagellata (blue), Perkinsozoa (green), Ciliophora (red) and Colponemida (brown). For each of the species the source of the protein predictions is indicated: genome (DNA, green) or transcriptome (RNA, dark red), and the BUSCO score indicates the completeness of these predictions. For detailed information on numbers and sources for this figure, see Table S3. 
bioRxiv preprint doi: https://doi.org/10.1101/2020.06.26.174284; this version posted December 7, 2020. The copyright holder for this preprint (which was not certified by peer review) is the author/funder, who has granted bioRxiv a license to display the preprint in perpetuity. It is made available under aCC-BY-NC-ND 4.0 International license.

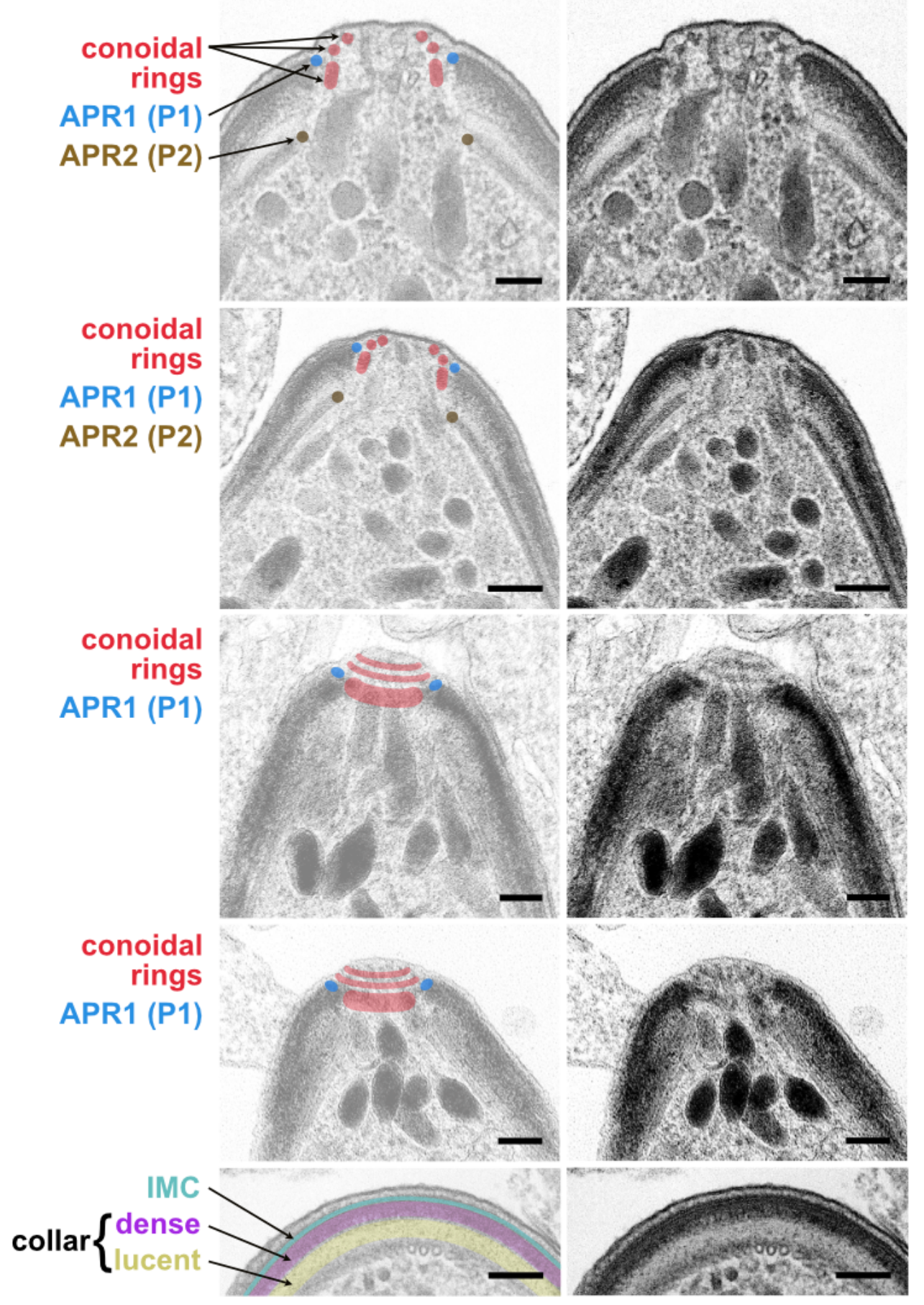

Fig S6. Ultrastructure of conoid complexes of $P$. berghei ookinetes. Transmission electron micrographs of $P$. berghei ookinetes taken from Fig 8 with conoid complex features annotated in image duplicate. Scalebar $=100 \mathrm{~nm}$. 
bioRxiv preprint doi: https://doi.org/10.1101/2020.06.26.174284; this version posted December 7, 2020. The copyright holder for this preprint (which was not certified by peer review) is the author/funder, who has granted bioRxiv a license to display the preprint in perpetuity. It is made available under aCC-BY-NC-ND 4.0 International license.

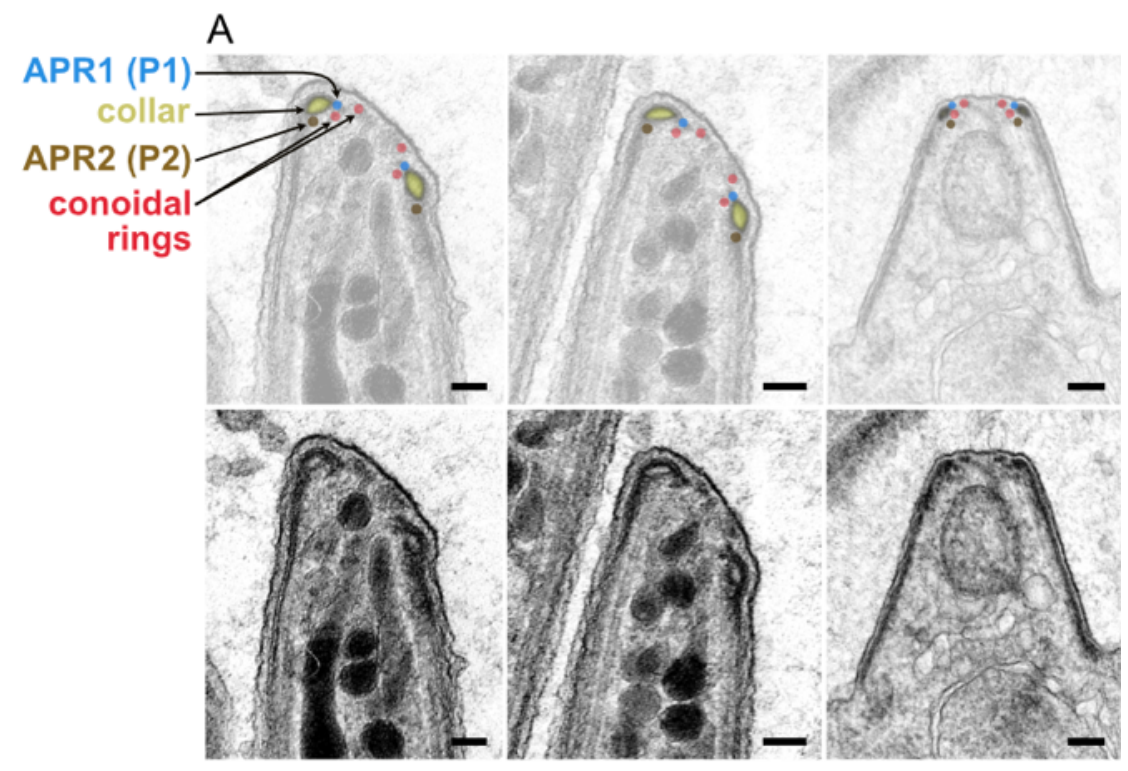

B

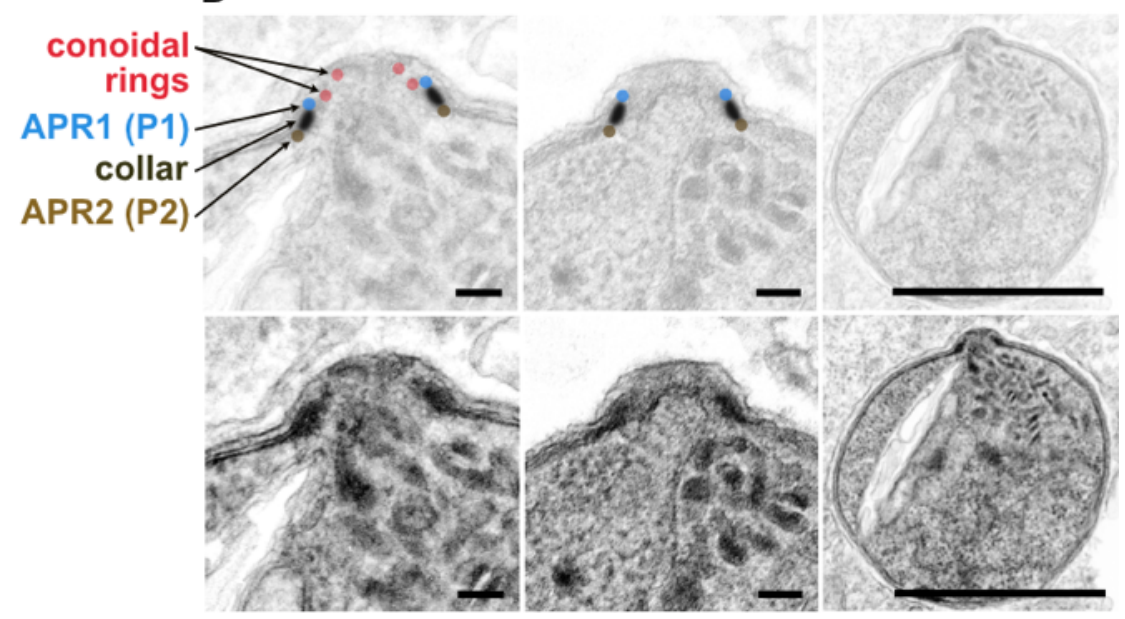

Fig S7. Ultrastructure of conoid complexes of $P$. berghei sporozoites and merozoites. Transmission electron micrographs of $\boldsymbol{P}$. berghei $\boldsymbol{A}$. sporozoites and $\boldsymbol{B}$. merozoites taken from Fig 8 with conoid complex features annotated in image duplicate. Scalebar $=100 \mathrm{~nm}$ for all except righthand panels of $\boldsymbol{B}$. where scalebar $=1 \mu \mathrm{m}$. 


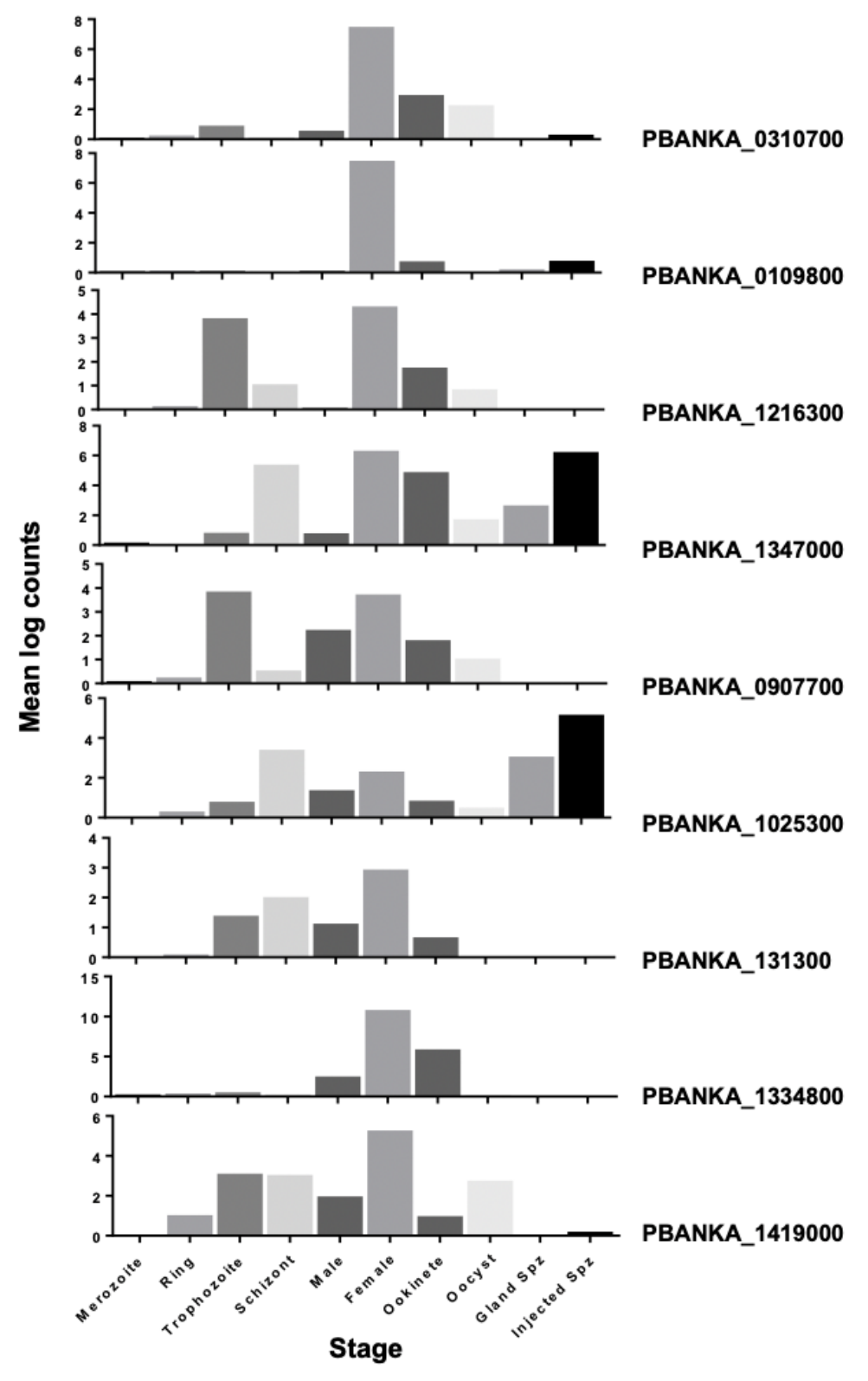

Fig S8. Differential transcript expression of $\boldsymbol{P}$. berghei proteins in different lifecycle stages. Mean normalised log counts of transcripts for each gene in different stages of Plasmodium berghei analysed from single cell RNAseq data [81]. 

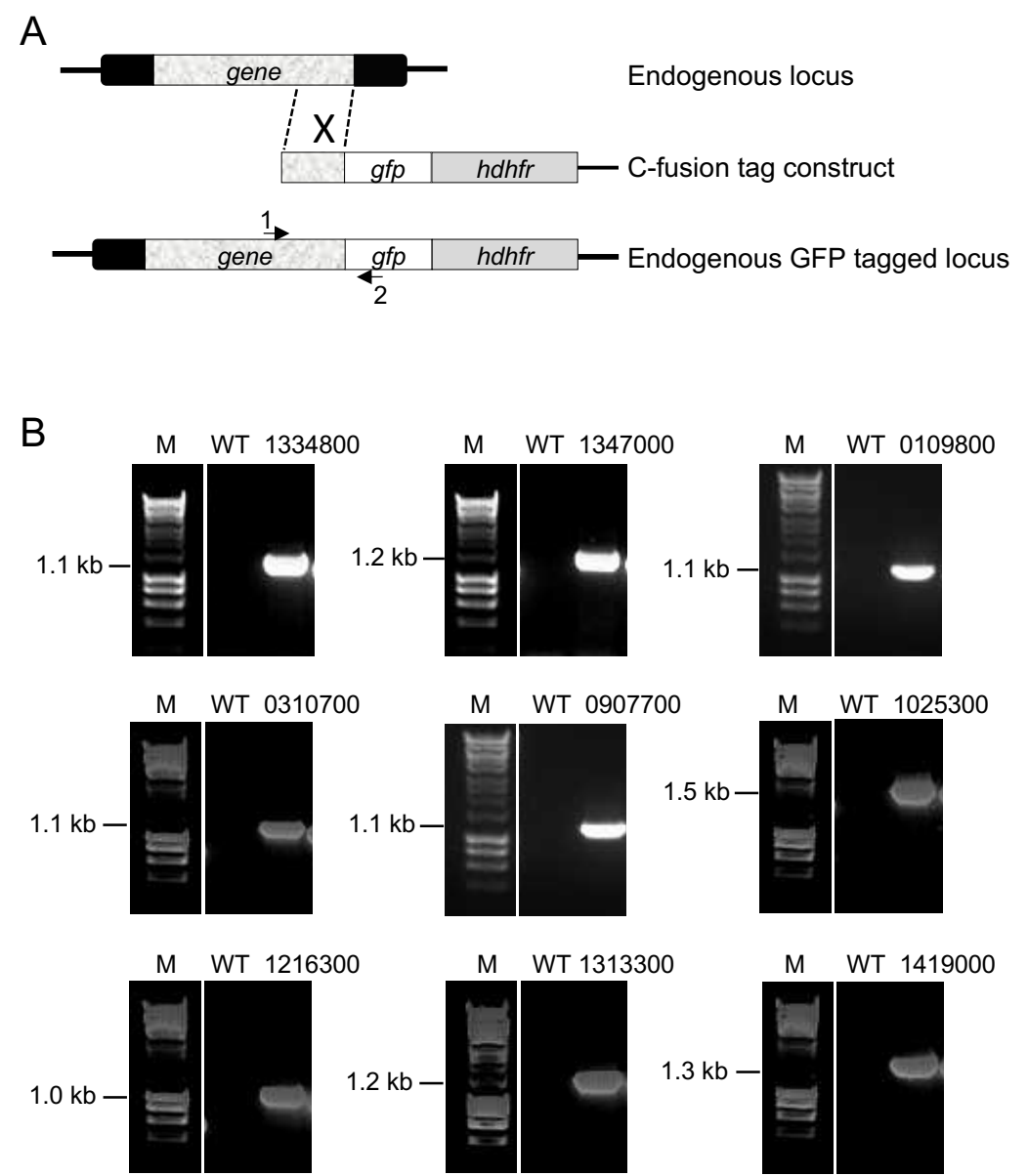

Fig S9. Strategy and validation for GFP coding sequence integration in $P$. berghei. (A) Schematic representation of the $P$. berghei endogenous gene locus, the integration constructs, and the recombined gene locus. (B) Validation of correct gene tagging by diagnostic PCR 


\section{Materials and Methods:}

\section{Growth and generation of transgenic $T$. gondii}

T. gondii tachyzoites from the strain RH and derived strains, including RH $\triangle$ ku80/TATi [82], were maintained at $37^{\circ} \mathrm{C}$ with $10 \% \mathrm{CO}_{2}$ growing in human foreskin fibroblasts (HFFs) cultured in Dulbecco's Modified Eagle Medium supplemented with $1 \%$ heat-inactivated fetal bovine serum, $10 \mathrm{unit} \mathrm{ml}^{-1}$ penicillin and $10 \mathrm{\mu g} \mathrm{ml}^{-1}$ streptomycin, as described elsewhere [83]. When appropriate for selection, chloramphenicol was used at $20 \mu \mathrm{M}$ and pyrimethamine at $1 \mu \mathrm{M}$. Scaling up of the parasite culture for hyperLOPIT experiments was done according to the method described by [83]. Reporter protein-tagging of endogenous gene loci was done according our previous work [36] with oligonucleotides shown in Table S2.

\section{BiolD}

Sample preparation: For the proximity biotinylation assay, we generated three different cell lines ( $T$. gondii tachyzoites RH $\triangle \mathrm{ku} 80 \mathrm{TATi}$ ) by in situ genomic C-terminal tagging of one of the three bait proteins (SAS6L, RNG2 or MORN3) with the promiscuous bacterial biotin ligase, BirA*. The protein BirA*-tagging method used is described in our previous work [42] with oligonucleotides shown in Table S2. We then followed the BiolD protocol of Chen et al. [73]. The biotinylation of the proximal proteins by the BirA* enzyme was promoted by addition of $150 \mu \mathrm{M}$ biotin into the ED1 growth media $24 \mathrm{~h}$ prior to parasite egress. The non-tagged parental cell line was used as a negative control for background biotinylation. The BirA* activity was validated by a western blot detection of the biotinylated proteins. $1 \times 10^{7}$ tachyzoites were lysed in the NuPAGE ${ }^{\mathrm{TM}}$ LDS Sample Buffer (ThermoFisher) and separated in the NuPAGE ${ }^{\mathrm{TM}}$ 4-12\% Bis-Tris gel (ThermoFisher) and blotted on a nitrocellulose membrane, which was then blocked by 3\% BSA for $1 \mathrm{~h}$. The membrane was then incubated in the presence of streptavidin-HRP conjugate (ThermoFisher; 1:1000 dilution in 1\% BSA) for $1 \mathrm{~h}$, followed by five 5 -minute washes in TBST (tris-buffered saline solution containing $0.05 \%$ $(\mathrm{w} / \mathrm{v})$ of Tween 20). The HRP chemiluminescent signal was visualised by the Pierce ${ }^{\mathrm{TM}}$ West Pico kit (ThermoFisher) and a digital camera.

For the proteomic analysis $\sim 2 \times 10^{9}$ tachyzoites were harvested after $24-\mathrm{h}$ biotinylation and egress. The parasites were separated from the host-cell debris by passing through a $3 \mu \mathrm{m}$ filter and washed $5 x$ in phosphate-buffered saline. The cell pellets were lysed in RIPA buffer and the volume of each sample was adjusted to $1.8 \mathrm{~mL}$ and $5 \mathrm{mg}$ of total protein content. $200 \mu \mathrm{L}$ of unsettled Pierce ${ }^{\mathrm{TM}}$ Streptavidin Magnetic Beads (ThermoFisher) were first washed in RIPA buffer and then incubated with the cell lysates for $1 \mathrm{~h}$ at room temperature with gentle rotation of the tubes. The beads were then washed $3 x$ in RIPA, $1 x$ in 2M UREA $10 \mathrm{mM}$ Tris-HCl pH 8.0 and again $3 x$ in RIPA, reduced in 10 $\mathrm{mM}$ DTT and $100 \mathrm{mM}$ ammonium bicarbonate solution for $30 \mathrm{~min}$ at $56^{\circ} \mathrm{C}$, alkylated in $55 \mathrm{mM}$ iodoacetamide and $100 \mathrm{mM}$ ammonium bicarbonate for $45 \mathrm{~min}$ at room temperature in the dark, and finally washed in $50 \mathrm{mM}$ ammonium bicarbonate for $15 \mathrm{~min}$ at room temperature with gentle rotation. The peptides were digested off the beads by an overnight $37^{\circ} \mathrm{C}$ incubation in $1 \mu \mathrm{g}$ of trypsin dissolved in $50 \mu$ of $50 \mathrm{mM}$ ammonium bicarbonate and the remaining peptides were extracted with $100 \mu \mathrm{l}$ of $10 \%$ formic acid. Both peptide extractions were combined, desalted using C18 solidphase extraction cartridges (SepPak C18, $100 \mathrm{mg}$ sorbent, Waters), dried in a vacuum centrifuge (Labconco), and resuspended in $0.1 \%$ (vol.) aqueous formic acid.

Peptide analysis by liquid chromatography and mass spectrometry: Peptide fractions were analysed in a $Q$ Exactive hybrid quadrupole-Orbitrap mass spectrometer (Thermo Fisher Scientific Inc., Waltham, MA, USA) coupled on-line with a nanoflow ultrahigh-performance liquid chromatography (nano-UPLC) system Dionex UltiMate 3000 RSLCnano (Thermo Fisher Scientific Inc., Waltham, MA, USA) through an EASY-Spray nano-electrospray ionization (nano-ESI) source (Thermo Fisher Scientific Inc., Waltham, MA, USA). Samples were loaded onto an Acclaim PepMap 100 C18 
trapping column ( $300 \mu \mathrm{m}$ i.d. $\times 5 \mathrm{~mm}$ length, $5 \mu \mathrm{m}$ particle size, $100 \AA \AA$ pore size; Thermo Fisher Scientific) from the UltiMate 3000 autosampler with $0.1 \%$ aqueous formic acid for 3 minutes at a flow rate of $10 \mu \mathrm{L} / \mathrm{min}$. After this period, the column valve was switched to allow elution of peptides from the pre-column onto the analytical column. The trapped peptides were then separated on an analytical reverse-phase nano EASY-Spray RSLC C18 column $(75 \mu \mathrm{m}$ i.d. $\times 50 \mathrm{~cm}$ length, $2 \mu \mathrm{m}$ particle size, $100 \AA$ pore size; Thermo Fisher Scientific) at a flow rate of $300 \mathrm{~nL} / \mathrm{min}$ using a gradient elution program. Solvent A was $0.1 \%$ (vol.) formic acid in water (HPLC-grade, Fisher). Solvent B was $0.1 \%$ (vol.) formic acid in water-acetonitrile (HPLC-grade, Rathburn) blend ( $20 \%: 80 \%$, vol.). The linear gradient employed was $2-40 \%$ B in 30 minutes. Further wash and equilibration steps gave a total run time of 60 minutes.

The peptides eluting from the nano-LC column were ionized by applying a positive voltage of $2.1 \mathrm{kV}$ to the nano-ESI emitter electrode. The mass spectrometer was operated in the data-dependent acquisition mode (DDA). The precursor survey mass spectra (MS1) were acquired between 380 and $1500 \mathrm{~m} / \mathrm{z}$ at a 70,000 resolution with an AGC target of $1 \mathrm{e} 6$ and a maximum C-trap fill time of $250 \mathrm{~ms}$. The top twenty most intense precursor ions were selected in the quadrupole using an isolation window of $1.5 \mathrm{~m} / \mathrm{z}$ and subjected to fragmentation in the HCD mode at a normalised collision energy of 25. A dynamic exclusion limit of $20 \mathrm{~s}$ was applied. The fragment ion spectra (MS2, or MS/MS) were acquired between 100 and $1600 \mathrm{~m} / \mathrm{z}$ at a 17,500 resolution with an AGC target of 5e4 and a maximum C-trap fill time of $120 \mathrm{~ms}$. The raw data were managed in XCalibur v2.1 (Thermo Fisher Scientific).

LC-MS/MS data processing and protein identification: The raw LC-MS/MS data were interpreted, and peak lists were generated using Proteome Discoverer 1.4 (Thermo Fisher Scientific). The peak lists were exported as Mascot generic files and searched against the annotated protein sequences of Toxoplasma gondii strain ME49 (ToxoDB.org release 29, retrieved on 20 December 2016; 8,322 sequences) and common contaminant proteins (cRAP, 115 sequences) with Mascot v2.6.0 (Matrix Science) assuming digestion by trypsin with up to two missed cleavage sites. The precursor and fragment ion tolerances were set to $5 \mathrm{ppm}$ and $0.1 \mathrm{Da}$, respectively. Carbamidomethylation of cysteine was set as a static modification. Oxidation of methionine and deamidation of asparagine and glutamine were allowed as variable modifications. Scaffold (version Scaffold_4.7.5, Proteome Software Inc., Portland, OR) was used to validate MS/MS based peptide and protein identifications. Peptide identifications were accepted if they could be established at greater than $95.0 \%$ probability by the Peptide Prophet algorithm [84] with Scaffold delta-mass correction. Protein identifications were accepted if they could be established at greater than $95.0 \%$ probability and contained at least 2 identified peptides. Protein probabilities were assigned by the Protein Prophet algorithm [85]. Proteins that contained similar peptides and could not be differentiated based on MS/MS analysis alone were grouped to satisfy the principles of parsimony. Total spectrum counts were used to calculate the enrichment of proteins in the BiolD pulldown samples relative to the wild-type control sample. The contaminant proteins were not considered for the analysis.

\section{hyperLOPIT Spatial proteomics}

The hyperLOPIT spatial proteomics data were acquired and analysed as described in [36]. Three independent hyperLOPIT datasets contained 4,189, 4,547, and 4,292 proteins identified at FDR $<5 \%$ based on at least one unique high-confidence peptide (FDR $<1 \%$ ) and quantified across all ten TMT quantification channels. These three 10plex datasets were considered individually. In addition, the data on proteins shared across pairs or all three individual datasets were concatenated affording three 20plex $(4,021,3,916$, and 4,078 proteins for $1 \cap 2,1 \cap 3$, and $2 \cap 3$, respectively) and one 30plex $(3,832$ proteins), thus, yielding seven datasets in total. For each dataset, the normalised protein abundance distribution profiles were derived from the TMT reporter ion intensity values. A Bayesian machine-learning classification method based on t-augmented Gaussian mixture models with 
maximum a posteriori prediction (TAGM-MAP) [86] was applied to probabilistically attribute proteins to 26 subcellular niches defined by 718 marker proteins. The protein localisation probability was calculated as the probability of a protein belonging to the most likely subcellular class and not being an outlier. Assignments at a localisation probability above $99 \%$ were accepted.

\section{Data availability}

The mass-spectrometry-based proteomics data have been deposited to the ProteomeXchange Consortium via the PRIDE partner repository with the dataset identifiers: PXD015269 and https://doi.org/10.6019/PXD015269; and PXD022785 and https://doi.org/10.6019/PXD022785.

\section{Immunofluorescence microscopy}

T. gondii-infected HFF monolayers grown on glass coverslips were fixed with $2 \%$ formaldehyde at room temperature for $15 \mathrm{~min}$, permeabilized with $0.1 \%$ TritonX-100 for $10 \mathrm{~min}$ and blocked with $2 \%$ BSA for $1 \mathrm{~h}$. The coverslips were then incubated with a primary antibody for $1 \mathrm{~h}$, followed by $1 \mathrm{~h}$ incubation with a secondary antibody. Coverslips were mounted using ProLong ${ }^{\circledR}$ Diamond Antifade Mountant with DAPI (Invitrogen). Images were acquired using a Nikon Eclipse Ti widefield microscope with a Nikon objective lens (Plan APO, 100x/1.45 oil), and a Hamamatsu C11440, ORCA Flash 4.0 camera.

3D-Structured Illumination Microscopy (3D-SIM) was implemented on either a DeltaVision OMX V4 Blaze (Applied Precision) or an Elyra 7 (Zeiss) with samples prepared as for widefield immunofluorescence assay (IFA) microscopy with the exception that High Precision coverslips (Marienfeld Superior, No1.5H with a thickness of $170 \mu \mathrm{m} \pm 5 \mu \mathrm{m}$ ) were used in cell culture and Vectashield (Vector Laboratories) was used as mounting reagent. For protruded conoid imaging of extracellular parasites, cells were treated for 45 seconds with $5 \mu \mathrm{m} 5$ - benzyl-3-iso-propyl-1Hpyrazolo[4.3-d]pyrimindin-7(6H)-one (BIPPO) prior to fixation. Samples were excited using 405, 488 and $594 \mathrm{~nm}$ lasers and imaged with a 60x oil immersion lens (1.42 NA). The structured illumination images were reconstructed in softWoRx software version 6.1.3 (Applied Precision). All fluorescence images were processed using Image J software (http://rsbweb.nih.gov./ij/).

\section{Electron microscopy}

Samples of extra cellular $T$. gondii tachyzoites and $P$. berghei ookinetes, oocysts, sporozoites and merozoites were fixed in $4 \%$ glutaraldehyde in $0.1 \mathrm{M}$ phosphate buffer and processed for electron microscopy as previously described [87]. Briefly, samples were post-fixed in osmium tetroxide, treated en bloc with uranyl acetate, dehydrated and embedded in Spurr's epoxy resin (TAAB Lab Supplies Ltd, UK). Thin sections were stained with uranyl acetate and lead citrate prior to examination in a JEOL1200EX or JEOL JEM1400 electron microscope (Jeol UK Ltd).

\section{Detection of putative orthologues in other alveolates}

Exhaustive expansion of identified homologues. To search in-depth for homologues across the Alveolata, an in-house set of 419 proteomes belonging to the Stramenopila-Alveolata-Rhizaria (SAR) clade was used. OrthoFinder [56] was applied to cluster these proteins into OrthoGroups (i.e., sets of proteins that are descended from a single protein in the last common ancestor of SAR). For each of the 107 putative apical proteins ('queries') of Toxoplasma gondii ME-49 (these 107 proteins correspond to the union of the proteins in Table 1 and Table S1), the OrthoGroup to which it belonged was identified. Of note, four pairs of $T$. gondii query proteins belonged to the same OrthoGroup (see Supplementary Table 3), indicating that these pairs of apical localising proteins are likely paralogues of one another. Subsequently, the presence-absence patterns for each of these OrthoGroups across the SAR was assessed. Based on the initial OrthoFinder presence-absence patterns, the OrthoGroups were separated into two categories in order to apply distinct search 
strategies: (1) OrthoGroups with a limited distribution, not present in clades other than apicomplexans, and (2) OrthoGroups with a wide distribution, present across alveolates, often with many species having multiple homologues. The search strategy corresponding to homologues of each $T$. gondii query can be found in S3 Table.

For search strategy (1), the protein sequences were filtered using PREQUAL v.1.02 [88] to identify and mask regions with non-homologous adjacent characters, aligned using MAFFT v7.471 (option 'auto') [89], and a profile HMM was built using hmmbuild from HMMER 3.3 (http://hmmer.org). This custom profile HMM was used to search for divergent homologues in the SAR proteome database using hmmsearch (E-value cutoff for the best scoring domain: 0.01); these were added to the OrthoGroup. The expanded OrthoGroup was then submitted to additional rounds of PREQUALMAFFT-hmmbuild-hmmsearch, until either 1) no new homologue was detected, or 2) the total number of accumulated OrthoGroup sequences exceeded 10,000, or 3) 10 rounds had been performed.

For search strategy (2), a single round of PREQUAL-MAFFT-hmmbuild-hmmsearch steps was applied with a more stringent E-value cut-off for the selection of new homologues, which was customised for each OrthoGroup. For this, the E-values of the sequences already in the OrthoGroup were retrieved. The highest of these E-values was used as the inclusion cutoff for new hits, unless the latter was higher than 0.001 (in which case, the E-value cutoff was set to 0.001 ).

Filtering homologues for putative orthologues. To exclude putative paralogues and or inclusion of spurious sequences by the HMM iterations, each sequence from the expanded OrthoGroups was used as a query for a sequence similarity search against the $T$. gondii proteome using BLASTp from BLAST 2.10.1+ [90] (E-value <10). If a query yielded a different $T$. gondii sequence as best hit, it was removed as a putative paralogue. Sequences that retrieved the original $T$. gondii sequence as best hit were annotated with 'rbh' (for 'reciprocal best hit') while sequences that did not hit any sequence in $T$. gondii were annotated with 'none'. The latter can happen specifically in fast-evolving protein families, for which the highly-sensitive HMM search was able to detect the homologue, contrary to a BLASTp search only. It is to be noted that, in some cases, putative orthologues (sequences that are clearly homologous to orthologues in other species) are too divergent to be retrieved as the best hit in a reverse BLASTp search against the Toxoplasma proteome. Such cases may well present themselves in our dataset, and caution is particularly warranted when only a few species of a given clade have a detected putative orthologue and others of the same clade seemingly do not. The numbers of putative orthologues in the Alveolata subset of our SAR proteome dataset were inferred from these OrthoGroup sets (Table S3). For the OrthoGroups that contained two query proteins (see 'Exhaustive expansion of identified homologues'), the collected sequences were split and selected based on which of the two T. gondii proteins represented their best BLASTp hit. The 'none' homologous sequences were retained for both protein queries.

The resulting putative orthologous sequences for each protein query can be found in FASTA files (S1 Data). The putative orthologues for $P$. berghei ANKA and $P$. falciparum 3D7 are listed by their GenBank and UniProt identifiers and original assembly gene names (S4 Table). For each alveolate species in our dataset, the completeness of its predicted proteome was inferred using BUSCO 4.0.5 with automatic selection of the reference lineage using the --auto-lineage-euk option [91]. These proteome completeness scores facilitate the interpretation of putative absences in the examined Alveolata species, for a low completeness may indicate that a putative orthologue is not necessarily absent but may also simply result from an incomplete dataset (Table S3, Fig S5).

Visualisation of putative orthologues across Alveolata. For Fig 6 and Fig S5, the binary presence/absence patterns of our putative orthology search were used (Table S3) to calculated 
Jaccard distances for all protein pairs across the Alveolata and proteins were clustered according to these distances using UPGMA. To generate the heatmaps in Fig 1 and S1 Fig, 'heatmap2' of the R package gplots (https://cran.r-project.org/web/packages/gplots/index.html) was applied onto a 'ternary' matrix, which distinguished between a protein being absent, it being present as a reciprocal best hit ('rbh'), or it being present as a none hit ('none') (see 'Filtering homologues for putative orthologues'). To indicate the phylogenetic relationships of the species, a tree dendrogram without meaningful branch lengths was assembled by reviewing recent literature for Apicomplexa [92-94], Dinoflagellata [95-99], Ciliata [100-106], and Colponemidia [107].

\section{Ethics statement}

The animal work performed in the UK passed an ethical review process and was approved by the United Kingdom Home Office. Work was carried out in accordance with the United Kingdom 'Animals (Scientific Procedures) Act 1986' and in compliance with 'European Directive 86/609/EEC' for the protection of animals used for experimental purposes. The permit number for the project licence is $40 / 3344$.

\section{Generation of transgenic Plasmodium berghei and genotype analyses}

To observe the location of $P$. berghei proteins, the $C$-terminus of the gene was tagged with green fluorescent protein (GFP) sequence by single crossover homologous recombination. To generate the GFP-tag line, a region of these genes downstream of the ATG start codon was amplified, ligated to p277 vector, and transfected as described previously [60]. The p277 vector contains the human dhfr cassette, conveying resistance to pyrimethamine. A schematic representation of the endogenous gene locus, the constructs and the recombined gene locus can be found in Fig S9. A list of primers used to amplify these genes can be found in Table S2. For the parasites expressing a C-terminal GFPtagged protein, diagnostic PCR was used with primer 1 (Int primer) and primer 2 (ol492) to confirm integration of the GFP targeting construct. The primer details can be found in Table S2.

\section{P. berghei phenotype analyses}

Blood containing approximately 50,000 parasites of the GFP-tagged lines was injected intraperitoneally (i.p.) into mice to initiate infections. Parasitaemia was monitored by microscopy on Giemsa stained thin smears. Four to five days post infection blood was collected with $10-15 \%$ parasitaemia and allowed to further develop in schizont and ookinete culture medium as described previously [108]. The schizonts/merozoites and ookinetes were examined after $24 \mathrm{~h}$ of culture with a Zeiss Axiolmager M2 microscope (Carl Zeiss, Inc) fitted with an AxioCam ICc1 digital camera. To examine the location of these proteins in sporozoites, 30-50 Anopheles stephensi SD 500 mosquitoes were allowed to feed for 20 min on anaesthetized, infected mice who's asexual parasitaemia had reached $15 \%$ and were carrying comparable numbers of gametocytes as determined on Giemsa stained blood films. On day 21 post-feeding, 20 mosquitoes were dissected, and their guts and salivary glands crushed separately in a loosely fitting homogenizer to release sporozoites, which were then used for imaging.

\section{References:}

1. World Health Organization. World malaria report 2018. 2018.

2. Striepen B. Parasitic infections: Time to tackle cryptosporidiosis. Nature. 2013;503: 189-191.

3. Montoya JG, Liesenfeld O. Toxoplasmosis. Lancet. 2004;363: 1965-1976. doi:10.1016/S01406736(04)16412-X

4. Rashid M, Rashid MI, Akbar H, Ahmad L, Hassan MA, Ashraf K, et al. A systematic review on modelling approaches for economic losses studies caused by parasites and their associated diseases in cattle. Parasitology. 2019;146: 129-141. doi:10.1017/S0031182018001282 
5. Santos Pacheco Dos N, Tosetti N, Koreny L, Waller RF, Soldati-Favre D. evolution, composition, assembly, and function of the conoid in Apicomplexa. Trends Parasitol. 2020;36: 688-704. doi:10.1016/j.pt.2020.05.001

6. Gould SB, Tham W-H, Cowman AF, McFadden GI, Waller RF. Alveolins, a new family of cortical proteins that define the protist infrakingdom Alveolata. Mol Biol Evol. 2008;25: 1219-1230. doi:10.1093/molbev/msn070

7. Frénal K, Dubremetz J-F, Lebrun $M$, Soldati-Favre $D$. Gliding motility powers invasion and egress in Apicomplexa. Nat Rev Microbiol. 2017;15: 645-660. doi:10.1038/nrmicro.2017.86

8. Harding CR, Meissner M. The inner membrane complex through development of Toxoplasma gondii and Plasmodium. Cell Microbiol. 2014;16: 632-641. doi:10.1111/cmi.12285

9. Kats LM, Cooke BM, Coppel RL, Black CG. Protein trafficking to apical organelles of malaria parasites - building an invasion machine. Traffic. 2008;9: 176-186. doi:10.1111/j.16000854.2007.00681.x

10. Lebrun M, Carruthers VB, Cesbron-Delauw M-F. Toxoplasma secretory proteins and their roles in cell invasion and intracellular survival. In: Weiss LM, Kim K, editors. Toxoplasma gondii The Model Apicomplexan. Second Edition. Elsevier; 2014. pp. 389-453. doi:10.1016/B978-0-12396481-6.00012-X

11. Schrével J, Valigurová A, Prensier G, Chambouvet A, Florent I, Guillou L. Ultrastructure of Selenidium pendula, the type species of archigregarines, and phylogenetic relations to other marine Apicomplexa. Protist. 2016;167: 339-368. doi:10.1016/j.protis.2016.06.001

12. Okamoto N, Keeling PJ. The 3D structure of the apical complex and association with the flagellar apparatus revealed by serial TEM tomography in Psammosa pacifica, a distant relative of the Apicomplexa. PLOS ONE. 2014;9: e84653. doi:10.1371/journal.pone.0084653.s002

13. Mylnikov AP. Ultrastructure and phylogeny of colpodellids (Colpodellida, Alveolata). Biology bulletin. 2009;36: 582-590. doi:10.1134/S1062359009060065

14. Dubremetz J-F, Ferguson DJP. The role played by electron microscopy in advancing our understanding of Toxoplasma gondii and other apicomplexans. Int J Parasitol. 2009;39: 883893. doi:10.1016/j.ijpara.2009.02.009

15. Russell DG, Burns RG. The polar ring of coccidian sporozoites: a unique microtubule-organizing centre. J Cell Sci. 1984;65: 193-207.

16. Morrissette N, Gubbels M-J. The Toxoplasma Cytoskeleton: Structures, Proteins and Processes. Toxoplasma gondii The Model Apicomplexan. Second Edition. Elsevier; 2014. pp. 455-503. doi:10.1016/B978-0-12-396481-6.00013-1

17. Scholtyseck $E$, Mehlhorn $H$, Friedhoff $K$. The fine structure of the conoid of Sporozoa and related organisms. Z Parasitenk. 1970;34: 68-94.

18. Paredes-Santos TC, de Souza W, Attias M. Dynamics and 3D organization of secretory organelles of Toxoplasma gondii. J Struct Biol. 2012;177: 420-430. doi:10.1016/j.jsb.2011.11.028

19. Suarez C, Lentini G, Ramaswamy R, Maynadier M, Aquilini E, Berry-Sterkers L, et al. A lipidbinding protein mediates rhoptry discharge and invasion in Plasmodium falciparum and Toxoplasma gondii parasites. Nat Commun. 2019;10: 4041. doi:10.1038/s41467-019-11979-z

20. Perkins FO. Zoospores of the oyster pathogen, Dermocystidium marinum. I. Fine structure of the conoid and other sporozoan-like organelles. J Parasitol. 1976;62: 959-974.

21. Hu K, Roos DS, Murray JM. A novel polymer of tubulin forms the conoid of Toxoplasma gondii. J Cell Biol. 2002;156: 1039-1050. doi:10.1083/jcb.200112086

22. Obornik M, Vancová M, Lai D-H, Janouškovec J, Keeling PJ, Lukes J. Morphology and ultrastructure of multiple life cycle stages of the photosynthetic relative of apicomplexa, Chromera velia. Protist. 2011;162: 115-130. doi:10.1016/j.protis.2010.02.004

23. Nichols BA, Chiappino ML. Cytoskeleton of Toxoplasma gondii. J Protozool. 1987;34: 217-226. 
24. Katris NJ, van Dooren GG, McMillan PJ, Hanssen E, Tilley L, Waller RF. The apical complex provides a regulated gateway for secretion of invasion factors in Toxoplasma. PLOS Pathog. 2014;10: e1004074. doi:10.1371/journal.ppat.1004074

25. Canning EU, Sinden RE. The organization of the ookinete and observations on nuclear division in oocysts of Plasmodium berghei. Parasitology. 1973;67: 29-40. doi:10.1017/s0031182000046266

26. Aikawa M. Ultrastructure of the pellicular complex of Plasmodium fallax. J Cell Biol. 1967;35: 103-113.

27. Hanssen E, Dekiwadia C, Riglar DT, Rug M, Lemgruber L, Cowman AF, et al. Electron tomography of Plasmodium falciparum merozoites reveals core cellular events that underpin erythrocyte invasion. Cell Microbiol. 2013;15: 1457-1472. doi:10.1111/cmi.12132

28. Graindorge A, Frénal K, Jacot D, Salamun J, Marq J-B, Soldati-Favre D. The conoid associated motor $\mathrm{MyoH}$ is indispensable for Toxoplasma gondii entry and exit from host cells. PLOS Pathog. 2016;12: e1005388. doi:10.1371/journal.ppat.1005388

29. Leung JM, He Y, Zhang F, Hwang Y-C, Nagayasu E, Liu J, et al. Stability and function of a putative microtubule-organizing center in the human parasite Toxoplasma gondii. Mol Biol Cell. 2017;28: 1361-1378. doi:10.1091/mbc.E17-01-0045

30. Long S, Brown KM, Drewry LL, Anthony B, Phan IQH, Sibley LD. Calmodulin-like proteins localized to the conoid regulate motility and cell invasion by Toxoplasma gondii. PLOS Pathog. 2017;13: e1006379. doi:10.1371/journal.ppat.1006379

31. Long S, Anthony B, Drewry LL, Sibley LD. A conserved ankyrin repeat-containing protein regulates conoid stability, motility and cell invasion in Toxoplasma gondii. Nat Commun. 2017;8: 2236. doi:10.1038/s41467-017-02341-2

32. Nagayasu E, Hwang Y-C, Liu J, Murray JM, Hu K. Loss of a doublecortin (DCX)-domain protein causes structural defects in a tubulin-based organelle of Toxoplasma gondii and impairs hostcell invasion. Mol Biol Cell. 2017;28: 411-428. doi:10.1091/mbc.E16-08-0587

33. Leung JM, Nagayasu E, Hwang Y-C, Liu J, Pierce PG, Phan IQ, et al. A doublecortin-domain protein of Toxoplasma and its orthologues bind to and modify the structure and organization of tubulin polymers. BMC Mol Cell Biol. 2020;21: 8. doi:10.1186/s12860-020-0249-5

34. Tosetti N, Santos Pacheco Dos N, Bertiaux E, Maco B, Bournonville L, Hamel V, et al. Essential function of the alveolin network in the subpellicular microtubules and conoid assembly in Toxoplasma gondii. eLife. 2020;9: e56635. doi:10.7554/eLife.56635

35. Back PS, O'Shaughnessy WJ, Moon AS, Dewangan PS, Hu X, Sha J, et al. Ancient MAPK ERK7 is regulated by an unusual inhibitory scaffold required for Toxoplasma apical complex biogenesis. PNAS. 2020;117: 12164-12173. doi:10.1073/pnas.1921245117

36. Barylyuk K, Koreny L, Ke H, Butterworth S, Crook OM, Lassadi I, et al. A Comprehensive subcellular atlas of the Toxoplasma proteome via hyperlopit provides spatial context for protein functions. Cell Host Microbe. 2020;28: 752-766. doi:10.1016/j.chom.2020.09.011

37. Christoforou A, Mulvey CM, Breckels LM, Geladaki A, Hurrell T, Hayward PC, et al. A draft map of the mouse pluripotent stem cell spatial proteome. Nat Commun. 2016;7: 8992. doi:10.1038/ncomms9992

38. Roux KJ, Kim DI, Raida M, Burke B. A promiscuous biotin ligase fusion protein identifies proximal and interacting proteins in mammalian cells. J Cell Biol. 2012;196: 801-810. doi:10.1083/jcb.201112098

39. de Leon JC, Scheumann N, Beatty W, Beck JR, Tran JQ, Yau C, et al. A SAS-6-like protein suggests that the Toxoplasma conoid complex evolved from flagellar components. Euk Cell. 2013;12: 1009-1019. doi:10.1128/EC.00096-13

40. Sidik SM, Huet D, Ganesan SM, Huynh M-H, Wang T, Nasamu AS, et al. A genome-wide CRISPR screen in Toxoplasma identifies essential apicomplexan genes. Cell. 2016;166: 1423-1435.e12. doi:10.1016/j.cell.2016.08.019 
41. Zhang M, Wang C, Otto TD, Oberstaller J, Liao X, Adapa SR, et al. Uncovering the essential genes of the human malaria parasite Plasmodium falciparum by saturation mutagenesis. Science. 2018;360. doi:10.1126/science.aap7847

42. Wall RJ, Roques M, Katris NJ, Koreny L, Stanway RR, Brady D, et al. SAS6-like protein in Plasmodium indicates that conoid-associated apical complex proteins persist in invasive stages within the mosquito vector. Sci Rep. 2016;6: 28604. doi:10.1038/srep28604

43. Lévêque MF, Berry L, Besteiro S. An evolutionarily conserved SSNA1/DIP13 homologue is a component of both basal and apical complexes of Toxoplasma gondii. Sci Rep. 2016;6: 27809. doi:10.1038/srep27809

44. Hu K, Johnson J, Florens L, Fraunholz M, Suravajjala S, DiLullo C, et al. Cytoskeletal components of an invasion machine--the apical complex of Toxoplasma gondii. PLOS Pathog. 2006;2: e13. doi:10.1371/journal.ppat.0020013

45. Lentini G, Dubois DJ, Maco B, Soldati-Favre D, Frénal K. The roles of Centrin 2 and Dynein Light Chain 8a in apical secretory organelles discharge of Toxoplasma gondii. Traffic. 2019;20: 583600. doi:10.1111/tra.12673

46. Leung JM, Liu J, Wetzel LA, Hu K. Centrin2 from the human parasite Toxoplasma gondii is required for its invasion and intracellular replication. J Cell Sci. 2019;132: jcs228791. doi:10.1242/jcs.228791

47. Heaslip AT, Ems-Mcclung SC, Hu K. TgICMAP1 Is a novel microtubule binding protein in Toxoplasma gondii. PLOS ONE. 2009;4: e7406. doi:10.1371/journal.pone.0007406.g008

48. Tran JQ, De Leon JC, Li C, Huynh M-H, Beatty W, Morrissette NS. RNG1 is a late marker of the apical polar ring in Toxoplasma gondii. Cytoskeleton. 2010;67: 586-598. doi:10.1002/cm.20469

49. Tosetti N, Santos Pacheco Dos N, Soldati-Favre D, Jacot D. Three F-actin assembly centers regulate organelle inheritance, cell-cell communication and motility in Toxoplasma gondii. eLife. 2019;8: 684. doi:10.7554/eLife.42669

50. Heaslip AT, Nishi M, Stein B, Hu K. The motility of a human parasite, Toxoplasma gondii, is regulated by a novel lysine methyltransferase. PLOS Pathog. 2011;7: e1002201. doi:10.1371/journal.ppat.1002201.g010

51. Frénal K, Jacot D, Hammoudi P-M, Graindorge A, Maco B, Soldati-Favre D. Myosin-dependent cell-cell communication controls synchronicity of division in acute and chronic stages of Toxoplasma gondii. Nat Commun. 2017;8: 15710. doi:10.1038/ncomms15710

52. Engelberg K, Chen C-T, Bechtel T, Sánchez Guzmán V, Drozda AA, Chavan S, et al. The apical annuli of Toxoplasma gondii are composed of coiled-coil and signalling proteins embedded in the inner membrane complex sutures. Cell Microbiol. 2020;22: e13112. doi:10.1111/cmi.13112

53. Jacot D, Tosetti N, Pires I, Stock J, Graindorge A, Hung Y-F, et al. An apicomplexan actinbinding protein serves as a connector and lipid sensor to coordinate motility and invasion. Cell Host Microbe. 2016;20: 731-743. doi:10.1016/j.chom.2016.10.020

54. Gould SB, Kraft LGK, van Dooren GG, Goodman CD, Ford KL, Cassin AM, et al. Ciliate pellicular proteome identifies novel protein families with characteristic repeat motifs that are common to alveolates. Mol Biol Evol. 2011;28: 1319-1331. doi:10.1093/molbev/msq321

55. Skariah S, Bednarczyk RB, McIntyre MK, Taylor GA, Mordue DG. Discovery of a novel Toxoplasma gondii conoid-associated protein important for parasite resistance to reactive nitrogen intermediates. J Immunol. 2012;188: 3404-3415. doi:10.4049/jimmunol.1101425

56. Emms DM, Kelly S. OrthoFinder: phylogenetic orthology inference for comparative genomics. Genome Biol. 2019;20: 238. doi:10.1186/s13059-019-1832-y

57. Okamoto N, Horák A, Keeling PJ. Description of two species of early branching dinoflagellates, Psammosa pacifica n. g., n. sp. and P. atlantica n. sp. PLOS ONE. 2012;7: e34900. doi:10.1371/journal.pone.0034900 
58. Gustafson PV, Agar HD, Cramer DI. An electron microscope study of Toxoplasma. Am J Trop Med Hyg. 1954;3: 1008-1022.

59. Brockley Paterson W, Desser SS. The polar ring complex in ookinetes of Leucocytozoon simondi (Apicomplexa: Haemosporina) and evidence for a conoid in haemosporidian ookinetes. Eur J Protistol. Elsevier; 1989;24: 244-251. doi:10.1016/S0932-4739(89)80061-6

60. Guttery DS, Poulin B, Ferguson DJP, Szöör B, Wickstead B, Carroll PL, et al. A unique protein phosphatase with kelch-like domains (PPKL) in Plasmodium modulates ookinete differentiation, motility and invasion. PLOS Pathog. 2012;8: e1002948. doi:10.1371/journal.ppat.1002948

61. Atkinson CT. Ultrastructure of the ookinetes of Haemoproteus meleagridis (Haemosporina: Haemoproteidae). J Parasitol. 1989;75: 135-141.

62. Bertiaux E, Balestra AC, Bournonville L, Brochet M, Guichard P, Hamel V. Expansion Microscopy provides new insights into the cytoskeleton of malaria parasites including the conservation of a conoid. bioRixv. 2020. doi:10.1101/2020.07.08.192328

63. Wall RJ, Zeeshan M, Katris NJ, Limenitakis R, Rea E, Stock J, et al. Systematic analysis of Plasmodium myosins reveals differential expression, localisation, and function in invasive and proliferative parasite stages. Cell Microbiol. 2019;: e13082. doi:10.1111/cmi.13082

64. Schrevel J, Asfaux-Foucher G, Hopkins JM, Robert V, Bourgouin C, Prensier G, et al. Vesicle trafficking during sporozoite development in Plasmodium berghei: ultrastructural evidence for a novel trafficking mechanism. Parasitology. 2008;135: 1-12.

doi:10.1017/S0031182007003629

65. Paterson WB, Desser SS, Barta JR. ultrastructural features of the apical complex, pellicle, and membranes investing the gamonts of haemogregarina magna (Apicomplexa: Adeleina) 1. J Euk Microbiol. 1988;35: 73-80.

66. Garnham, P.C.C., Bird RG, Baker R, Desser SS, El-Nahal HMS. Electron microscope studies on motile stages of malaria paraistes. Transactions of the Royal Society of Tropical Medicine and Hygiene. 1969;63: 187-194.

67. Garnham PC, Bird RG, Baker JR. Electron microscope studies of motile stages of malaria parasites. IV. The fine structure of the sporozoites of four species of Plasmodium. Transactions of the Royal Society of Tropical Medicine and Hygiene. 1963;57: 27-31. doi:10.1016/00359203(63)90007-5

68. Garnham, P.C.C., Bird RG, Baker JR, Bray RS. Electron microsope studies of motile stages of malaria parasites. II. The fine structure of the sporozoite of Laverania (Plasmodium) falcipara. Transactions of the Royal Society of Tropical Medicine and Hygiene. 55 ed. 1: 98-102.

69. Bannister LH, Hopkins JM, Dluzewski AR, Margos G, Williams IT, Blackman MJ, et al. Plasmodium falciparum apical membrane antigen 1 (PfAMA-1) is translocated within micronemes along subpellicular microtubules during merozoite development. J Cell Sci. 2003;116: 3825-3834. doi:10.1242/jcs.00665

70. Vlachou D, Schlegelmilch T, Runn E, Mendes A, Kafatos FC. The developmental migration of Plasmodium in mosquitoes. Curr Opin Genet Dev. 2006;16: 384-391. doi:10.1016/j.gde.2006.06.012

71. Graumans W, Jacobs E, Bousema T, Sinnis P. When is a Plasmodium-infected mosquito an infectious mosquito? Trends Parasitol. 2020;36: 705-716. doi:10.1016/j.pt.2020.05.011

72. Larsen J. An ultrastructural study of Amphidinium poecilochroum (Dinophyceae), a phagotrophic dinoflagellate feeding on small species of cryptophytes. Phycologia. 1988;27: 366-377.

73. Chen AL, Kim EW, Toh JY, Vashisht AA, Rashoff AQ, Van C, et al. Novel components of the Toxoplasma inner membrane complex revealed by BiolD. MBio. 2015;6: e02357-14. doi:10.1128/mBio.02357-14 
74. Chen AL, Moon AS, Bell HN, Huang AS, Vashisht AA, Toh JY, et al. Novel insights into the composition and function of the Toxoplasma IMC sutures. Cell Microbiol. 2017;19: e12678. doi:10.1111/cmi.12678

75. Beck JR, Rodriguez-Fernandez IA, de Leon JC, Huynh M-H, Carruthers VB, Morrissette NS, et al. A novel family of Toxoplasma IMC proteins displays a hierarchical organization and functions in coordinating parasite division. PLOS Pathog. 2010;6: e1001094. doi:10.1371/journal.ppat.1001094

76. Anderson-White BR, Ivey FD, Cheng K, Szatanek T, Lorestani A, Beckers CJ, et al. A family of intermediate filament-like proteins is sequentially assembled into the cytoskeleton of Toxoplasma gondii. Cell Microbiol. 2011;13: 18-31. doi:10.1111/j.1462-5822.2010.01514.x

77. Suvorova ES, Francia M, Striepen B, White MW. A novel bipartite centrosome coordinates the apicomplexan cell cycle. PLOS Biology. 2015;13: e1002093. doi:10.1371/journal.pbio.1002093

78. Liu J, Wetzel L, Zhang Y, Nagayasu E, Ems-McClung S, Florens L, et al. Novel thioredoxin-like proteins are components of a protein complex coating the cortical microtubules of Toxoplasma gondii. Euk Cell. 2013;12: 1588-1599. doi:10.1128/EC.00082-13

79. Liu J, He Y, Benmerzouga I, Sullivan WJ, Morrissette NS, Murray JM, et al. An ensemble of specifically targeted proteins stabilizes cortical microtubules in the human parasite Toxoplasma gondii. Mol Biol Cell. 2016;27: 549-571. doi:10.1091/mbc.E15-11-0754

80. Frénal K, Polonais V, Marq J-B, Stratmann R, Limenitakis J, Soldati-Favre D. Functional dissection of the apicomplexan glideosome molecular architecture. Cell Host Microbe. 2010;8: 343-357. doi:10.1016/j.chom.2010.09.002

81. Howick VM, Russell AJC, Andrews T, Heaton H, Reid AJ, Natarajan K, et al. The Malaria Cell Atlas: Single parasite transcriptomes across the complete Plasmodium life cycle. Science. 2019;365. doi:10.1126/science.aaw2619

82. Sheiner L, Demerly JL, Poulsen N, Beatty WL, Lucas O, Behnke MS, et al. A systematic screen to discover and analyze apicoplast proteins identifies a conserved and essential protein import factor. PLOS Pathog. 2011;7: e1002392.

83. Roos DS, Donald R, Morrissette NS, Moulton ALC. Molecular tools for genetic dissection of the protozoan parasite Toxoplasma gondii. Methods in Cell Biology. European J Cell Biol; 1994. pp. 27-63. doi:10.1016/S0091-679x(08)61845-2

84. Keller A, Nesvizhskii Al, Kolker E, Aebersold R. Empirical statistical model to estimate the accuracy of peptide identifications made by MS/MS and database search. Anal Chem. 2002;74: 5383-5392. doi:10.1021/ac025747h

85. Nesvizhskii Al, Keller A, Kolker E, Aebersold R. A statistical model for identifying proteins by tandem mass spectrometry. Anal Chem. 2003;75: 4646-4658. doi:10.1021/ac0341261

86. Crook OM, Mulvey CM, Kirk PDW, Lilley KS, Gatto L. A Bayesian mixture modelling approach for spatial proteomics. PLoS Comput Biol. 2018;14: e1006516. doi:10.1371/journal.pcbi.1006516

87. Ferguson DJP, Henriquez FL, Kirisits MJ, Muench SP, Prigge ST, Rice DW, et al. Maternal inheritance and stage-specific variation of the apicoplast in Toxoplasma gondii during development in the intermediate and definitive host. Euk Cell. 2005;4: 814-826. doi:10.1128/EC.4.4.814-826.2005

88. Whelan S, Irisarri I, Burki F. PREQUAL: detecting non-homologous characters in sets of unaligned homologous sequences. Hancock J, editor. Bioinformatics. 2018;34: 3929-3930. doi:10.1093/bioinformatics/bty448

89. Katoh K, Standley DM. MAFFT multiple sequence alignment software version 7: improvements in performance and usability. Mol Biol Evol. 2013;30: 772-780. doi:10.1093/molbev/mst010

90. Altschul SF, Gish W, Miller W, Myers EW, Lipman DJ. Basic local alignment search tool. J Mol Biol. 1990;215: 403-410. doi:10.1016/S0022-2836(05)80360-2 
91. Seppey M, Manni M, Zdobnov EM. BUSCO: Assessing Genome Assembly and Annotation Completeness. Methods Mol Biol. New York, NY: Springer New York; 2019;1962: 227-245. doi:10.1007/978-1-4939-9173-0_14

92. Mathur V, Kolisko M, Hehenberger E, Irwin NAT, Leander BS, Kristmundsson Á, et al. Multiple Independent Origins of Apicomplexan-Like Parasites. Curr Biol. 2019;29: 2936-2941.e5. doi:10.1016/j.cub.2019.07.019

93. Janouškovec J, Paskerova GG, Miroliubova TS, Mikhailov KV, Birley T, Aleoshin VV, et al. Apicomplexan-like parasites are polyphyletic and widely but selectively dependent on cryptic plastid organelles. eLife. 2019;8: 441. doi:10.7554/eLife.49662

94. Galen SC, Borner J, Martinsen ES, Schaer J, Austin CC, West CJ, et al. The polyphyly of Plasmodium: comprehensive phylogenetic analyses of the malaria parasites (order Haemosporida) reveal widespread taxonomic conflict. R Soc Open Sci. 2018;5: 171780. doi:10.1098/rsos.171780

95. LaJeunesse TC, Parkinson JE, Gabrielson PW, Jeong HJ, Reimer JD, Voolstra CR, et al. Systematic revision of Symbiodiniaceae highlights the antiquity and diversity of coral endosymbionts. Curr Biol. 2018;28: 2570-2580. doi:10.1016/j.cub.2018.07.008

96. Sarai C, Tanifuji G, Nakayama T, Kamikawa R, Takahashi K, Yazaki E, et al. Dinoflagellates with relic endosymbiont nuclei as models for elucidating organellogenesis. PNAS. 2020;117: 53645375. doi:10.1073/pnas.1911884117

97. Janouškovec J, Gavelis GS, Burki F, Dinh D, Bachvaroff TR, Gornik SG, et al. Major transitions in dinoflagellate evolution unveiled by phylotranscriptomics. PNAS. 2017;114: e171-e180. doi:10.1073/pnas.1614842114

98. Kretzschmar AL, Verma A, Murray S, Kahlke T, Fourment M, Darling AE. Trial by phylogenetics Evaluating the multi-species coalescent for phylogenetic inference on taxa with high levels of paralogy (Gonyaulacales, Dinophyceae). bioRxiv. 2019. doi:https://doi.org/10.1101/683383

99. Price DC, Bhattacharya D. Robust Dinoflagellata phylogeny inferred from public transcriptome databases. J Phycol. 2017;53: 725-729. doi:10.1111/jpy.12529

100. Irwin NAT, Pittis AA, Mathur V, Howe $L$, Keeling PJ, Lynn DH, et al. The function and evolution of motile DNA replication systems in ciliates. Curr Biol. 2021;31: 1-11. doi:10.1016/j.cub.2020.09.077

101. Rataj $M, V$ d'ačný P. Multi-gene phylogeny of Tetrahymena refreshed with three new histophagous species invading freshwater planarians. Parasitol Res. 4 ed. 2020;119: 15231545. doi:10.1007/s00436-020-06628-0

102. Boscaro V, Santoferrara LF, Zhang Q, Gentekaki E, Syberg-Olsen MJ, del Campo J, et al. EukRefCiliophora: a manually curated, phylogeny-based database of small subunit rRNA gene sequences of ciliates. Environ Microbiol. 2018;20: 2218-2230. doi:10.1111/1462-2920.14264

103. Luo J, Ma M, Lu B, Li X, Warren A, Shi Y, et al. The taxonomy and phylogeny of the poorly known heterotrich ciliate Ampullofolliculina lageniformis Hadži, 1951 (Ciliophora: Heterotrichea). Journal of Eukaryotic Microbiology. 2019;66: 925-936. doi:10.1111/jeu.12743

104. Yan Y, Fan Y, Chen X, Li L, Warren A, Al-Farraj SA, et al. Taxonomy and phylogeny of three heterotrich ciliates (Protozoa, Ciliophora), with description of a new Blepharisma species. Zool J Linn Soc. 3rd ed. 2016;177: 320-334. doi:10.1111/zoj.12369

105. Sheng Y, He M, Zhao F, Shao C, Miao M. Phylogenetic relationship analyses of complicated class Spirotrichea based on transcriptomes from three diverse microbial eukaryotes: Uroleptopsis citrina, Euplotes vannus and Protocruzia tuzeti. Mol Phylogenet Evol. 2018;129: 338-345. doi:10.1016/j.ympev.2018.06.025

106. Rotterová J, Salomaki E, Pánek T, Bourland W, Žihala D, Táborský P, et al. Genomics of New Ciliate Lineages Provides Insight into the Evolution of Obligate Anaerobiosis. Curr Biol. 2020;30: 2037-2050.e6. doi:10.1016/j.cub.2020.03.064 
107. Tikhonenkov DV, Strassert JFH, Janouškovec J, Mylnikov AP, Aleoshin VV, Burki F, et al. Predatory colponemids are the sister group to all other alveolates. Mol Phylogenet Evol. 2020;149: 106839. doi:10.1016/j.ympev.2020.106839

108. Saini E, Zeeshan M, Brady D, Pandey R, Kaiser G, Koreny L, et al. Photosensitized INA-Labelled protein 1 (PhIL1) is novel component of the inner membrane complex and is required for Plasmodium parasite development. Sci Rep. 2017;7: 15577. doi:10.1038/s41598-017-15781-z 